\title{
A Methodological Framework for Participatory Processes in Water Resources Management
}

\author{
Jörg Krywkow
}

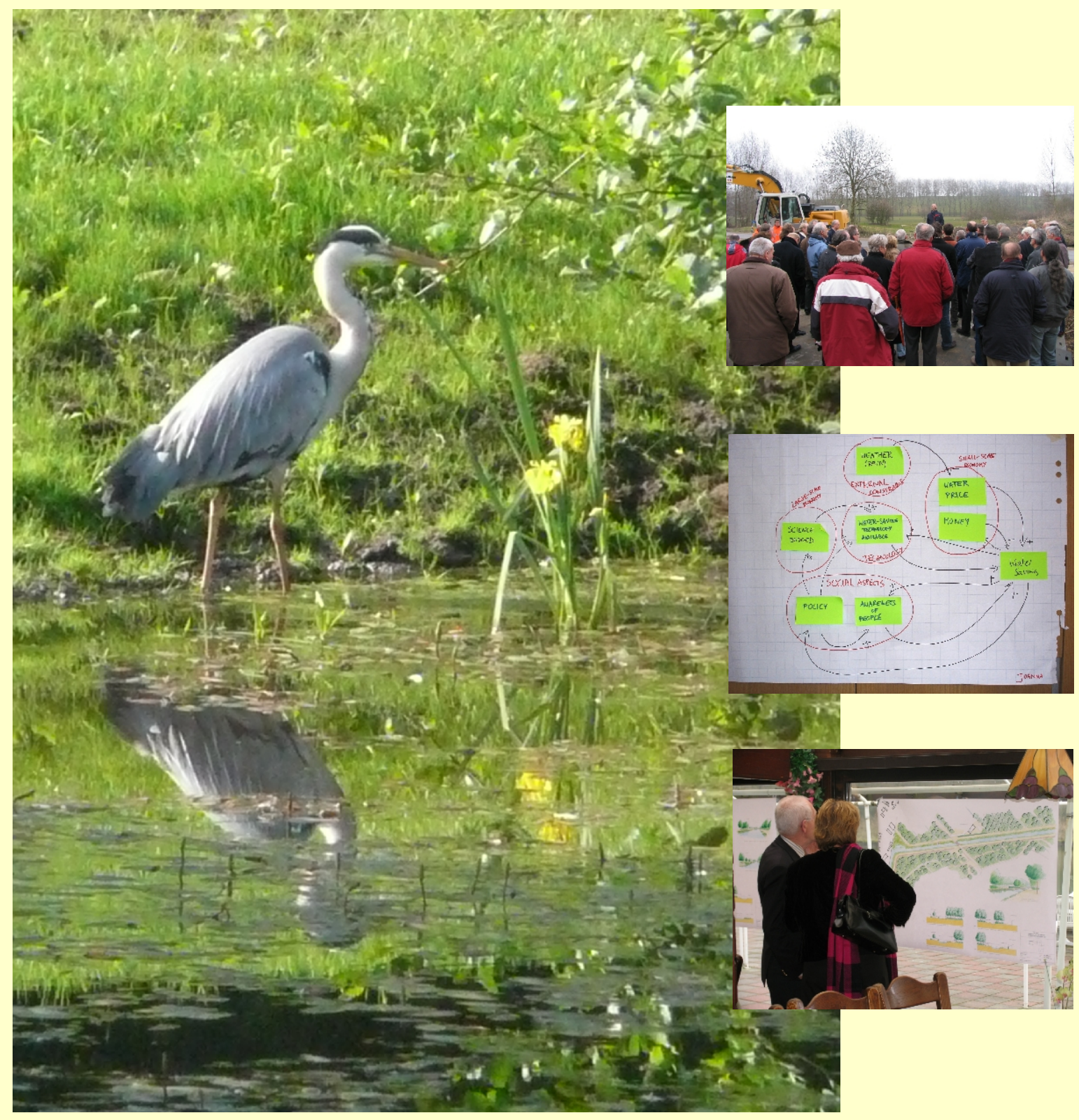




\title{
A Methodological Framework for Participatory \\ Processes in Water Resources Management
}

\author{
J. Krywkow
}

June 2009 


\title{
A METHODOLOGICAL FRAMEWORK FOR PARTICIPATORY PROCESSES IN WATER RESOURCES MANAGEMENT
}

\author{
DISSERTATION
}

to obtain

the degree of doctor at the University of Twente, on the authority of the rector magnificus, prof. dr. H. Brinksma,

on account of the decision of the graduation committee, to be publicly defended

on Thursday the 18th of June at 16:45

by

Jörg Krywkow

born on the 4th of February 1963

in Neuruppin, Germany 


\section{Promotor:}

Prof. Dr. Anne van der Veen

Promotion committee:

Prof. Dr. F. Eising

Prof. Dr. Claudia Pahl-Wostl

Prof. Dr. John Robinson

Prof. Ir. Eelco van Beek

Prof. Dr. Ir. A.G. Dorée

Dr. Matt Hare

Dr. Erik Mostert
Hoogleraar voor Economie van het Ruimtegebruik, Universiteit Twente, Enschede

Universiteit Twente, Construerende Technische Wetenschappen, chair/secretary

Institute of Environmental Systems Research, Department of Mathematics \& Computer Science, University of Osnabrück

Institute of Resources, Environment and Sustainability, and Department of Geography, University of British Columbia

Universiteit Twente, Construerende Technische Wetenschappen, Civiele Techniek, Afdeling Waterbeheer

Universiteit Twente, Construerende Technische Wetenschappen, Civiele Techniek, Afdeling Bouw/Infra United Nations University, EHE, Bonn Technische Universiteit Delft

Cover and Photographs: Caroline van Bers and Jörg Krywkow Typeset in LATEX

Copyright (c) 2009 by Jörg Krywkow All rights reserved. No part of this publication may be reproduced, stored in a retrieval system, or transmitted, in any form or by any means, electronic, mechanical, photo-copying, recording or otherwise, without the prior written permission of the author

Printed by Wöhrmann Print Service, Zutphen, The Netherlands ISBN 978-90-365-2835-1 
The discussion about the value and appropriateness of public and stakeholder participation is ongoing. Often proponents and opponents of the use of participatory approaches ignore each other based upon different ideologies rather than rational arguments. This observation is based on my experience in European-based research and consultancy, as well as my role as a stakeholder in several processes related to water management. As both an observer and a participant of these processes, it seems natural and logical to me to that multi-stakeholder perspectives form a part of environmental decision making.

Some of my academic colleagues, however, have a different perspective on the value of participatory processes, and are not willing to deviate from academic virtues such as rigour, accuracy, peer-reviewed outcomes, conformity to methods and statistical significance for sake of solving problems at stake. Moreover, the implementation of a participatory process including stakeholders with their varaious perspectives may entail a significant increase in uncertainty. From a scientific perspective the outcomes and results of research that involve stakeholder or public participation are not always straight-froward, and may be subject of discussion.

From the practitioner's perspective, participatory processes may imply other pitfalls and drawbacks such as loss of control, difficult or time-consuming tasks, waking up sleeping dogs, communication failure, evoking conflicts or even failing to attain project goals. Planners, engineers, economists or ecologists spend years acquiring knowledge that is required to carefully plan, design and implement modifications to environment, infrastructure or urban space. From their perspective the incorporation of lay knowledge appears questionable or even ironic.

Moreover, much confusion exists about the legitimacy, the rationale and the appropriateness of participatory processes. This holds not only for the question of applying participation or not, but also of how to do it. Self-organised 'grass-roots' movements that primarily seek to influence long-term policy agendas, often strive for a critical mass of support for their cause without a strict agenda, are often confused with carefully designed and implemented participatory decision processes that aim for a relatively 
short-term modification of the environment. Both processes have different means and instruments to bring about their respective objectives.

In the field of water management, the European Commission enacted the European Water Framework Directive that prescribes the early involvement of stakeholders (and the public) in river basin management. As a consequence participatory processes must form a part of river basin management, which set some normative values that can no longer be neglected. In practice, water managers have two possibilities: either implement a process that fulfils the minimum requirements of the directive, or incorporate participation as a vital part of the planning process.

Throughout my work as a consultant in European water management projects I have encountered the phenomenon of 'distorted multi-disciplinarity'. It means that responsible authorities provide excellent engineers, accountants, ecologists, spatial planners and related professions, but no 'participatory managers'. This latter role is usually assigned to a 'project manager' and his or her assistants (if there are any). These project managers are themselves engineers, ecologists or land use planners, but usually not experts in participatory processes and often lack experience in their planning and management. As a consultant as well as stakeholder I have, as a consequence, encountered unprofessional participatory procedures where the experts missed the opportunity to take advantage of valuable local knowledge or refused to recognise the added value of incorporating that knowledge. The participatory process was often implemented as a peripheral activity or for the purpose of risk mitigation (e.g. preventing individuals from delaying the planning process through legal means). If an interactive process is initiated, it often becomes a one-way process (planners consult stakeholders) with the result that little lay knowledge is incorporated.

A number of European research projects such as NeWater ${ }^{1}$, Striver ${ }^{2}$ and Harmon$\mathrm{iCOP}^{3}$ have produced valuable knowledge about participatory processes in river basin management. The collaboration with practitioners in numerous case studies was exemplary, and a mutual understanding of perspectives among practitioners, stakeholders and scientists was achieved. However, once the projects are finalised, it becomes difficult to maintain the dissemination and accessibility of this knowledge. This holds true especially for practitioners, who may not no longer have or never had the scientific support of workshops and face-to-face exchanges of experience. As a result new projects often begin with a foundation of knowledge that has been gained in previous projects. Furthermore, the argument that case-study-specific experiences are difficult to exchange is repeatedly heard. As a result, the many guidebooks that are produced, often as an output of these projects have limited benefit for practitioners who in many cases must start a project from scratch. How can all of this collective knowledge be used for a new project with specific constraints and objectives that are usually unique?

In the summer of 2004, I was invited to join the consultancy Seecon in order to work on the EU-funded InterReg project TRUST. Within this project five different water management initiatives requested support for their participatory effort for the purpose of capacity building. The problems that have been discussed in the beginning of this

\footnotetext{
${ }^{1}$ http://www.newater.info/

${ }^{2}$ http://www.striver.no/

${ }^{3}$ http://www.harmonicop.uos.de/
} 
preface could be applied to the TRUST project. Furthermore, the case studies were situated in three European countries. In general there was little knowledge of public and stakeholder participation, and the idea that scientific methods can be systematically applied throughout a project was completely novel to the practitioners. Furthermore, the consultants did not have a ready-to-go methodology available. As a result, a great deal of research and development was required to successfully support the five case studies. On the other hand, the scientific knowledge of the consultants could be enriched with the experiences and requirements of the practitioners in the TRUST project. In this way, problem-oriented research formed the basis of the project. The capacity building process turned out to be a 'real' social learning process, with much feedback from practitioners. The practitioners learned a great deal that could be used for future projects, and appreciated the cross-boundary exchange of experience. However, at the end of the project, I was still asked to provide them with a 'cookbook' of how to design, plan and implement a participatory process in water management projects. Admittedly, the "case-studies-are-not-transferable" paradigm was in my mind and that of many of my colleagues, and a mechanistic 'cookbook' is not adaptive enough to handle the individual constraints and local circumstances of practitioners. The idea emerged to develop a methodological framework for the application of participatory methods that provides practitioners with tangible guidelines to choose from a large array of available methods and apply them to their specific requirements.

The idea of a taxonomy and catalogue of participatory methods came originally from Matt Hare, and was further developed in long and productive brain-storming sessions between Matt and me. A first version of a taxonomy and catalogue is published as part of the TRUST inception report (Hare and Krywkow, 2005). For the fruitful co-operation, the intense exchange of ideas and the valuable advice I have received throughout and beyond the TRUST effort, I would like to express my gratitude to Matt Hare.

The initial version of a 'standardised' evaluation procedure was developed by Karina Speil ${ }^{4}$ (Rasche, 2005). The evaluation process was first applied in the TRUST project, and serves as the controlling part of the methodological framework as introduced in this thesis. I would like to thank Karina for the work she carried out in the TRUST project. This project also involved the water managers of TRUST/TGIII, who challenged us to develop ideas and help to solve their problems. I would like to express my special thanks to the colleagues of the TRUST/TGIII project.

In addition to the TRUST project, I was involved in two other European projects: NeWater and FLOODsite ${ }^{5}$, that compelled me to write the thesis in parallel to my project responsibilities, but - more importantly - provided me with insights to other water management projects including participation methodologies, research challenges, outcomes and networking. I would like to express my gratitude to Anne van der Veen for giving me the opportunity to work on these projects, for promoting and reviewing this thesis, and perhaps most importantly for nine years of collaboration, during which I

\footnotetext{
${ }^{4}$ nee Karina Rasche

${ }^{5}$ http://www.floodsite.net/
} 
learned a great deal and benefited from his encouragement, patience and trust especially when I encountered unexpected obstacles.

I extend a warm thank you to my project colleagues, especially, Claudia Pahl-Wostl and her research team at the Institute of Environmental Systems Research of the University of Osnabrück as well as my Seecon colleagues. Furthermore, I would like to thank my colleagues from the department of Water Engineering and Management (WEM) of the University of Twente.

Special thanks to Judith Janssen and Hans Hein who supported me in preparation of my thesis defense.

For their support in reviewing the English grammar and wording I would like to thank Catherine Buck and Douglas Baker. Last but certainly not least, I would like to thank Caroline van Bers for not only markedly improving my English over the years, but also for her critical questions in reviewing the drafts, and finally her infinite patience.

Jörg Krywkow

Enschede, June 2009 


\section{Summary}

The European Water Framework Directive (WFD) is a norm-setting document for river basin management in the European Union. The requirements of article 14 refer to the early involvement of stakeholders (and the public) in decision making processes. The question is no longer whether or not stakeholder participation is useful in river basin management, but how to accomplish an effective and efficient collaboration among policy makers, experts and lay people. Well before the inception of this regulatory document much research has been undertaken to better understand the interaction among practitioners, researchers and stakeholders in the decision processes of water management projects. These research projects brought scientific insights together with stakeholder needs and the contemporary European policy agenda. The quality of research is for the most part high, the results are useful, and newly developed management approaches fulfil the requirements of the WFD. However, once the research projects are completed, and the practitioners move on to other activities, the applicability of this (often case-study-based) research comes into question. A multitude of guidebooks and best-practice documents have been published, but still many of these documents are not known to water managers across Europe, and they are sometimes difficult to comprehend and especially difficult to adapt to individual requirements.

The application of participatory methods in decision making processes has grown into a sophisticated 'discipline' that requires knowledge and experience to understand and apply. However, most water managers in Europe are not experts in the field of participatory management.

Furthermore, when attempting to implement participatory methods in water management, the dualism of case-study-specific requirements and a universally applicable methodology is a problem that practitioners frequently encounter. For example, crossboundary experiences are often not directly applicable or relevant. This thesis endeavours to overcome this problem, and to develop an approach that enables practitioners with little knowledge of participatory processes to select methods that are appropriate for the specific requirements of a local project. 
For this purpose, a taxonomy of participatory methods has been developed that removes uncertain parameters within participatory methods and assigns them to two categories: 1) case study specific objectives such as achieving consensus, increasing support for the project or identifying new problems, and 2) local constraints of the specific water management effort such as budget limitations, available expertise or number and type of stakeholders. Local objectives as well as constraints of a particular project cannot be mechanistically transferred to other management projects, but must be determined in an analysis of the local context.

From social science, psychology, sociology and related disciplines as well as from case study research, a whole array of methods are available that can be applied to participatory processes. However, the applicability and impact of these methods on such a process is not always obvious to practitioners. For a selected number of methods a uniform set of implementation criteria in the form of a catalogue entry (a initial version of a catalogue was previously published) was developed. This way methods received a comparable set of parameters that relate to the specific limitations and requirements of a local case study. Furthermore, participatory methods were assigned to classes according to their goal-achieving properties. As a result, a typology was created that serves as a basis for further evaluation and selection procedures with the aim of designing, implementing and controlling participatory processes.

The taxonomy was operationalised in two ways: 1) a controlling approach that supports the evaluation and monitoring of ongoing processes, and 2) a decision approach to select methods for the planning and design of participatory processes. The controlling approach is based upon the assumption that methods are effective if goals are reached. However, in this research it is not the achievement of goals that is measured, but the intensity (or strength) of six parameters (activity, equality, transparency, power sharing, flexibility and reach). Similar to the taxonomy of methods, these intensity criteria are comparable parameters that are relevant for participatory processes in general. The intensity criteria are standardised parameters that can be applied to a multitude of objectives that may be related to classes of methods in the taxonomy. If one or more criteria are determined to be insufficiently intensive, conclusions may be drawn about the appropriate choice of (a class of) methods or an incorrect application of this method. In this way, midterm evaluation including feedback and corrections of an ongoing process are possible. The advantage is a transboundary comparability of cases, as well as the availability of control instruments that do not strictly require specific expertise as well as experience with controlling mechanisms. The intensities of criteria can be retrieved with a standardised set of questions that may be posed to practitioners, experts and especially stakeholders.

The taxonomy of methods as well as the controlling approach was applied in the InterReg project TRUST involving five case studies in three Western-European countries. All of the case studies had different water-related issues, constraints and objectives. The methodology as introduced above was a first version developed in close co-operation between scientists and water managers. Capacity building and transboundary learning were key issues of the case study work. The taxonomy together with evaluation and monitoring based upon intensity criteria enabled the water managers to compare approaches and discuss various issues in a 'common language'. Towards the end of the 
case study analysis a 'dependency phenomenon' was discovered. Even after all capacity building activities that they had engaged in, water managers did not feel sufficiently competent to design a participatory process for a new project without the support of experts.

For this reason a 'selection support system' was developed that enables practitioners to select appropriate methods based upon their project goals as well as their local constraints. Based upon the taxonomy, an alignment scheme together with a decision tree walks practitioners through a process of excluding participatory methods that are not relevant for their local project, and the remaining methods are listed sequentially so that the skeleton for a participatory plan is generated. In this way potentially applicable and effective methods can be extracted from a large (and sometimes confusing) pool of methods that would otherwise be overwhelming for practitioners with little or no knowledge of the array of participatory methods at their disposal.

The motivation for developing this methodological framework is to support those practitioners who want to identify the most effective methods for their designated goals under specific local conditions and constraints. Moreover this approach dares to impose a uniform structure on a variety of participatory methods, while permitting sufficient flexibility for adaptation to local circumstances.

Future research is required in the development of a 'support tool' for designing and planning participatory processes in water resources management. Moreover, this methodological framework may then serve as a basis for the improved communication and accessibility of knowledge among scientists, stakeholders, practitioners and policy makers. The most effective implementation of this framework, however, requires a platform such as a web portal, where knowledge from all involved parties can be compiled, structured and made available for lay people, experts, managers and decision makers alike. 
The Europese Kaderrichtlijn Water (KRW) stelt de kaders voor rivierbeheer in de Europese Unie. Artikel 14 uit de richtlijn stelt eisen met betrekking tot de rol van belanghebbenden in een vroeg stadium van het besluitvormingsproces. De vraag is niet langer of de participatie van belanghebbenden in rivierbeheer van nut kan zijn, maar veelaleer hoe een efficiënte en effectieve samenwerking tussen beleidsmakers, experts en leken tot stand gebracht kan worden. Ruim voordat een aanvang werd gemaakt met dit beleidsstuk, was al veel onderzoek verricht om een beter begrip te krijgen van de wisselwerking tussen praktijkmensen, onderzoekers en belanghebbenden in de besluitvorming rond waterbeheerprojecten. Deze onderzoeken brachten wetenschappelijke inzichten samen met de behoeften van belanghebbenden en de hedendaagse Europese beleidsagenda. De kwaliteit van het onderzoek is meestal hoog, de resultaten zijn nuttig en nieuw ontwikkelde managementmethoden voldoen aan de eisen gesteld door de KRW. Zodra echter de onderzoeksprojecten afgerond zijn en de betrokken praktijkmensen verder gaan met andere activiteiten, rijzen vragen ten aanzien van de toepasbaarheid van de (vaak op gevalstudies gebaseerde) onderzoeksresultaten. Er is een veelvoud aan richtlijnen en best-practice documenten gepubliceerd, maar de meerderheid hiervan is nauwelijks bekend onder waterbeheerders in Europa. Daarnaast zijn deze richtlijnen en documenten vaak moeilijk te begrijpen, en bovendien moeilijk aan te passen aan specifieke gevallen.

De toepassing van participatiemethoden in besluitvormingsprocessen is uitgegroeid tot een goed ontwikkelde 'discipline', die vraagt om kennis en ervaring om toe te kunnen passen. De meeste waterbeheerders in Europa zijn echter in de meesten gevallen geen experts op het gebied van participatieve methoden.

Daarnaast vormt het dualisme van casestudie specifieke eisen enerzijds en een algemeen toepasbare methode anderzijds, vaak een probleem wanneer geprobeerd wordt participatieve methoden in het waterbeheer in de praktijk toe te passen. De ervaringen met grensoverschrijdende projecten bijvoorbeeld zijn vaak niet direct opnieuw toepasbaar of relevant. Dit proefschrift tracht bij te dragen aan de oplossing van dit prob- 
leem door een aanpak te ontwikkelen die praktijkmensen met weinig kennis van participatieve processen in staat stelt om participatieve methoden te selecteren die tegemoet komen aan de specifieke eisen van een lokaal project.

Voor dit doel is een taxonomie van participatieve methoden ontwikkeld, die onzekere parameters binnen participatieve methoden verwijdert en ze toewijst aan twee categorieën: 1) casestudie-specifieke doelstellingen, zoals het bereiken van consensus, het vergroten van draagvlak voor een project of de identificatie van nieuwe problemen, en 2) lokale randvoorwaarden aan de inspanningen van het specifieke waterbeheer, zoals het beschikbare budget, de beschikbare expertise, of het aantal en het type belanghebbenden. Lokale doelstellingen en randvoorwaarden kunnen niet zonder meer worden toegepast op andere beheersprojecten, maar moeten worden bepaald in een analyse van de lokale omstandigheden. Vanuit de sociale wetenschappen, psychologie, sociologie en gerelateerde disciplines is een heel assortiment van methoden beschikbaar die toegepast kunnen worden in participatieve processen. Voor praktijkmensen is de toepasbaarheid en invloed van dergelijke methoden in het besluitvormingsproces echter niet altijd helder. Voor een aantal gekozen methoden is een eenduidige set implementatiecriteria in de vorm van een catalogus ontwikkeld; een eerste versie is reeds gepubliceerd. Op deze manier is aan verschillende participatieve methoden een vergelijkbare set parameters toegekend, die verband houden met de specifieke vereisten en beperkingen van een lokale casestudie. Daarnaast, en dit is een vernieuwend aspect, zijn de methoden toegewezen aan klassen, overeenkomstig de doelgerichte eigenschappen van de methoden. Hieruit resulteert een typologie, die dient als basis voor verdere evaluatie- en selectieprocedures die het ontwerp, de implementatie, en het beheer van participatieve processen tot doel hebben. De taxonomie is op twee manieren geoperationaliseerd: 1) een controlerende benadering, die de evaluatie en het monitoren van doorlopende participatieve processen ondersteunt, en 2) een besluitvormingsbenadering, om methoden voor de ontwikkelingen en het ontwerp van participatieve processen te selecteren.

De controlerende benadering is gebaseerd op de aanname dat methoden effectief zijn als doelen bereikt worden. In het huidige onderzoek wordt echter niet gemeten of doelen bereikt worden, maar wordt gekeken naar de intensiteit, of sterkte, van zes parameters (activiteit, gelijkwaardigheid, transparantie, delen van macht, flexibiliteit en reikwijdte). Net als bij de taxonomie van methoden zijn deze intensiteitscriteria vergelijkbare parameters die relevant zijn voor participatieve processen in het algemeen. De intensiteitscriteria zijn gestandaardiseerde parameters die kunnen worden toegepast op een veelvoud aan doelstellingen, die kunnen worden gerelateerd aan de klassen uit de taxonomie. Als de intensiteit van een of meer van de criteria wordt beoordeeld als onvoldoende, kunnen conclusies getrokken worden over de meest geschikte keuze voor een bepaalde (klasse van) methode(-n) of over een onjuiste toepassing van deze methode. Op deze manier is het mogelijk een proces halverwege te evalueren en de uitkomsten terug te koppelen, en naar aanleiding daarvan eventuele aanpassingen te maken. Twee voordelen zijn een grensoverschrijdende vergelijkbaarheid van casestudies, en de beschikbaarheid van beheersinstrumenten die niet per se specifieke kennis, of ervaring met controlemechanismes vereisen. De intensiteit waarop de verschillende criteria scoren kan beoordeeld worden aan de hand van een groep standaard vragen, die 
beantwoord kunnen worden door praktijkmensen, experts en vooral belanghebbenden zelf.

De taxonomie van methoden en de controlerende benadering zijn toegepast in het InterReg project TRUST, dat betrekking heeft op vijf casestudies in drie West-Europese landen. Alle casestudies betroffen andere watergerelateerde kwesties, randvoorwaarden en doelen. De methode die hierboven is beschreven betreft een eerste versie, ontwikkeld in nauwe samenwerking met wetenschappers en waterbeheerders. Centraal in het casestudie onderzoek stonden het ontwikkelen van capaciteit en grensoverschrijdend leren onder participanten. Samen met evaluatie en monitoring op basis van de intensiteitscriteria, stelt de taxonomie de waterbeheerders in staat om verschillende benaderingen te vergelijken en verschillende kwesties te bespreken in een 'gedeelde taal'. Aan het einde van de casestudie werd een afhankelijkheidsfenomeen ontdekt: zelfs nadat waterbeheerders alle activiteiten gerichten op het ontwikkelen van capaciteit en kennis hadden doorlopen, voelden zij zich nog steeds onvoldoende in staat om een participatief proces voor een nieuw project op te zetten, zonder de ondersteuning van experts. Om deze reden werd een 'selectie ondersteuningssysteem' ontwikkeld, dat mensen in staat stelt om geschikte methoden te selecteren op basis van hun lokale doelstellingen en randvoorwaarden.

Gebaseerd op de taxonomie, leiden een trajectschema en een beslisboom de praktijkmensen door een proces waarin ongeschikte participatieve methoden, die niet relevant zijn voor het betreffende lokale project, afvallen, en waarin de overgebleven methoden overeenkomstig het tijdsverloop van het proces worden gerangschikt, zodat het geraamte voor een participatief plan ontstaat. Op deze manier kunnen mogelijk toepasbare en effectieve methoden geselecteerd worden uit een grote, en soms verwarrende, verzameling van methoden, waaruit praktijkmensen met weinig of geen kennis van de beschikbare methoden anders moeilijk wegwijs zouden kunnen geraken.

De motivatie om dit methodologische raamwerk te ontwerpen is het ondersteunen van die praktijkmensen, die willen vaststellen wat de meest effectieve participatieve methode is voor hun specifieke doel, onder specifieke lokale omstandigheden en randvoorwaarden. Deze benadering gaat bovendien zo ver dat er een uniforme structuur wordt opgelegd aan een variëteit aan participatieve methoden, terwijl er voldoende flexibiliteit blijft voor aanpassing aan lokale omstandigheden.

Een suggestie voor toekomstig onderzoek is de ontwikkeling van een 'ondersteunende softwaretool' voor het ontwerpen en plannen van participatieve processen in waterbeheer. Het hier gepresenteerde methodologische raamwerk kan dan bovendien dienen als basis voor verbeterde communicatie tussen, en betere toegang tot kennis voor, wetenschappers, belanghebbenden, praktijkmensen en beleidsmakers. De meest effectieve implementatie van het raamwerk echter, vereist een platform zoals bijvoorbeeld een webportal, waar kennis van alle betrokken partijen verzameld, gestructureerd, en beschikbaar gemaakt kan worden voor zowel leken, experts, en waterbeheerders als voor beleidsmakers. 
Preface

$\begin{array}{lll}\text { Summary } & \text { v }\end{array}$

Samenvatting viii

1 Introduction 1

1.1 The 'spectre' of participation . . . . . . . . . . . . . . . . 1

1.2 Previous experiences with participatory processes . . . . . . . . . 2

1.3 Responsibility and norms . . . . . . . . . . . . . . . 6

1.4 Management problems ................... 7

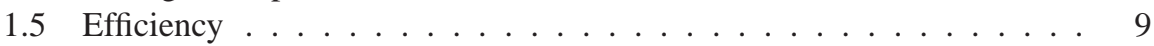

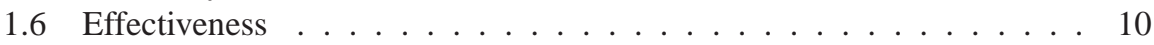

1.7 Research questions and outline . . . . . . . . . . . . . . 11

2 Fundamental philosophical, theoretical and methodological concepts $\quad \mathbf{1 4}$

2.1 Introduction . . . . . . . . . . . . . . . . . . . . 14

2.2 Philosophical and theoretical basis . . . . . . . . . . . . . 16

2.2.1 Sustainability and sustainable development . . . . . . . . . 18

2.3 Governance: how to implement policy . . . . . . . . . . . . . . . . 22

2.3.1 Governance approaches and their components . . . . . . . . . 23

2.3.2 Governance models . . . . . . . . . . . . . . . . 24

2.4 Integrated environmental assessment - a methodological framework . . 27

2.4.1 The evolution of IEA . . . . . . . . . . . . . . . . . . . 28

2.4 .2 Methodology .................. . . 29

2.4.3 Examples of combining participatory methods with expert meth-

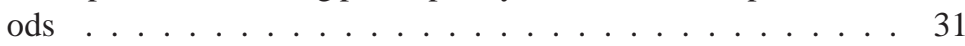

2.5 Multi-disciplinarity, inter-disciplinarity and trans-disciplinarity . . . . . 33 
3 A methodological structure for participatory water resources management 35

3.1 Introduction . . . . . . . . . . . . . . . . 35

3.2 Literature review . . . . . . . . . . . . . . . . . . . . . . . . . . . 46

3.2.1 Discussion ........................ 41

3.3 Fundamental terms and notions . . . . . . . . . . . . . . . 42

3.3.1 Types of participants of a participatory process . . . . . . . . 42

3.3.2 Methods ..................... 43

3.3 .3 Processes ..................... 44

3.4 Classes of participatory methods - a new category . . . . . . . . . . . 46

3.4.1 Matching classes of participatory methods with targeted goals . 46

3.5 Levels, classes and methods of participation - the macro structure . . . . 49

3.5 .1 Information provision $\ldots \ldots \ldots 53$

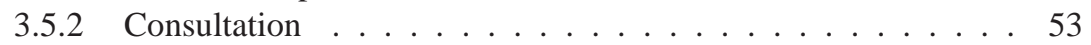

3.5 .3 Active involvement . . . . . . . . . . . . . . . . 53

3.5 .4 Social learning . . . . . . . . . . . . . . . . . . . . . . . . . . . . . . 54

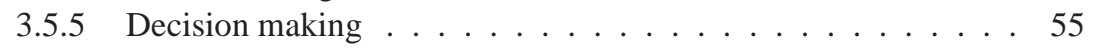

3.5.6 Discussion - levels of participation . . . . . . . . . . 55

3.6 Implementation criteria of participatory methods - the micro structure . 56

3.6.1 Grouping and description of implementation criteria . . . . . 57

3.6.2 Discussion of implementation criteria . . . . . . . . . . . . . 60

3.7 Summary and conclusions . . . . . . . . . . . . . . . 60

4 Monitoring and evaluation of participatory processes - the COPIR approach 62

4.1 Introduction . . . . . . . . . . . . . . . . . 62

4.2 Evaluating, monitoring - controlling .................... 63

4.3 The COPIR approach . . . . . . . . . . . . . . 66

4.3.1 Determining intensity criteria . . . . . . . . . . . 67

4.3.2 Intensity criteria derived from levels of participation . . . . . . 68

4.3.3 Intensity criteria derived from general normative values . . . . . 68

4.3.4 Can six intensity criteria represent multiple goals? . . . . . . . 69

4.3.5 Definition and application of intensity criteria . . . . . . . . . 70

4.3.6 Obtaining, classifying and presenting process intensity values . 74

4.3 .7 Reporting . . . . . . . . . . . . . . . 76

4.4 Summary and Conclusions . . . . . . . . . . . . . . 77

5 The case studies $\quad 79$

5.1 Introduction . . . . . . . . . . . . . . . . . . . . 79

5.2 Applied methods and capacity building activities . . . . . . . . . 81

5.2.1 Participatory plans . . . . . . . . . . . . . . 81

5.2.2 Evaluation and monitoring: the implementation of the COPIR

approach ......................... 83

5.2 .3 Goal achievement . . . . . . . . . . . . . . . . . 86

5.3 Case study description and results . . . . . . . . . . . . . . 87 
5.3.1 British Waterways (BW): Stroud canal restoration . . . . . . . . 87

5.3.2 Glasgow City Council (GCC): the regeneration of Ruchill Park 90

5.3.3 POM West-Vlaanderen: constructing a new fresh water basin . 93

5.3.4 Water Board of Schieland and the Krimpenerwaard (HHSK): a new water way . . . . . . . . . . . . . . . 96

5.3.5 The Province of North-Holland (PNH): improving and extending a recreation area . . . . . . . . . . . 100

5.4 The evaluation and monitoring process as a whole . . . . . . . . . 102

5.5 Summary and conclusions . . . . . . . . . . . . . . 105

6 A selection procedure for participatory process design 106

6.1 Introduction . . . . . . . . . . . . . . . . . . . 106

6.2 Decision trees . . . . . . . . . . . . . . . . 107

6.3 The alignment of methods . . . . . . . . . . . . . . . . 107

6.3.1 Participatory management . . . . . . . . . . . . . 108

6.3.2 First alignment level: phases . . . . . . . . . . . . . 110

6.3.3 Second alignment level: Tasks . . . . . . . . . . . . . 111

6.4 Selecting participatory methods with the help of a decision tree . . . . . 113

6.4.1 Contingency table 1: Matching classes of participatory methods with objectives . . . . . . . . . . . . . . 114

6.4.2 Contingency table 2: Number of participants . . . . . . . . 115

6.4.3 Contingency table 3: required moderator skills . . . . . . . . . 117

6.4.4 Contingency table 4: Required expertise . . . . . . . . . 118

6.4.5 Cost/effort share . . . . . . . . . . . . . . . . . . . 119

6.5 Synthesis of alignment of methods with the decision tree . . . . . . . 119

6.6 Conclusions . . . . . . . . . . . . . . . . 120

7 Conclusions and prospects $\quad 122$

$\begin{array}{ll}\text { Bibliography } & 128\end{array}$

$\begin{array}{ll}\text { A List of case study activities } & 140\end{array}$

B Example for a catalogue entry: Large group response exercise 142

$\begin{array}{ll}\text { About the author } & 144\end{array}$ 
2.1 Steps in the iterative policy cycle (Pahl-Wostl, 2008, p.3) . . . . . . 26

3.1 Scale of participation in the "life cycle" of an environmental problem

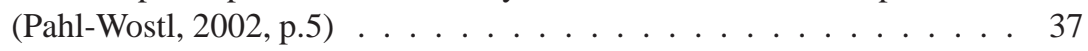

3.2 Methods-goals matrix (van Asselt et al., 2001, p.9) _ . . . . . . . 39

3.3 Levels of participation according to the guidance document of the WFD (European Commission, 2003, p.(iv)) . . . . . . . . . . . . 51

3.4 Levels and classes of participation (Hare and Krywkow, 2005, p.19) . . 52

4.1 The six dimensions of the intensity of participation (Krywkow et al.,

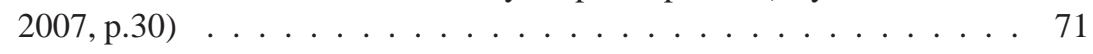

4.2 The relationship among Intensities, objectives and classes of participation 73

4.3 Levels of intensities in a radial chart . . . . . . . . . . . . 74

4.4 Types of participatory processes (Rasche et al., 2006, p.6) . . . . . . 76

5.1 Location of the five case studies _ . . . . . . . . . . . . . 79

5.2 Example of a planning sheet: GCC $2007 \ldots \ldots \ldots$. . . . . . 84

5.3 Mutations in the intensity of participation 2005 and 2007 (BW) . . . . 90

5.4 Mutations in the intensity of participation 2005 and 2007 (GCC) . . . 93

5.5 Mutations in the intensity of participation 2005 and 2007 (POM) . . . 95

5.6 Mutations in the intensity of participation 2005 and 2007 (HHSK) . . 99

5.7 Mutations in the intensity of participation 2005 and 2007 (PNH) $\ldots 102$

6.1 The constraints - method - objectives framework $(\mathrm{CMO}) \ldots \ldots$ 
3.1 Matching goals to classes of participatory methods (adapted from Hare and Krywkow (2005, p.18)) . . . . . . . . . . . . . . . . 48

3.2 The ladder of Citizen Participation Arnstein (1969) . . . . . . . . . . . 49

3.3 Levels of participation according to (Mostert, 2003a) . . . . . . . . . . 50

3.4 Summary of implementation criteria (Hare and Krywkow, 2005) . . . . 59

3.5 Resources breakdown (Hare and Krywkow, 2005) . . . . . . . . . . . . 59

4.1 Evaluation criteria (Rowe and Frewer, 2004) in relationship to the six dimensions of intensity . . . . . . . . . . . . . 69

4.2 Definition of values of intensity dimensions (Rasche et al., 2006, p.5) 72

4.3 Interview questions in relationship to the intensity criteria (Rasche et al., 2006; Krywkow et al., 2007) . . . . . . . . . . . . 75

5.1 Evaluation points within the TGIII process . . . . . . . . . . . . 85

5.2 Goal achievement of each partner . . . . . . . . . . . . . . . 86

5.3 Relevant stakeholders of the BW project . . . . . . . . . . . . . . . 88

5.4 Main participatory activities of the BW project . . . . . . . . . . . 89

5.5 Relevant stakeholders of the GCC project (Krywkow, 2007) . . . . . . 91

5.6 Main participatory activities of the GCC project . . . . . . . . . . . . . 92

5.7 Relevant stakeholders of the POM project . . . . . . . . . . . . . . 95

5.8 Main participatory activities of the POM project . . . . . . . . . . . . . 96

5.9 Relevant stakeholders of the HHSK project . . . . . . . . . . . . . . . 98

5.10 Main participatory activities of the HHSK project . . . . . . . . . . . . 98

5.11 Relevant stakeholders of the PNH project . . . . . . . . . . . . . . 101

5.12 Main participatory activities of the $\mathrm{PNH}$ project . . . . . . . . . . . 101 
6.1 A framework for the design of a participatory process including phases (columns), tasks (bold), methods (normal font) and goals (circled num-

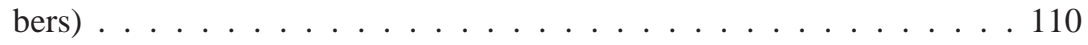

6.2 Matching goals to classes of participatory methods (adapted from table 5.2) . . . . . . . . . . . . . . . . 115

6.3 Contingency table 2: number of participant and appropriate methods, adapted from Hare and Krywkow $(2005,20) \ldots \ldots$

6.4 Contingency table 3: required moderator skills _ . . . . . . . . 117

6.5 Contingency table 4: Expertise (application skills) . . . . . . . . 118

A.1 Overview of main TRUST TGIII activities (Krywkow, 2007, p.13) . . 140

A.1 Overview of main TRUST TGIII activities (Krywkow, 2007, p.13) . . 141

B.1 Summary of implementation criteria . . . . . . . . . . . . . . 142

B.2 Resources breakdown . . . . . . . . . . . . . . . . . . . . 143 


\section{List of Abbreviations}

$\mathrm{ABM}$

ACF

AEAM

AWM

BW

CAS

CBA

$\mathrm{CMO}$

COPIR

DT

$\mathrm{EU}$

FP6

FR

GCC

HHSK

IAD
Agent-based Models

Advocacy Coalition Framework

Adaptive Environmental Assessment and Management

adaptive water management

British Waterways

complex adaptive systems

Cost-Benefit Analysis

the Constraints-Methods-Objectives scheme

Constraints, Objectives, Process, Intensities, Reporting

Decision tree

European Union

Sixth EU Framework Programme for Research and Technological Development

final report of the TRUST/TGIII project

Glasgow City Council

Hoogheemraadschap van Schieland en de Krimpenerwaard (the 'Schieland en de Krimpenerwaard' District Water Board

Analysis and Design Framework

xvii 
IEA Integrated Environmental Assessment

IER interim evaluation reporting: evaluation method as applied in the TRUST project

INTERREG IIIb Interregional co-operation between regional and other public authorities across the entire EU territory and neighbouring countries. $\mathrm{IIIb}=$ trans-national co-operation

IR

Inception Report of TRUST/TGIII

ISO International Organization for Standardization

IVM Integraal Verkenning Maas (Integrated Assessment of the river Maas)

IWRM Integrated Water Resources Management

MAS

Multi-agent System

MCA

Multi-criteria Analysis

NGO

non-governmental organisation

PM

participatory methods

$\mathrm{PNH}$

Provincie Noord-Holland

PNS

post-normal science

POM

Provinciale Ontwikkelingsmaatschappij West-Vlaanderen (executive organisation of the Province of West Flanders)

PS planning sheet: monitoring method as applied in the TRUST project

RAINS The 'Regional Air Pollution INformation and Simulation' model

TGIII theme group 3 of the TRUST project

TRUST Transformation of Rural and Urban Spatial sTructures: a project within the INTERREG IIIb programme

UN United Nations

WFD Water Framework Directive 
CHAPTER 1

Introduction

\subsection{The 'spectre' of participation}

This thesis concerns participatory processes in environmental decision making with a focus on water resources management. Public and stakeholder participation ${ }^{1}$ is a controversial subject since this process entered the political and science arena. Supporting arguments such as increased democratisation, transparency, equity and distributed responsibility are offset by criticisms including increased complexity, higher costs, delays in the decision process, unequal access to information and stakeholder fatigue. Many pragmatically-oriented decision makers see a discrepancy between political visions and practical implementation. Often public participation is viewed as an ideological construct that is desirable but not practical or only partially implementable if additional resources are made available for its administration.

Walter (2006) claims that public participation is a utopia of a well-educated middle class that implies a number of risks and unwanted side-effects to political processes. His first argument is, not surprisingly, that the visions of liberal citizens are in many cases incompatible with the practical administrative work of the responsible authorities. Furthermore, access to and the impetus for undertaking participatory activities seem to correlate with the level of education, and this restrictive access may lead to the establishment of a 'participatory process oligarchy'. As a result, a less-educated (and arguably larger proportion) of society would be excluded from comprehending and engaging in relevant political processes. If this is true, Arnstein's vision of increasing citizen power as depicted in the ladder of participation (Arnstein, 1969) had mutated into a dystopia. Moreover, the Silent Revolution as postulated by Inglehart (1977) would have turned its visions against its own protagonists. Post-modern values such as political freedom or

\footnotetext{
${ }^{1}$ A detailed definition of this term is provided in section 3.3.3.
} 
environmentalism could only be relevant for an intellectual elite within the middle class of Western societies. Walter's scepticism goes further while referring to the growing implications of globalisation including the predominance of economic and market values (acceleration, mobility and flexibility) within the reasoning of political, economic and administrative decision makers on the one hand, and the difficulty for lay people to invest energy in the improvement of their, in many cases, temporary habitats. As an inevitable consequence, the societal role of social capital and altruism is, at the same time, decreasing.

Furthermore, Walter (2006) claims that as much as globalisation-friendly economic liberalists believe in the invisible hand (Smith, 1776) and thus in self-regulating market dynamics, committed citizens tend to believe in the self-organisation of activists. This, however, would imply even more uncertainty resulting from unpredictable human behaviour on a scale between stakeholder fatigue (i.e. no participatory activity) and 'hyperactive' players (who tend to veto all proposals). Walter (2006) argues further that contemporary societies increasingly face the management of complexity, which can be most effectively and efficiently accomplished by the delegated power of a parliamentary democracy including professional administrative and executive structures. This includes, among other activities, welfare management, infrastructure investment and maintenance, as well as risk management. Apart from introducing additional uncertainty, the implementation of public and stakeholder participation reduces political and executive control, makes policy processes more inconsistent and requires additional resources. The congruity of Walter's view with the role of governmental authorities according to Smith (1776) is apparent.

In summary, it can be said that Walter (2006) does not categorically reject the participation of lay people ${ }^{2}$ in policy processes, but is concerned about the negative implications of its operationalisation, the lack of efficiency and effectiveness, the introduction of additional complexity, goal diversity and uncertainty, the emergence of dominating elites and a (possible) reversal of formerly well-intended motivations, values and norms. Walter's arguments form a red thread through the relevant publications and are, for example, picked up by Harding (1998) who adds issues such as the dominance of one or more interest groups ${ }^{3}$, 'waking up sleeping dogs', lobby activities, difficulty in comprehending technical issues and manipulation due to the dissemination of selective or 'tainted' information.

\subsection{Previous experiences with participatory processes}

Various participatory processes and case studies highlight the problems that may arise in the collaboration of responsible administrations with the public and stakeholders. The following case examples provide an overview of the challenges:

Case example I: Leussen (2000) describes the course of the so-called Maaswerken project evolving from a solely engineering project with the aim of increasing flood

\footnotetext{
${ }^{2}$ lay people referring here to those individuals who have specific interest in but no particular expertise in a policy process.

${ }^{3}$ This is different from a 'well-educated elite' and refers to self-serving goals such as maximising profit or the overuse of common pool resources
} 
protection on the Maas River in the Netherlands to a multi-disciplinary project striving for the incorporation of environmental considerations as well as stakeholder interests. Particular features of this large infrastructure and flood protection project are:

- the large scale - $200 \mathrm{~km}$ of a stretch of river;

- the multitude of involved governmental authorities ranging from state ministries to local municipalities, NGOs, commercial enterprises, citizen groups and advocacy groups;

- the growing complexity of concatenated problems and side effects;

- the extraordinary length of the process (1995 until the present $\left.{ }^{4}\right)$ without the implementation of a complete set of measures;

- changing strategies of planning and implementation over the years; and

- dwindling stakeholder support correlated with the length of time the project has been underway.

The interaction of the responsible authorities with relevant stakeholders was difficult. For example, in the year 1998 the project organisation Maaswerken published a report with a number of preferred solutions for the implementation of measures along the river Maas in the Dutch province of Limburg (De Maaswerken, 1997a). The multitude of public and stakeholder objections were published in a heavy two-volume report (De Maaswerken, 1997b). The aim of Maaswerken was to achieve consensus on the proposed measures. Consensus was never reached, and none of the relevant measures were implemented.

In her endeavour to analyse the integration of expert knowledge with lay knowledge in the follow-up projects of Maaswerken, IVM I and IVM II, Wesselink (2007) observed (a) excessive complexity of problems, knowledge and perspectives and (b) the difficulty in (social) learning within this policy process.

Case example II: Panebianco and Pahl-Wostl (2004) endeavoured to initiate a participatory process in conjunction with an agent-based modelling approach. The focus of the scientists was on the development of sewage systems in East German municipalities in the first decade of the renewal phase after the reunification. The intention was to analyse capacity problems and examine alternatives together with users, suppliers and responsible authorities. An agent-based model was designed to support a group process, and allocate alternative solutions. However, the scientists underestimated the problems at stake, the controversial interests and political sensitivity of the issue. Most stakeholders refused to commit to a group model process. In the end it was impossible to proceed with the original approach, and a compromise had to be found.

Case example III: Hommes et al. (2009) examine the case study of the extension of Mainport Rotterdam, involving reclamation of land from the North Sea, that may have significant effects on the Wadden Sea to the northeast of the harbour site. The Wadden

\footnotetext{
${ }^{4}$ Meanwhile the Maaswerken project passed on to the IVM I and IVM II project
} 
Sea is a vulnerable wetland protected by the European Bird and Habitat Directives. Expert knowledge and judgement was the basis for the design of the plans. Additionally, stakeholders perspectives where collected and discussed in several meetings. The Dutch Fish Product Board had some significant objections to the official plans based upon their concerns about the possible disturbance of fish migration. Furthermore, this association felt excluded from the early and decisive phase of the negotiation process. Not before the second phase of negotiations were the objections of the Dutch Fish Product Board taken into consideration.

However, there are also a multitude of positive examples for participatory activities. Some recent examples that have been referred to in this research project are described below.

Case example IV: The European FP6 project NeWater ${ }^{5}$ had a focus on methods of adaptive water management with some emphasis on integrated and participatory approaches. One of the five case studies took place in the Amudarya river basin in Uzbekistan. The main issues in this river basin are desertification, irrigation and the availability of clean water for the residents in the basin. Hirsch et al. (2007) reports that stakeholders from all administrative and societal levels ranging from the Ministry of Agriculture and Water Management to NGOs, farmers and fishermen were invited to participate in stakeholder workshops. These workshops endeavoured to develop tools to support water management and allocation planning. Hirsch et al. (2007) observes that Uzbekistan has little to no tradition of public and stakeholder participation. This notwithstanding, all involved stakeholders realised the importance and added value of participatory processes in the management of the Amudarya basin ranging from improved information provision to more efficient co-ordination of measures and learning processes. NeWater experts provided training sessions for water managers, who valued the support, and have started to implement their new knowledge in their day-to-day work.

Case example V: Rouchier et al. (2001) describe a multi-agent system to model an artificial society. This modelling approach is based upon a real-world case study that investigates land use conflicts between herder and farmers in North Cameroon. The main problem was caused by transhumance when herders drove their livestock across arable land to their seasonal grazing areas every year. CIRAD, the research institution that supported the research project, ${ }^{6}$ sent scientists to visit both farmers and herders, and used computer models for (a) knowledge elicitation and (b)social learning and conflict resolution in their field work. In addition to collecting data for their simulation model, researchers helped to realise solutions between the conflicting parties.

Case example VI: In their research on new methods for integrating water management with spatial planning (ontwikkelingsplanologie) Rijkswaterstaat(the water authority for the Netherlands) conducted three pilot studies together with local stakeholders. One case study covers coastal protection in conjunction with nature protection in the Dutch province of Zeeland (Landman et al., 2006). Although the methodological approach was novel, and the problems - including the various stakeholder perspectives -

\footnotetext{
${ }^{5}$ http://www.newater.info/

${ }^{6}$ http://publications.cirad.fr
} 
were rather complex, Rijkswaterstaat scientists were able to achieve a consensus based upon an integrated planning approach. Interviews and workshops were the main methods for this pilot study.

The case study examples above cannot prove, but do suggest that Walter's assertions do not apply to all policy processes with the potential for public or stakeholder participation. Moreover, several case studies contradict Walter's statements:

- the fact that scientists were able to involve individuals with lower levels of education in a participatory process as demonstrated in the African herder-farmer conflict, and even contribute to a solution to the conflict, suggests that the "middle class elite' claim is at least not generally applicable;

- the fact that training, application and management of participatory processes in river basin management in Uzbekistan, a country with rather weak democratic structures and traditions is welcome, contradicts Walter's assumption that citizen and stakeholder participation requires a 'democratic' Western society with postmodern norms and values;

- the identification and resolution of complex problems requires expertise. However, the case of the extension of Mainport Rotterdam illustrates that stakeholders are able to contribute to the identification and evaluation of complex problems;

- the controversial interests in the case of the sewage system in Eastern Germany, and the refusal of stakeholders to commit to a dialogue represents a so-called 'messy problem' (Vennix, 1999). A solution without a dialogue can only result, at least for a number of stakeholders, in discontent, tensions and procrastination in the problem solving process; and

- there is no doubt that stakeholder perspectives and perceptions can add more complexity and uncertainty to a project. However, as indicated in the previous item these perspectives and perceptions can also contribute valuable information to a decision process, and have potential to detect design errors and other problems such as side effects that have not been identified in the formal planning or pre-planning process.

On the other hand, a number of salient observations can be made wherever a successful participatory process was carried out in the examples cited: (1) the responsible authorities or experts were well prepared, and had sufficient knowledge and experience in the methods to be applied; (2) although often more difficult to apply and to comprehend, integrating problems and perspectives appears to be more promising than and superior to sectoral approaches; (3) there was sufficient time for both informing stakeholders about often complex issues and applying methods for problem-solving together with the involved individuals; and (4) the processes were strictly goal-oriented and planned through the entire course of the project. The example of Walter (2006) demonstrates that the discussion of participation must factor in a diversity of economic, societal and political fields and the appropriateness of the application of stakeholder 
and public participation in these fields. In general, self-organised 'grass-root' movements must be clearly distinguished from a systematic implementation of participation in decision processes. As stated in the beginning of section 1.1 this thesis is focused on water management. The subsequent sections demonstrate that explicitly formulated normative values require the implementation of stakeholder participation in European water management. Hence, in the following chapters the question is not whether or not to apply participation, but how to apply participation as a methodology. This thesis strives to make the published results of relevant research more easily accessible for practitioners in order to systematically and efficiently implement participatory methods together with expert methods in a decision process.

\subsection{Responsibility and norms}

The problem of complexity in environmental decision processes remains, with or without the inclusion of lay people. The problem of complexity will be discussed in section 2.2.1. Given the arguments listed above, assigning responsibility for problem solving entirely to the responsible authorities including the appointed experts without consulting stakeholders would not appear to be the interest of all actors involved. Public authorities have the responsibility as well as the duty to solve problems. However, 'democratic' societies have installed institutionalised power control mechanisms such as a constitution or planning legislation, entitling the public and stakeholders to participate in policy processes. Sharing the power in (environmental) decision processes has been largely institutionalised in these countries, and may be seen as a normative value that provides the rationale for applying participation in policy processes.

Mostert (2003a, p.179) postulates that there is "no shortage of international declarations referring to public participation as a key water management principle". The Aarhus Convention (UNECE, 1998) provides guiding principles for governmental authorities in how to manage information provision, public opinions and participation in environmental matters. This convention also promotes access to relevant information and the opportunity to participate in policy processes on the part of European citizens. The Dublin Statement, principle no. 2 (United Nations, 1993) requires a participatory approach "... involving users, planners and policy makers on all levels". The Hague Declaration (World Water Council, 2000) identifies seven "challenges" of which the following are most relevant for water management: meeting basic needs (access to clean water), protecting ecosystems (sustainable water management), sharing water resources, managing (hazardous) risks, valuing water, governing water wisely. Many of these issues were reaffirmed at the 4th World Water Forum in Mexico in March, 2006 and incorporated in the Local Government Declaration on Water (The Lisbon Principle) (World Water Council, 2006), which also promotes an integrated, sustainable and equitable approach to (local) water management, and the principle of governing water as a common good. These documents are examples of declarations that serve as policy guidelines, but are not legally binding.

A milestone in the establishment of public and stakeholder participation in the legislation of European Union member states, and a step forward to more concrete regulations, is the European Water Framework Directive (WFD) EU (2000). The WFD 
declares river basins as administrative units for river basin management within member states of the EU. Article 13 EU (2000, L327/16) outlines the implementation of national and international river basin plans. Article 14 EU (2000, L327/16) provides guidelines for "public information and consultation". Time frames for planning and publishing river basin management plans are prescribed, and public comments have to be recorded a minimum of six months prior to any decision or policy implementation. The involvement of the public is stressed. Although the WFD does not prescribe specific steps of public and stakeholder participation, the mere fact that this directive must be incorporated in the legislation of the EU member states prior to the year 2009 is a step forward in the direction promoted by the aforementioned conventions and declarations. More detailed advice on public and stakeholder participation is provided in the Guidance document on participation in the WFD (Drafting Group, 2002).

In addition to international declarations and conventions, the International Organization for Standardization (ISO) prescribes international standards for business, government and society. The quality management principles are documented in the ISO 9000 (ISO, 2000), and include principles on how to involve lay people in a management process. These principles are rather broad and non-committal, but criteria such as transparency, identifying constraints, sharing knowledge and experience as well as creativity in furthering an organisation's mission are included.

Irrespective of legal considerations, the aforementioned declarations, guidelines and regulations taken together provide a normative basis for objectives and goals of water resources management and the accompanying participative processes. The main requirements for a participatory process derived from these documents include the following:

- an integrated approach to water resources management;

- sustainable water management;

- transparency in governance and the policy process;

- comprehensive, structured, accessible and comprehensible information provision prior to and during the policy process;

- early involvement of the public and stakeholders in the policy process;

- recognition and acceptance of various perspectives on water management issues; and

- equity for all involved social entities during the policy process.

These criteria provide the guiding principles and normative foundation for the analysis and methods presented in this dissertation.

\subsection{Management problems}

The cases outlined in the previous section demonstrate various endeavours of authorities to apply participatory processes with mixed success. If participation is a desirable process within water resources management, a number questions must be addressed in 
order to successfully integrate public and stakeholder participation in a planning project or decision making process:

- How should lay knowledge be integrated with expert knowledge?

- How can complex issues within the planning context be conveyed to lay people?

- How should the various perspectives and views of involved stakeholders be handled?

- How can lay knowledge be elicited and incorporated in the planning process?

- Does the incorporation of lay knowledge result in higher levels of complexity and uncertainty in the problem space, and, if so, how can this be handled?

- If lay people should be involved in planning and decision-making activities, how is this to be accomplished?

- Should a participative process be monitored and controlled? If so, how can this be accomplished?

- How can contradictory perspectives and opinions or even conflicts concerning the problem and/or its solution be solved?

- How can resources be secured for the entire course of a participatory process?

Answers to these questions are provided in the array of guidebooks, manuals, web sites and other media available on this theme of participation. However, the problem space is complex, the diversity in local context is huge, and the supply of available methods is proliferating. One of the particular observations throughout the research undertaken for this dissertation, both in the field work and in the literature, is the fact that water resources management relies on engineers, spatial planners, economists and ecologists, but not on participatory managers who are familiar with the available methods, and have experience in interaction with stakeholders. In practise, the incorporation of participatory processes in water management and planning is often poorly conceived, and the impact and benefits of stakeholder participation on an entire planning process are frequently misinterpreted or underestimated. This holds true particularly when uncertainty increases, and negotiations are delicate. The range of management approaches may extend from authoritarian and strictly hierarchical (top-down) regimes with little leeway for active involvement and adaption of new perspectives to completely handing over the design and decision process to self-organised groups of stakeholders. Selforganisation may be seen here as a bottom-up process of individuals and groups with particular interest in one or several issues at stake and a significant impulse for influencing decisions.

Nevertheless, 'social assessment' should receive more attention, because throughout a 'policy life cycle' (Pahl-Wostl, 2002) social processes are far more dynamic and mutational than processes of the physical environment. Moreover, 'social assessment' is an inaccurate term, since the assessment of the social system is part of, but not sufficient for incorporating the public and stakeholders in a policy process. In fact, the 
management of the participatory processes requires more attention, skills, flexibility and knowledge than generally believed. Hence, the central premise of this thesis is:

Effective and efficient participatory processes in water resources management may not be abandoned to self-organisation nor should such processes be reduced to a minor item within project activities or decision-making processes, but must be well-planned and managed by individuals who have expertise on par with that of engineers, spatial planners and ecologists.

Implicit in this statement, however, are a number of questions, most importantly: What constitutes 'effectiveness and efficiency' and how can they be achieved in participatory processes associated with water resources management? This question forms the basis of the research presented here.

\subsection{Efficiency}

Efficiency has several definitions in administration, business and economics. Whereas in business and policy evaluation the efficiency ratio is simply the percentage of revenue (expenses / revenue) or costs / benefit, in economics the definition is more elaborate. An economy is efficient when as many as goods as possible are produced using as few resources as possible. Economists from Smith (1776) to Menger (1871) believed that a market economy was more efficient than other alternatives. In welfare economics several models of efficiency have been developed: in a market with a given set of allocations (goods or incomes) and individuals a change from one allocation can make at least one individual better off without making another worse off is termed Pareto improvement. Pareto efficiency is achieved when no more Pareto improvement can be made. In other words an optimum is reached under a set of given assumptions. The so-called first welfare theorem asserts that a system of free markets will result in Pareto efficiency (for example Greenwald and Stiglitz (1986) and Ng (1979)); another example is the Kaldor-Hicks efficiency, that has less stringent assumptions, and compensation may be directed from the better-off to the worse-off. This, however, will result in Pareto efficiency. Kaldor-Hicks efficiency is being introduced with the argument that in real-world markets there is no social action (i.e. policy instruments) resulting in better outcome without making at least one individual worse off (Hicks, 1939; Kaldor, 1939).

It may be enticing to apply clear quantifiable economic principles to the interaction of authorities in a participative environmental decision process. However, a number of criteria cannot be satisfied:

1. goods and incomes in an economic market are quantifiable, whereas values and priorities in an environmental decision process are not;

2. public goods or common pool resources, often the main focus within an environmental decision process, result in an 'agency dilemma' and 'asymmetric information' (Stiglitz, 1987). In other words the public goods cannot be unequivocally assigned to particular individuals. The knowledge gradient between authorities (including experts) and the public concerning public goods may be steep at least in the initial phase; 
3. rationality cannot be assumed, since the individuals involved in such a decision process may not necessarily be maximising their utility;

4. a policy process proposing measures within a localised system can impose externalities to particular individuals;

5. property rights can play a role in such a policy process, especially if private land is required for development, placing the affected individuals in a strong bargaining position.

Given that these criteria are not satisfied by the use of a free market analogy in an environmental decision process, optimisation approaches such as cost-benefit analysis are virtually non-applicable. Although, effectiveness remains the main focus of this research, efficiency will be discussed in this thesis through the introduction of a set of indicators that support water managers in selecting the most appropriate methods, tools and instruments based upon limited resources. The aim here is an 'optimal use' of resources. However, the efficiency ratio (expenses / revenue) is the most applicable efficiency concept.

\subsection{Effectiveness}

Bressers and Hoogerwerf (1995, p.24) define effectiveness as the degree to which a particular policy or policy instrument contributes to the achievement of a particular goal. Hence a policy (instrument) is $100 \%$ effective, if the goal is achieved. This means that, if evaluating the effectiveness of a policy process and its goal achievement, there is an effectiveness range from $0 \%=$ failure to $100 \%=$ success. However, Bressers and Hoogerwerf (1995) point out that the effectiveness of a policy may be less than the achievement of the related goal if parameters other than a policy (instrument) contributed to the achievement of an aspired goal. Conversely, a policy (instrument) can be fully effective even if the aspired goal is not completely achieved, assuming external parameters induced the failure (e.g. defective technology). Furthermore, and this is most interesting for (usually) complex environmental decision problems, Bressers and Hoogerwerf (1995) distinguishes between planned effects (objectives) of a policy (instrument) and undesired or side effects. If an array of policy instruments are involved in the achievement of not a single but a variety of goals, side effects are nearly inevitable.

Furthermore, with the typical environmental problem there is not a single objective but an array of objectives. This, however, increases uncertainty and the results of an assessment are more a matter of interpretation, even if sophisticated analysis and evaluation methods such as multivariate statistics or multi-criteria analysis (MCA) are employed for the evaluation of effectiveness.

In addition, Coenen (1995) as well as Mohr (1995) discuss the causal chain between the problem, the policy applied and the consequences of the policy. In light of the complex relationship between multiple policy instruments, multiple objectives and side effects in environmental decision making, causal chains are no longer applicable, but causal networks are.

The problem of defining effectiveness in environmental decision processes is extensively discussed in Rowe and Frewer (2004), and the difficulty in identifying (a degree 
of) effectiveness is stressed. Since the problems at stake, the perspectives of stakeholders and the aspired goals may result in a multi-dimensional array of possible variables, effectiveness cannot be defined with a single criteria or goal. This suggests that evaluation criteria for effectiveness are required, and raises the issue of whether or not these criteria can be generalised. Rowe and Frewer (2004) distinguish between universal criteria (i.g. fairness, costs, resources) and local criteria (i.g. attaining consensus, educating stakeholders, achieving a 'complete' involvement) for effectiveness. Furthermore, the question of perspectives is raised: fairness is for example important from a democratic perspective, whereas costs and resources as well as stakeholder support are particularly significant for decision makers. Additionally, process versus outcome effectiveness can be differentiated. A participatory process might have been evaluated as effective, and at the same time the results can be unsuited to the achievement of the targeted goals.

In order to examine the effectiveness of policy processes, an appropriate evaluation procedure is required, as stated in the guiding document of the WFD (Drafting Group, 2002). Thus, effectiveness, achieving goals with given instruments, methods and tools (of a participatory process) will be the central question of this document.

\subsection{Research questions and outline}

The research questions of this thesis are:

\section{Is there a consistent methodological framework for participatory processes in water resources management that is independent of the local context, but flexible and adaptive enough to handle specific issues, and uncertainty?}

On the one hand water managers request comprehensible, consistent and categorical procedures, but on the other hand, universal goals and available methodologies do not always comply with the required local adaptive capacity. Furthermore, a multitude of guide books, instructions, best practise guidelines and research reports are available. However, for many practitioners their value is limited due to the variety of approaches, perspectives and focal points presented. The gap between methodological knowledge and the requirements of practitioners is still present.

In order to contextualise participatory processes in human-environmental systems chapter 2 introduces the abstract representation of such a system including complexity, uncertainty, and multi-disciplinary approaches. The implications of human action on a physical system (hydrosphere, biosphere, pedosphere, atmosphere) are complex and involve feedback of the system with consequences on the living conditions of human beings. If a decision process interferes with the human-environment system, a sound knowledge of this system is required to avoid undesired (long-term) effects. Integrated environmental assessment (IEA) is a promising methodology that implies a multi-disciplinary approach including participatory methods, and tries to achieve sustainability goals. The interdependence of the three domains ecology, economy and the social world are analysed in a holistic way.

Furthermore, since stakeholder and public participation are processes established in the social domain, a closer look on methods that analyse individual behaviour and social 
action is needed. A literature review provides a selection of contemporary methods to analyse and model human behaviour.

Also in chapter 2, the notion of governance as a way to implement policy instruments in order to achieve normative goals is discussed. Governance may be seen here as a management style that regulates how institutional values are balanced with individual goals of involved social entities. Governance, in the participatory context, can also be seen as a means of encouraging responsible authorities to involve lay people in a policy process. A literature review looks at the term governance and its implications for environmental decision processes.

Chapter 3 begins with a review of the relevant guidebooks and articles examining whether or not a methodological framework is available, and how the methodology is implemented in guidance for practitioners. Subsequently, a taxonomy of the relevant terminology: (1) discusses separate notions; (2) introduces the new term classes of participation (classifying methods of participation in a structured way); (3) introduces a renewed methodological scheme that puts methods, classes and levels of participation in context; and (4) introduces a macro- as well as a micro-structure of the methodology that separates the variability of methods in terms of objectives and implementation criteria (constraints).

2. How can water managers be enabled to select appropriate methods for their work, and if required to adjust the methods throughout the course of a project?

The literature review in chapter 3 will reveal problems that water managers might have identifying appropriate guidelines for designing, implementing and monitoring a participatory process. Every project has different constraints such as the nature of the problem itself, availability of resources, the stakeholder community and local traditions. For this reason a mechanistic approach of applying general guidelines is doomed to failure. Available methodologies, tools and instruments need to be employed in an adaptive and flexible way in order to meet the requirements of the specific projects.

In addition, the taxonomy of participatory methods chapter 3 introduces a uniform set of implementation criteria for an effective and - to a lesser extent - efficient application of participatory methods in a policy process given local assumptions and constraints. These criteria not only refer to the available monetary and human resources and the available expertise including required soft skills, but also to the goals of the decision process. Goal-oriented management is the guiding principle in the quest for a general methodological framework for stakeholder and public participation.

Chapter 5, the case study description, depicts how the new methodological framework was developed and implemented in five sub-projects. The overall aim was to adapt the available methodology of participatory methods to the individual requirements of the case studies. Therefore an approach was developed that enabled the water managers to identify problems and to teach water managers to apply participatory methods in their own region. Thus capacity building was a vital part of the collaboration between water managers and scientists. The distinctiveness of this project was the co-development of methods. Scientists could not offer ready-to-go solutions, but developed methods that accompanied the five case studies throughout large parts of the decision process. The 
water managers applied these methods, and the results and effects were a matter for discussion and exchange.

Chapter 6 provides an operationalisation of the newly developed methodological scheme as introduced in chapter $\mathbf{3}$, and experiences that were gained in close collaboration with the water managers. The aim is here to enable water managers to design a participatory plan without professional support such as experienced throughout the case study effort. Methods stemming from artificial intelligence and data mining are applied in order to generate a decision tree for the selection of methods based upon the methodological scheme presented in chapter $\mathbf{5}$ as well as variable parameters of the case study.

\section{Is there a generally applicable method to monitor and evaluate participatory processes independent of the context of a specific project?}

Goal achievement and effectiveness of a decision process are focal points of this research. The implementation of effective instruments, tools and methods requires knowledge and experience. Nevertheless, control is indispensable for quality assurance during the policy process. A new method, developed by Rasche (2005) is employed here, and discussed in chapter 4. Instead of evaluating goal achievement directly, intensity indicators are introduced. This approach evaluates goal achievement by means of six generally applicable (standard) indicators, and makes the control of effectiveness comparable between various case studies. Furthermore, the evaluation procedure is not a mere ex post effort, but was applied during the entire project phase in of all case studies. For this reason interviews with the authorities were conducted, and evaluation reports have been produced as reported in chapter 5. In addition, the results of the interviews are plotted in special diagrams and presented in the same chapter. 


\section{CHAPTER 2}

\section{Fundamental philosophical, theoretical and methodological}

\subsection{Introduction}

Chapter 1 poses questions of the usefulness, applicability and appropriateness of participatory processes as a means for (co) managing environmental decision processes. A number of pros and cons are discussed, and the virtues as well as the pitfalls of applying participatory processes are highlighted. On the one hand, participatory processes seem to be a requirement in the management as well as research of complex environmental problems. On the other hand there are voices who doubt the scientific value of these approaches. This chapter responds to two main questions:

1. What is the scientific legitimacy of applying participatory approaches in the management and research of complex environmental problems? Is it legitimate to incorporate normative and subjective values in a research or management endeavour?

2. How are participatory processes integrated into the theory and methodology of environmental decision and research approaches. How are expert methods and participatory methods coupled? What is the role of participatory methods within the applicable set of methods?

When discussing integration, multi-disciplinarity and holistic approaches it is difficult to examine the concepts without some degree of disaggregation. This, however, might compromise the perspective on the whole. The relevant literature suggests a positive correlation of the degree of integration of participatory and expert methods with the effectiveness of management or research efforts. Yet it is difficult if not impossible to 
provide empirical evidence for this statement. A closer look at the role of participatory methods within integrated approaches in environmental research and management might reveal the imperative of participatory processes, if effectiveness, public acceptance and legitimacy are goals of management or research efforts.

The following sections are structured in a 'hierarchical way'. First, the legitimacy of public or stakeholder participation is explored, and an examination is made of the philosophical and theoretical concepts that support the implementation of participatory methods (including the introduction of uncertainty and, to a limited extent, the weakening of scientific rigour).

Section 1.3 provides an overview of institutional norms that support, encourage and - in the case of the WFD - require the application of participatory processes in environmental decision processes. Responsible authorities are committed to involving the public and stakeholders. Section 3.3.1 will provide a definition of the types of social entities that may be involved in a participatory process. In general a participatory process should involve representatives from three different societal groups: 1) lay people including the general public and stakeholders, 2) experts such as engineers, planners and ecologists, and 3) the responsible authorities. Of course, the affiliation of individuals may be not always be straightforward, but here a principle classification of participants of a policy process is relevant.

Scholars such as Walter (2006) argues that governmental authorities are the legitimate and democratically elected representatives of the populace, and must therefore be trusted to carefully and professionally take decisions. As demonstrated in section 1.1, objections to this proposition are common. Jasanoff (1990) discusses several issues that contradict the assumption of entirely and exclusively trusting a responsible governmental authority in the case of social regulation of rather complex decision processes and projects such as public health, environmental protection or investment in public goods. Some issues such as complexity and uncertainty are inherent, and will always be a challenge for all involved parties in a decision process. Moreover, Jasanoff (1990) mentions imperfect knowledge, the weighting of recommendations and even the possibility to manipulate scientific knowledge and misinterpret data as issues that might influence the outcomes of policy process. In a comparison between 'regulatory science' and 'research science' Jasanoff (1990, p.80) presents a number of attributes that highlight significant differences that should be known when discussing the role of science in policy processes. Examples are goals ("truth" is relevant to policy versus "truth" of originality), products (studies and data analysis, often unpublished versus published papers) or accountability institutions (parliament, courts, media versus professional peers). As a consequence, Jasanoff argues for an early involvement of stakeholders as well as an increase in the quality of regulatory science, for example with the introduction of a peer review. However, as Jasanoff (1990) states, 'regulatory science' is not equivalent to normal science in the sense of Kuhn (1962) (see section 2.2). Therefore, the significance of stakeholder involvement must be highly rated.

Obviously, a significant degree of normative and subjective values has to be incorporated into the research and management. This raises a whole array of red flags for many, especially those scientists who are inclined towards disciplinary and rigorous science. And indeed, the challenge is here to balance among 'subjective' values and 'objective' 
scientific data and results in a decision process. Chapter 1 introduces a number of institutional norms that may influence objectives of environmental decision making.

Apart from examining legitimacy this chapter pursues the question of the rationale for applying participatory methods. In addition to this, the concept of sustainability introduces values such as long-term management, biodiversity, species protection, and preventing pollution. It also introduces holistic views: values that incorporate uncertainty and complexity instead of avoiding it. At this point, the consistency of applied concepts from the assumed philosophy to the applicable methodology emerges. Theories and methods have to be analysed separately, but some concepts that are captured in the beginning of this chapter are carried along to its end.

The concept of sustainability is pursued in a brief review of a selected number of governance approaches. Governance may be seen as a way to implement institutional regulations and changes by means of a given management structure. A particular governance style determines how normative as well as subjective values are put into practice. This has a significant impact on the range of applicable participatory methods within a governance regime. If sustainability is carried on in the governance discussion, only a limited number of governance approaches are appropriate.

The endeavour to find a consistent methodological structure for participatory water resources management can only be realised through an integrated and multi-disciplinary approach. A methodological framework for such an approach is known as Integrated Environmental Assessment (IEA). This framework combines expert methods, such as models and simulations, with participatory methods in order to achieve a holistic, multidisciplinary and goal-oriented analysis and management. IEA as well as a number of chosen methods that combine expert with participatory methods are introduced in section 2.4 .

Finally, the notion of multi-disciplinarity and the role of participatory methods in it is discussed. The diversity of disciplinary combinations is unlimited. Therefore careful deliberation must be made in determining the correct combination for solving complex problems.

\subsection{Philosophical and theoretical basis}

In chapter 1 it is implied that participatory processes in a human-environmental context cannot be seen detached from a wider framework that examines the causalities of activities with impact on several aspects on human-technology-environmental interaction. Moreover, the effects of human activities on the environment and on other individuals including feedback and response cannot be explained with causal chains and linear relationships. Nor would disciplinary approaches be appropriate to discover effects, feedbacks and problem solutions. Harding (1998, p.13-14) states that environmental decision-making bears a number of issues that may result in conflict and 'undesirable' results. The issues are:

- decisions should be based upon sustainability;

- sustainability can be interpreted; 
- environmental management should include problem analysis, data collection, data analysis and dealing with risk and uncertainty;

- (public) participation is essential and should start from the beginning of a project;

- the role and duties of experts and representatives of authorities are crucial;

- the existence of "our formal institutions, structures and processes for decision making which may hinder or facilitate the effectiveness of addressing the above mentioned issues".

It is remarkable that Harding (1998) does not strictly distinguish among normative, methodological and governance (management) issues. Hence, these issues may be assumed to be interrelated and difficult to untangle when examining various concepts of environmental decision-making.

Furthermore, Harding (1998) stresses the fact that many scientists and engineers underestimate the role of non-technical issues, and thus the application of participatory processes, in a decision process: (1) either they are not aware about the relevance or (2) they ignore the relevance for the ease of procedures such as avoidance of additional costs, expenditure of time, more workload or of addressing new and 'messy' problems (Großkurth, 2008). For the specific sector of water management Pahl-Wostl (2002, p.3) observed that "technological fixes are very efficient in solving a number of urgent environmental problems". However, with increased environmental awareness in contemporary societies, the dissatisfaction with 'end-of-pipe' solution is increasing. This implies that, at least in Western societies, the exclusion of the public and stakeholders increasingly loses legitimacy. New institutional norms such as introduced with the WFD (EU, 2000) endorse that development.

However, the question may be raised: how can science, engineering and public administration handle the challenge of incorporating non-technical issues in an environmental decision context?

Along with with the societal development in the second half of the twentieth century signified by an increasing awareness on the part of the public for environmental issues, a 'new kind of science' emerged (Großkurth, 2008). Gibbons et al. (1994) introduced the mode 2 concept, as a new way of scientific knowledge (co)production, which is contextdriven, problem-focused and interdisciplinary. Real-world problems are the focus of this approach. Together with societal context and societal accountability, a selected number of normative aspects are included in this concept.

A similar approach is the concept of post-normal science (PNS) introduced by Funtowicz and Ravetz (1993). The main focus is on problem-solving strategies where highdecision stakes and system uncertainties receive much emphasis. As in Gibbons et al. (1994) the incorporation of 'extended peer communities' as well as policy issues are requested, and the notion of objectivity is abandoned in favour of (value) pluralism.

These two concepts of science may be seen as an antithesis of the concept normal science, coined by Kuhn (1962). Science is seen here as "puzzle solving" to comply with a central paradigm. A failure of results is thus a mistake of the scientist, but never refuting the paradigm. Not before deviant results accumulate, a paradigm shift or a scientific revolution is possible and results must be viewed in a new framework. 
Additionally, positivism (Cohen et al., 2007) contradicts the PNS/Mode2 concepts, arguing for strict scientific methodology, empirical validity, objective approaches and the belief in scientific progress. The avoidance of bias and uncertainty is inherent in both normal science as well as positivism.

As with all philosophical and scientific orientations, PNS/Mode 2 received criticism. Godin (1998) argues that mode 2 is more of a political ideology than a descriptive theory. Scientific knowledge and normative values are blended. Caswill and Shove (2000) emphasise three critical issues of PNS/Mode2 approaches: (1) lack of distance from the subject of study; (2) too much involvement and interaction can inhibit the development of theory and (3) there is a need for quality control of research and results. The latter issue can of course be questioned since quality control requires some sort of normative values, but that discussion goes beyond the scope of this document.

Despite all the criticism, PNS/Mode 2 concepts provide a widely acknowledged theoretical basis, for example, in sustainability research, environmental decision-making and in a number of governance models (Großkurth, 2008). However, when adopting PNS/Mode2 approach a number of terms such as uncertainty, complexity, ambiguity, subjectivity, and normativity should be discussed. In the following sections, the incorporation of these themes in scientific concepts and their implementation in the methodology are presented. In all of this, the term sustainability plays a significant role.

\subsubsection{Sustainability and sustainable development}

As previously mentioned, environmental decision-making comprises theoretical, methodological, management as well as normative aspects. Central concepts are sustainability and sustainable development. The Brundtland Commission (1987, p.43) defines sustainable development as "... development that meets the needs of the present without compromising the ability of future generations to meet their own needs". Although the definition of the Brundtland Commission ${ }^{1}$ is widely recognised and frequently cited, there are more definitions and interpretations of the term sustainable development. A popular definition of sustainability is: "improving the quality of human life while living within the carrying capacity of supporting eco-systems" (IUCN et al., 1991) However, in environmental decision-making the seven principles of Brundtland Commission (1987, p.49) are relevant for policy action:

1. Revive growth;

2. Change the quality of growth;

3. Conserve and enhance the resource base;

4. Ensure a sustainable level of population;

5. Reorient technology and manage risks;

6. Integrate environment and economics in decision making;

\footnotetext{
${ }^{1}$ Although the name 'Brundtland Commission' is widely known and cited, the official name of the commission is: United Nations World Commission on Environment and Development
} 
7. Reform international economic relations;

8. Strengthen international co-operation.

Whereas the the items [1], [4], [6] and [7] are issues on a higher (global) level, the issues [2], [3] and [5] are directly applicable to a regional or local environmental context, and are thus relevant for the design and implementation of participatory processes. Sustainability and sustainable development emerged from the concern to effectively handle the increasing impact of human activities on nature on the one hand, and a development of human society under conditions of limited resources in compliance with general recognised norms and values (Robinson, 2004). The concept 'sustainability' is complex, and its three dimensions, also known as the three pillars of sustainability, are environmental, social and economic. These three dimensions or domains are interleaved and form a so-called holon. Since the 1980s, the concept of sustainable development has evolved. Whereas the integration of environment and economy has much consensus within the research community, the term 'social dimension' is still under discussion (Dale, 2001). The concept of the three pillars is based upon integrists' models such as developed by Koestler (1978). The human-environmental system is seen as a coherent system of mutually influencing domains, with the characteristics self-organising, holarchic and open.

The goals of governance systems that adopt sustainable development in their policy are best summarised in the UN Millennium Declaration (United Nations General Assembly, 2000), which includes the fundamental values: freedom, equality, solidarity, tolerance, respect for nature, and shared responsibility.

Both inter-disciplinary methodology and normative values of the sustainability concept raise a number of issues that form some of the main characteristics of sustainability:

1. Normativity: sustainability is a normative concept, that may or may not be adopted in the governance of responsible authorities. The UN Millennium goals as well as institutional norms as discussed in chapter (1) seem to consequently emerge from the experience and the societal development of human societies in the twentieth century. However, these goals as well as the long-term management, the recognition of the finite availability of resources, and the integration of issues are arbitrary and cannot be derived from first principles (Bak, 1997; Großkurth, 2008). Norms are an expression for behavioural expectations, and are definitely a result of societal activities, and cannot be derived from the beliefs and goals of one individual or a small group. As a consequence, norms must be incorporated when designing a decision process ${ }^{2}$ that includes participation.

2. Complexity: In his book about quantum information theory, Lloyd (2006) claims that he once gave a presentation that listed 32 different definitions of complexity. In other words the definition of complexity is complicated, and holds at the same time for several fields of research. However, there are some general characteristics of complexity as it is seen as something that takes place in a 'relational regime' called system that consists of parts or elements which interact

\footnotetext{
${ }^{2}$ This is crucial for the definition of targeted goals
} 
with each other. The relationships among the parts of a system may differ in form, and can occur on several scaling levels within a system (Bak, 1997). In his seminal article, Weaver (1948) introduces the relationship between growing complexity and decreasing predictability of the system's properties. Furthermore, he distinguishes between 'disorganised' and 'organised' complexity. The latter phenomenon is of interest for this research, and was already mentioned in chapter 1 as 'self-organisation'. Self-organised criticality, generating emergent properties with statistical significance, was adopted and further developed, for example by Bak (1997).

Among the many definitions of and approaches to complexity, complex adaptive systems (CAS) are of preferential interest for this research. Ahmed et al. (2005, p.1) proposes the definition "a complex adaptive system consists of inhomogeneous, interacting adaptive agents ${ }^{3}$. Adaptive means capable of learning". The adaptive capacity in terms of learning capability may be assigned to a group of stakeholders in a participatory process. The concept of social learning ${ }^{4}$ represents a central notion in the methodology of participation. An effective social learning process is an assumption for a successful, accepted and effective environmental management effort (Geldof, 2002; Pahl-Wostl, 2008). The main characteristics of CAS are: no super-ordinated (controlling or decision) power; memory and feedback; adaptation based upon the history of the feedback; non-linearity; influence by and adaptation of external processes; sensitivity to initial conditions (Holland, 1992; Ahmed et al., 2005; Geldof, 2002).

The advantage of an integrated, multi-disciplinary and holistic approach is, for instance, enabling decision makers to incorporate (side) effects that can only be recognised by exploring the system as a whole, including the heterogeneous society of involved actors. The variety of disadvantages is indeed more multi-layered. The predictability problem was already mentioned above. This problem is aggravated when processes stemming from different domains influence each other (i.e. human activity on nature, economic growth on consumption behaviour, on nature, feedback loops such as climate change impact on the economy). Exact science, rigorous methods of hypothesis testing, reproducible experiments and quantifiable predictions and measurements are not unconditionally applicable. The issue of uncertainty plays a significant role in systems research.

3. Uncertainty: "If probabilities of various events or outcomes cannot be quantified, or if the events themselves are unpredictable, some would say the problem is one of uncertainty, and not of risk" (Loucks and van Beek, 2005, p.256). Risk and uncertainty are often juxtaposed, however there is some difference. Hubbard (2007) defines risk as a "... state of uncertainty where some of the possibilities involve a loss, catastrophe, or other undesirable outcome". These two definitions indicate that the uncertainty is a (system) parameter that is difficult to measure or predict, whereas risk already implies the normative value of loss. The value loss has to be

\footnotetext{
${ }^{3}$ Real-world agents is another term for actors, and can be adopted for individuals and groups of individuals in a participatory process

${ }^{4}$ The definition for social learning is provided in chapter (3)
} 
defined by the individual who analyses the system (Knight, 1921). The fact that for the definition of uncertainty and risk, three authors from three different disciplines (water management, business, economics) could be cited indicates that the terms uncertainty as well as risk are ubiquitous and occur throughout all sectors and research domains.

Uncertainty cannot be avoided in the research of CAS and in natural resource management, especially when (computer) models are applied as simulation, prediction or learning tools (Pahl-Wostl, 2007a). Moreover, van der Sluijs et al. (2005, p.481) identify various types of uncertainty of which " ... uncertainty in the knowledge base, differences in framing of the problem, and the inadequacy of the institutional arrangements at the science-policy interface" are relevant types for the research of participatory processes. Furthermore, van der Sluijs et al. (2005) claim that methods such as Monte Carlo analysis, subjective probability or Bayesian probability are not adequate to handle these types of uncertainty because unquantifiable uncertainties dominate the quantifiable ones. For this reason van der Sluijs et al. (2005) developed the NUSAP ${ }^{5}$ method. As well as these types, the knowledge base of complex environmental problems contains dimensions of uncertainty: "technical (inexactness), methodological (unreliability), epistemological (ignorance), and societal (social robustness)" van der Sluijs et al. (2005, p.481). According to van der Sluijs et al. (2005) quantitative methods only address the technical dimension. Scholars such as Brugnach and Pahl-Wostl (2008); Pahl-Wostl (2007a); Gleick (2003) confirm that in the management of natural resources and the analysis of CAS, a combination of "hard and soft system approaches" Brugnach and Pahl-Wostl (2008, p.188) is required. Additionally, (Brugnach and Pahl-Wostl, 2008) warn that ignorance or insufficient incorporation of uncertainty in analysis and prediction models may cause failure in support for decision-making processes or can be misinterpreted. The same authors propose to incorporate subjectivity in the models to approach the CAS requirements of learning and change, and in order to deal with uncertainty.

4. Subjectivity: As indicated in van der Sluijs et al. (2005) subjectivity is one of the dimensions of the knowledge base that constitutes uncertainty. Subjectivity refers to individual views, perspectives, opinions, beliefs, desires or experience, that may be based upon diverse philosophical, ethical, and moral conceptions (Robinson, 2004). Apart from norms and physical characteristics of a system subjective values are an essential component that is required to be incorporated in sustainability research and environmental management. Subjective values are subject to a social learning process within adaptive management (Brugnach and Pahl-Wostl, 2008).

5. Ambiguity: Sustainability is not as a clear a concept as mathematics or physics. There is no canonical concept on how to solve problems, how to combine methods or how to handle uncertainty, nor are there any uniform targets.

\footnotetext{
${ }^{5}$ Numerical Unit Spread Assessment Pedigree (http://www.nusap.net/)
} 
The PNS/Mode2 concepts require the incorporation of the five issues mentioned above. Whereas the philosophical concepts discuss the legitimacy of the incorporation of normativity, complexity, uncertainty, subjectivity and ambiguity, the sustainability concept to a certain extent implies tangible methods, and proposes approaches to handle these issues. The research methodology of sustainability is context driven. A selection of methods is indispensable, and at the same time influences the research outcomes (ambiguity). As a consequence local experts and lay people should be included in the problem analysis, and methodology as well as research and management targets must be transparent and open. A further step toward more rigour in the management of sustainability issues is governance as a principle method to balance individual subjectivity, with societal norms as well as scientific and technical opportunities and limitations.

\subsection{Governance: how to implement policy}

Governance styles are more or less effective in handling system-internal as well as external modifications in the development of these systems. Policy science offers a number of models to describe and analyse these styles, for example, in terms of their effectiveness and appropriateness in environmental decision making. Kooiman (1993) describes governance as a concept that comprises all implications of interactions among all involved actors.

Hoogerwerf (1998) describes policy as the aspiration to a set of goals with limited means and limited time. Hoogerwerf views the basic structure (and meaning) of policy in terms of goal achievement by means of policy instruments. The notion of policy instruments holds several definitions stemming from economics and policy science. Macro-economic instruments are often seen as a means for addressing market failure, whereas environmental policy focusses on human impact on nature. This may include air and water pollution, biodiversity, waste water management, natural resources protection and other issues (Stavins, 2003). Furthermore, in recent years climate change impact become of growing interest on all policy and decision levels.

Whereas Kooiman (1993) and Hoogerwerf (1998) argue for top-down approaches to governance, Bressers and Kuks (2001) define governance as the policy context of societal development. A complex economy requires appropriate governance whereby a clear distinction between public and private interests appears to be increasingly difficult to separate. Here social action is in the foreground rather than being the (semi) products of a policy process.

In the general context of governance Bressers and Klok (1987) define a broader term for instruments that includes all means for the implementation of a policy beyond monetary and taxation means, or in other words, the process of social action supporting or opposingf a particular policy. The process and results of a policy do not only depend on the input, but also on the goals, information and share of power among the involved actors.

Furthermore, Bressers and Kuks (2001) discuss the implications of scale levels on the effectiveness of governance, which implies the limitations of various 'governments'. This has consequences on problem-solving approaches, especially when the problem is dispersed over several administrative (governance) levels. One prominent example 
are environmental issues on the level of international river basins such as the Rhine or Nile. In day-to-day administration, higher level administrations (e.g. EU, countries) are generally seen as policy designers, and the lower administration (e.g. municipalities) as the policy executives.

Rhodes (2000) distinguishes among six types of publications about governance: (1) corporate governance; (2) good governance; (3) the minimum state; (4) new public management; (5) socio-cybernetic systems and (6) international governance. Obviously, the type (4) literature 'new public management' is of greater interest for the research that is presented in this document.

\subsubsection{Governance approaches and their components}

Scholars such as Conzelmann (1998) and Smith (1998) advocate the concept of multi-level governance. Since the inauguration of the European Union as an overarching decision instance the implications of policy design and execution on various administrative levels become increasingly relevant. This may descend to a local level of (environmental) decision making, whereby responsible local authorities are confronted with self-interested stakeholders, for instance, in common pool or property rights conflicts. Multi-level governance does not only imply policy issues on various levels of administration (and social action) but includes multi-facetted problems, which add another dimension of complexity to a governance system.

The multi-actor network is a problem-oriented approach to governance where authority is legally or voluntarily distributed over several policy levels, involved where problems are required to be solved. Multi-actor activities can be represented in (1) a hierarchical form and (2) in a network form of organisation (van Heffen et al., 2000; Rosenau, 2000; Rhodes, 2000). The multi-actor network builds upon the multi-level governance approach.

Multi-instrumental steering mechanisms and multi-resource-based implementation is an approach that focusses on the implementation of policy strategies. In contrast to multi-actor frameworks, the multi-variate character of policy action is examined with a focus on the mechanisms (O'Toole Jr., 2000). In summary, each of the approaches employs aspects of governance that can be retrieved in many of the interpretations of of governance.

Bressers and Kuks (2001) summarise the 'components' of governance as following:

1. administrative, institutional and other scaling levels;

2. actors in the policy network;

3. goals and problem perception;

4. strategies and instruments;

5. organisation, executive and resources.

These components form a canonical structure that is reflected in most governance models. Bressers and Kuks (2001) discuss a variety of governance models, of which the models of Sabatier (1988) and (Ostrom et al., 1994; Ostrom, 1998) are highlighted. 
The two models do not focus on the intrinsic policy processes, but on the context of these processes. Those models are briefly discussed in the following section.

\subsubsection{Governance models}

Governance approaches and interpretations refer to various 'schools of thinking' depending on the scientific perspectives, the incorporated normative values as well as the objectives of the particular research undertaking. In addition to the two aforementioned models, this section introduces the adaptive water management (AWM) approach. This approach refers to the implementation of governance in water resources management, and provides a theoretical basis and a wider context for the topic of participatory water management. Furthermore, the examples subsequently introduced reflect on an evolution of governance models, and indicate which models provide a basis for the implementation of stakeholder and public participation in a policy process.

\section{The Advocacy Coalition Framework (ACF)}

Sabatier (1988) introduces the Advocacy Coalition Framework (ACF) as a pool of administrative actors as well as stakeholders ${ }^{6}$ bearing a collective world view, and trying to coordinate social action. The analysis of the incorporation of 'technical information' (expertise) in the administrative process is of elevated interest here (Sabatier and Jenkins-Smith, 1993). Several advocacy coalitions may be active within a single sector or a single 'policy sub system'. Constituents of an advocacy coalition have the same 'policy beliefs', have access to the same resources, employ their set of instruments and together develop a distinctive (goal achievement) strategy. However, subsystems can influence each other by means of external restrictions and resources. Collective beliefs and world views as a unifying impetus for coalitions are rated higher within this model than the distinction between administration and lay people. Problem perception, costs allocation, management style, the incorporation of expertise, decision makers and lay people are the core values of this framework (Sabatier, 1988; Sabatier and JenkinsSmith, 1993; Sabatier, 2007).

\section{The Institutional Analysis and Design Framework (IAD)}

For the examination of participatory processes in an environmental decision context, the research on common pool resources and rule-based, institutional approaches to governance are of particular interest (Ostrom et al., 1994; Ostrom, 1998). The Institutional Analysis and Design Framework (IAD) of Ostrom et al. (1994) is an approach with emphasis on the relationship between institutional arrangements and the results of interaction processes among individuals. A central aspect of this approach is the interaction among actors in a social space or in other words, rule-based social action within a network. The rules determine position, scope, authority, aggregation, information and payoff clauses. Interestingly, the rules are not stringently objective, but may provide room for individual perspectives and interpretations. Ostrom (1999) defines an action arena as the place where actors have various levels of access to resources and different authorisations to carry out actions. Actors can intervene at various stages in the decision-making tree. Moreover, actors have particular functions. The set of payoffs

\footnotetext{
${ }^{6}$ In this context the notion 'stakeholder' is applied to 'non-administrative' actors.
} 
that assign benefits and costs of actions and outcomes is determining for social action. Ostrom defines the policy problem as an interaction of actors and their impact on the environment (target system). Ostrom's actor network makes way for polycentric policy approaches where a hierarchical structure of a responsible authority including the stakeholders or a command and control structure is not vital anymore. Apart from institutional norms and arrangements, characteristics of the community, the type of public and non-public goods and events form the rule base for the action arena.

\section{Adaptive Water Management (AWM)}

A continuation of Ostrom's IAD and application in the field of water resources management is the Adaptive Water Management (AWM) approach of Pahl-Wostl (2007b). The scholar identified a number of problems in water management that not only originate from resource problems such as population growth, land use change or change in consumption behaviour, and climate change impact phenomena such as floods and droughts, but also from management failure. There were earlier approaches to AWM such as discussed in Geldof (2002). The main focus here was on complex adaptive systems, that is seen as a source of problems (if not recognised by water managers), and a solution at the same time. Geldof (2002) argues that the acceptance of complexity and its incorporation in the daily water management plays a significant role for a transition toward a more adaptive, integrated water management.

A broader perspective on AWM is provided by Pahl-Wostl (2008), who claims that 'water crises' are often crises of 'traditional' governance, that provides end-of-pipe solutions instead of an integrated approach with sustainable solutions. Hence the normative term sustainability is already an integrative part of this concept. Pahl-Wostl (2008, p.2) advocates "the need for a radical change, for a paradigm shift in water management". A paradigm shift in water management includes:

- participatory management and collaborative decision making;

- integration of issues and sectors;

- management of problem sources not effects;

- decentralised and more flexible management approaches,

- more attention to human behaviour through "soft" measures;

- environment explicitly incorporated in management goals;

- open and shared information sources (including linking science and decision making);

- iterative learning cycles incorporated into the overall management approach (PahlWostl, 2008, p.2).

Despite the growing knowledge of the virtue of AWM "for the last several decades" Pahl-Wostl observes a retarded transition towards AWM especially at the operational level of water resources management, and therefore developed a 'Framework of Analysis'. AWM is a more comprehensive and broader approach in comparison to earlier 
environmental management approaches such as introduced by Holling (1975) and Walters (1986), who apply "... well-defined experiments to test different hypotheses about system behaviour" (Pahl-Wostl, 2008, p.3). In this AWM approach learning processes under uncertain conditions are seen as a guiding paradigm rather than the subject of small-scale experiments. Figure 2.3.2 depicts the iterative policy cycle as a systematic approach to (social) learning.

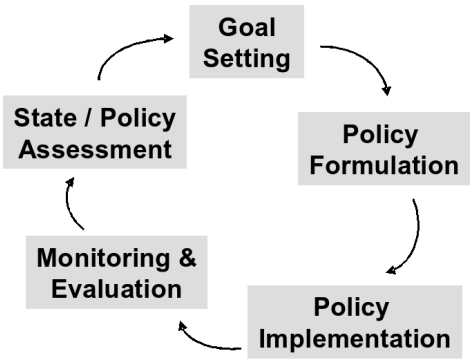

Figure 2.1: Steps in the iterative policy cycle (Pahl-Wostl, 2008, p.3)

The policy cycle implies: goal setting under various perspectives; scenario building as a means of dealing with uncertain (future) development; evaluation of decisions with the option of modification; monitoring to include more than one source of knowledge; transparent assessment of the performance of management by various involved actors; open and transparent access to (changing) information; learning processes at all phases of the policy cycle; and the possibility of modifications to a policy that are comprehensible to all involved actors. A transition from an 'expert culture' of water management to a more integrated and adaptive approach can only be accomplished in a holistic way. The exchange of particular elements in a system including technology, institutions or methodology is not possible because of the complexity of the entire system. This fact might be a main barrier for a transition. A second barrier is so-called lock-in effects by previously implemented technological solutions such as centralised waste water treatment systems. Apart from high re-investment costs, institutional regulations are another significant barrier (Pahl-Wostl, 2008, 2007b).

There are three key issues of AWM: (1) Adaptation refers to structural change of a given management regime. It may be a reactive as well as a proactive process; (2) Transition involves a change in the management paradigm; (3) Adaptive capacity is the ability of a system to anticipate or process external and internal disturbances. Together with the sustainability concept, the three key issues account for a long-term, integrated management as opposed to (short-term) optimisation of 'traditional' water management approaches.

The characteristics of AWM are: management is viewed as a learning process; the governance style is polycentric and horizontal with stakeholder participation; problem analysis across sectors with integrated policy implementation; multiple scales are incorporated including: trans-boundary issues; transparency, accessibility and openness in 
information provision; preference for decentralised technologies; and diversification of financial resources (Pahl-Wostl, 2008, p.9).

Scale levels play a significant role in AWM as in complex adaptive systems in general. In this context three levels are distinguished: Landscape or macro level including institutional as well as local norms, legal frameworks, cultural values and environmental variability; management regime or meso level as previously mentioned; and niches or micro level where innovations and new areas of applications take place. When attempting to examine and understand transitions in "human-technology-environment" systems (Pahl-Wostl, 2008, p.13) the understanding of multi-scale processes is important. Furthermore, scale levels help to structure the implications of rapidly changing technologies and socio-economic conditions. A closer look into a management regime reveals another three levels of social action: (1) the general level of governance (e.g. country or EU level) that holds (2) several actor networks as a basis for (3) specific negotiation and learning platforms (Pahl-Wostl et al., 2007).

As already indicated in section 2.2.1, social learning plays a significant role in the concept of AWM. The negotiation and learning platform gives space for renegotiating or newly adopting higher level rules and regulations. The results of these negotiations are supposed to influence decision processes, which includes feedback loops or learning cycles.

\subsection{Integrated environmental assessment - a methodological frame- work}

As sustainability is seen as a holon containing coherent and mutually influencing domains (the three pillars), integrated environmental assessment (IEA) may be seen as a methodological framework to undertake sustainability research or exploring and managing a CAS. Although sustainability research holds a variety of methodological approaches, IEA is the most comprehensive methodological framework that includes essential sustainability concepts such as normativity, complexity, uncertainty, ambiguity and subjectivity. Moreover, the holistic character of sustainability is reflected in the multi-disciplinary and problem-oriented approach of IEA. The main elements of this IEA are disciplinary tools, integration tools and assessment frameworks. The predominant role of participatory methods lies in the integration tools, where disciplinary elements such as models have to be linked to each other. Furthermore, participatory methods have the potential to set both subjective values and preferences as well as norms and societal goals in an analytical or management context (Toth and Hizsnyik, 1998).

In parallel with the recognition of the research on sustainability in the 1980s, policy demanded consistent and more rigorous frameworks that can process, analyse and communicate relevant information. In particular, pollution and later on climate change issues needed to be analysed and presented in a wider context that includes impact on economy, nature and society (Toth and Hizsnyik, 1998). With time, IEA methods evolved and the variety of targeted problems increased.

As with other theoretical and methodological concepts, diverse definitions of IEA exist. Toth and Hizsnyik (1998) specify two essential criteria for the definition of IEA: 
(1) the multi- or interdisciplinary character, and (2) the policy-relevant output (see also Tol and Vellinga (1998)). However, there are more aspects to it. Weyant (1996, p.371) defines IEA as a "convenient framework for combining knowledge from a wide range of disciplines". All of the cited authors emphasise the purpose of IEA as tool to explore future development in order to support policy formation and robust policy options to handle issues in a human-environmental context. Weyant (1996) goes further in viewing IEA as a synthesising and communication tool.

\subsubsection{The evolution of IEA}

Toth and Hizsnyik (1998) observe an evolution in environmental assessment over 30 years. The problem perception in the sixties recognised local incidents with simple causal relationships that are 'easy to fix'. The characteristics of problems at stake were seen as gradually changing, equilibrium states where important, and the impact of local activities on higher-scale effects were omitted or not recognised. With the development of larger and more sophisticated computer models in addition to growing hardware capacity more data could be processed, but also more complex interrelationships could be modelled. A turning point in the methodological approach as well as the problem perception may be seen in the Club of Rome model 'Limits to growth' (Meadows et al., 1972). This model revealed two issues at the same time: (1) the growth of (in this case) five variables that are mutually influential (world population, industrialisation, pollution, food production and resource depletion) are calculated over a particular time span. Thus these variables are from various domains, effective on different scaling levels, and represent a complex system including non-linearity and several causal relationships; and (2) the choice of variables and their mathematical representation (e.g. logarithmic, linear, incremental) significantly influence the results. The latter evoked much criticism because of the arbitrary choice of mathematical methods. The variability of the methodological approach including the impact on results may be seen as another facet of ambiguity as well as subjectivity ${ }^{7}$, and is therefore another source of uncertainty. The further development of IEA and similar approaches was generally characterised as an aspiration for more rigorous frameworks to handle complex environmental problems in a policy context (Toth and Hizsnyik, 1998; Holling, 1986). The development of a framework for participatory management as discussed in chapter (3) and (6) is another attempt to contribute to this aspiration.

In comparison to the research of the 1960s, contemporary models and assessment frameworks are now based on the assumption that changes in a system may be sudden, discontinuous and infrequent. Transitions among various states of equilibria can be fast. Rapid local changes are often seen as a result of gradual global scale processes. Currently, the most prominent example of scaling issues is climate change impact. Yet, both the data requirements and availability as well as the technology (e.g. spatial and temporal collection and analysis tools) are rapidly growing. However, as with the new model context, the large amount of available (and processible) data involved a new or more effective kind of uncertainty (Toth and Hizsnyik, 1998).

\footnotetext{
${ }^{7}$ In this case the subjectivity of the experts is addressed
} 


\subsubsection{Methodology}

The strength of IEA is the integration of methods, that can also be viewed as a challenge, since there is no canonical guideline for integration (ambiguity). This, however, introduces new sources of errors and misjudgement. As mentioned earlier, Toth and Hizsnyik (1998) distinguish two types of methods: (1) 'primary disciplinary elements' and (2) 'primary integration tools'. The first type are data-driven methods such as circulation models, hydrological models, demographic models, economic valuation techniques or opinion surveys. The second type are synthesis tools such as checklists, impact matrices, flow diagrams or network charts. The entirety of an IEA framework may be designed as integrated modelling or environmental impact assessment that draws on both types of methods. The composition of a framework depends on the specific circumstances (problem, context, objective).

In contrast to Toth and Hizsnyik (1998), Rotmans (1998) distinguishes between (1) analytical methods and (2) participatory methods. The first type is similar to the 'disciplinary elements' and includes models. Whereas Rotmans (1998) assigns scenarios and risk analysis to the analytical methods, Toth and Hizsnyik (1998) proceeds differently. Scenarios are integration tools and risk analysis is a type of IEA framework equivalent to impact assessment, policy exercise and similar approaches. Independent of the methodological taxonomy, both publications emphasise the role of participatory methods (PM) within an IEA framework. PM developed to be a flexible link between the policy agenda including the questions of decision makers and the results of scientists such as modellers or analysts. PM increasingly enable scientists and managers that use an IEA framework to address the relevant questions, and to incorporate norms and subjectivity. For example, the integration of PM with models can result in stakeholders co-designing the model, selecting model parameters and variables, defining objectives and choosing the interface for model use according to their own priorities (Rotmans, 1998). Moreover, PM can help to collect and generate data, and support validation and verification of models.

In summary, PM in IEA have the potential to improve communication among policy makers, scientists and lay people, support the suitable design of models, support the identification of relevant (local) problems, serve as learning methods and structure the information for policy processes.

\section{Models}

Whereas between the 1970s and the end of the century, models became larger and more complicated, contemporary models return to more simplicity. Rotmans (1998, p.158) already identified a "...trend [...] toward greater disaggregation ..." Modularised would be the better term since 'disaggregation' may suggest a diminution of complexity in modelling approaches. The advantages of a modularised methodology is a higher flexibility and (potential) independence from local constraints. This does not only apply to models and other data-driven approaches but also for participatory methods. Apart from achieving more effectiveness, the aspiration for more flexibility in the application of participatory methods is a central topic of this thesis.

Types of integrated models are: policy optimisation models, policy evaluation models, macro-economic models, and biosphere-oriented models (Rotmans, 1998). Two 
examples of integrated assessment models. One is an expert model and the other one includes lay knowledge in design and application:

- The Regional Air Pollution INformation and Simulation (RAINS) model was developed to perform an integrated assessment of the exploration of alternative strategies to manage acid deposition in Europe and Asia. The computer software consists of three main modules: (1) emission-cost module; (2) the acid deposition and ecosystems impact module; and (3) the optimisation module. The objective of the model is to let users test alternative emission control strategies, a preeminent topic during the 1980s. Energy pathways can be manipulated, and scenario building and analysis are possible to explore future energy consumption. Some of the modifiable parameters are: fuel types, economic sectors, emission control technologies or pre-selected regions or countries. In addition, an optimisation tool (based upon linear programming) is available to identify cost-optimal allocations of emission reductions. The model is a policy optimisation tool to analyse scenarios. RAINS is definitely an expert-driven tool that can be applied by policy makers. The participation of lay people is not intended (Alcamo et al., 1990).

- Georgia Basin-QUEST is an interdisciplinary, regional computer-modelling tool that supports exploration of the future development in the Georgia Basin in British Columbia, Canada. The model is a policy exercise tool to explore 'desirable' future developments in the region. It consists of economic, air pollution, transport, agriculture, water and other modules. Sustainability is the principle determining the selection of and the relationship among sectors on the one hand, and providing normative values on the other. From the PM perspective the model design is (partially) community driven with input from several key public groups. The design has impact on the use of the model for scenario building. Assumptions and results are relatively easy to understand, and may be employed as a basis for learning, discussing and addressing policy-relevant questions. Although much emphasis is put in modularity and transparency of a model, the installation and implementation of the software appears to be a resource-intensive monolithic block. Furthermore, the model cannot be transferred to other regions without alterations. However, the sophisticated design and the incorporation of lay knowledge as well as its user-friendliness make this tool a useful support for the development of policy strategies in a given region (Carmichael et al., 2004).

The crux with integrated modelling approaches is the dialectic of simplicity and completeness. The modeller has to make a choice which already introduces the his or her own subjectivity. For this reason, models should be part of an assessment or evaluation process. Blind faith in models may result in surprising if not nonsensical outcomes $^{8}$.

When modelling CAS Ahmed et al. $(2005,4)$ discovered six different ways to model these systems: (1) ordinary differential equations, difference equations and partial differential equations; (2) cellular automata; (3) evolutionary game theory; (4) agent-based models; (5) networks and (6) fractional calculus. Whereas, for example, differential

${ }^{8}$ Of course, this depends on the subjective perspective of the observer 
equations or fractional calculus focuses on processes within a CAS, agent-based modelling is capable of including behavioural patterns that cause processes. This modelling approach has a high potential to include subjective and normative values as well as results of participatory activities in the modelling process. A brief description of modelling examples is given in section 2.4.3.

\section{Assessment types}

Apart from model types, IEA involves several types of assessments. Whereas a model is only a module of an entire IEA, a complete assessment may combine models with other methods:

- Adaptive Environmental Assessment and Management (AEAM) (Holling, 1975): an early framework for bridging gaps among knowledge and perspectives of experts, policy makers and stakeholder who are confronted with complex management problems. Stakeholder workshops are applied to handle uncertainty and different perspectives and priorities while (co)designing an integrated model;

- Teaching and training for environmental management: several kinds of methods are applied to teach managers how to understand and handle complex problems, the diversity of perspectives and world views or institutional regulations. Among these methods are computer models, games and comprehensive training curricula involving various teaching methods. An example for the training of water managers is the publicly available 'NeWater curriculum on Adaptive River Basin Management' ${ }^{\text {'9 }}$ (Terwisscha van Scheltinga et al., 2009);

- Policy exercise: The Georgia Basin QUEST model is an example of a policy exercise. However, apart from models, simple scenario techniques can be applied for this type of assessment (Toth and Hizsnyik, 1998);

- Risk analysis: this type of assessment has become a new line of research, involving a variety of methods (e.g. models, scenarios, statistics) applied to multiple sectors such as flood risk, epidemiology, economics or management. In general a (local or regional) system is examined for possible disturbances including the implications for the involved actors, assets, infrastructure etc.. Slovic et al. (1984); Slovic (1987) have developed the concept of risk perception to involve individual perspectives on risk in the analysis process.

The listing of assessment types is not complete, but demonstrates the variability of IEA approaches. However, the combination of analytical and participatory methods remains the universal characteristic of all assessment types. The consequent application of this combination supports an effective handling of models within policy processes.

\subsubsection{Examples of combining participatory methods with expert methods}

As mentioned above, modelling approaches using differential equations or fractals are rather abstract, and the connection with participatory methods is not easily made

\footnotetext{
${ }^{9}$ Opencourseware available from http://www.newatereducation.nl/
} 
within the modelling process. However, there are a number of 'analytical' methods, that have obvious links to participatory processes. Two examples are presented here:

\section{Multi-criteria Analysis (MCA)}

Multi-criteria Analysis (MCA) is an assessment and evaluation tool that can handle criteria from various research domains such as economy, ecology or behavioural science. For this reason it is suitable for IEA procedures. In comparison to Cost-Benefit Analysis (CBA), MCA is capable of incorporating other criteria than monetary values. However, and this is a source of much criticism, MCA can only provide a relative evaluation without absolute (monetary) values. This method consists of two main elements: (1) criteria such as investment costs, ecological value, travel time and risk; and (2) the weighting of these values. The two elements can be both subjective and normative values, and should be subject of an open and transparent participatory process, for example, employing survey and workshop techniques. MCA involves a number of optimisation methods that may influence the outcome of an assessment. However, more influential are the subjective and normative values of both the criteria and weighting. The close combination of analytical and participatory aspects reveals the requirement for expertise for and thoughtful application of both aspects of MCA (Janssen, 2001; van Herwijnen, 1999; Yeh et al., 1999).

The application of MCA is manifold, ranging from risk analysis to feasibility studies. As an example Raaijmakers et al. (2008) explored flood risk mitigation measures, by applying an MCA and incorporating the preferences and the risk perception (Slovic et al., 1984; Slovic, 1987) of stakeholders in the Spanish Ebro Delta. The study revealed the extent to which stakeholders would agree with land use changes as a means of keeping the follow-up costs of flood impact low.

\section{Agent-based Models (ABM)}

Agent-based modelling (ABM) is an attempt to create a computer-based artificial society in an artificial environment representing real world social entities (persons, organisations, institutions) as agents. As with many models ABM starts with a conceptual framework, and must not be confused with a concrete programming code. Computer agents have autonomy. There is no central or top-down power that determines agents' activities. Agents act in an explicit space represented as an n-dimensional lattice or a social network. Agents are able to recognise neighbours and interact with them. Agents may have bounded rationality, which means no global information and limited computer power (Epstein, 1999).

The architecture of an agent can also be seen as the symbolic representation of a realworld actor. A strategy (of goal persuasion) of an agent is a representation of an actor's behaviour. ABM uses various types of agents as well as several types of modelling techniques and algorithms. A Multi-agent System (MAS) is characterised by the ability of the agents to interact (perception, communication, co-operation, competition, etc.) with each other. It can also be seen as an artificial society representing a group of interacting actors (Wooldridge, 2002; Weiss, 2000; Axtell, 2000). A multi-agent system is characterised by its ability to improve the system performance by collaborating with each other. Learning techniques are important (Axelrod, 1997). 
ABM provides the researcher with a modelling technique that allows an independent and distributed approach to investigating the behaviour of actors. 'Agent-based thinking' allows the modeller to impose structural thinking on the empirical investigation. However, field observation as well as the application of participatory methods may have an impact on the generation of an agent architecture. This means that ABM and participatory methods need to be highly interlinked. Moreover, the principle of agentbased modelling allows the modeller to observe the impact of human activities on a given environment, and model that in a computer-based abstract target system. For this reason $\mathrm{ABM}$ has to be developed parallel with and linked to the environmental model (Pahl-Wostl, 2005).

In the case of a common resource pool problem, the use of adaptive rather than optimising behavioural strategies of agents is the preferable modelling approach. Adaptive behaviour is seen as an alternative to rational choice stemming from game theory Axelrod (1997). The behaviour of adaptive agents is in principle not predictable. However, simulating behaviour can yield insights to fundamental processes of interaction to enhance the understanding of conflict and co-operation.

As an example, Berger et al. (2007) applied a multi-agent system (MAS) to a complex water resources management problem in order to explore the outcome of policy change and the introduction of technical innovation in a river basin in Chile. In particular, the privatisation of water rights and irrigation issues modified the situation of farmers. A multi-stakeholder platform served as input for the agent-based model. Stakeholders and modellers collaborated in modelling the problem, and discussing the results in a collaborative learning and research platform. Modellers received new insights into a complex water management situation. In return, farmers delivered valuable information for the model design.

\subsection{Multi-disciplinarity, inter-disciplinarity and trans-disciplinarity}

As discussed in section 2.4, from the methodological point of view IEA is a multidisciplinary approach to problem solving, and this is demonstrated in terms of (1) applying integrated models (with components from various disciplines); (2) combining models from various disciplines; (3) combining models with participatory methods and (4) employing a variety of participatory methods in a policy or decision process. However, Heckhausen (1987) claims that multi-disciplinary research ${ }^{10}$ is just the simplest form of integration. How then is multi-disciplinary knowledge integrated?

Hinkel (2008) discusses how (cognitive) knowledge can be integrated in trans - disciplinary assessment. Trans-disciplinarity "as the true form of inter-disciplinarity" is coined by Mittelstraß (1987) who endeavours to integrate disciplinary knowledge instead of a mere methodological integration, and tries "overcoming disciplinary insularity" (Hinkel, 2008, p.5). Klein (1990, p.56) states that "Multi-disciplinarity [...] is essentially additive not integrative". Trans-disciplinarity may be seen as a "problemoriented research principle" (Hinkel, 2008, p.5), and this is of elevated interest for environmental impact research and environmental management, where problems are raised outside the realm of pure scientific problem definition, and address policy-relevant is-

\footnotetext{
${ }^{10}$ In the sense of combining methods and not theories
} 
sues. Again, at this point the role of participatory processes emerges as an integrative element.

As an approach towards true trans-disciplinary research Hinkel (2008) endeavours to introduce a formalisation process that incrementally translates linguistic terms into formal expressions as far as mathematical equations. He distinguishes among three dimensions of integration: (1) social integration - integrating interests and subjective perspectives as accomplished on the consultation leve $1^{11}$ as well as social learning level of a participatory process; (2) cognitive or knowledge integration - integrates heterogeneous knowledge of the involved actors, both experts and lay people. Knowledge elicitation methods are suitable (participatory) methods at least in the beginning of such a process; (3) technical integration is the integration of artefacts that are relevant for a problem solving (or management) process (Hinkel, 2008, p.14).

\subsection{Summary and discussion}

Chapter 2 discusses the role of participatory methods in complex environmental management and research approaches. The concept of environmental management and research is argued from the philosophical and theoretical perspective, includes the principles of sustainability, describes several governance approaches, introduces the meta method integrated environmental assessment and provides some tangible examples of the combination of modelling techniques with participatory methods in assessment approaches. At the same time, the legitimacy of PM as well as its rationale, the functions within assessment approaches and examples for applications are discussed. Several types of legitimacy have been examined: 1) normative legitimacy as manifested in several declarations and legal documents and discussed in section 1.3 ;2) institutional legitimacy which refers to the role of actors in a policy process; 3) scientific legitimacy as discussed in section 2.2 and 2.2.1, especially with respect to the theoretical and methodological basis of participatory methods; and 4) methodological legitimacy which is discussed in section 2.3 and 2.4 and refers to the combination of analytical methods with participatory methods and the role of PM in multi-disciplinary approaches. The rationale for applying participatory methods lays in the requirements of problem-solving research: handling uncertainty, subjectivity and ambiguity; the role of PM as an integrative element in transdisciplinarity; and the role of knowledge exchange as well as learning processes among actors in a policy process.

In conclusion, it can be said that PM play a crucial role in context-driven, problemfocussed and interdisciplinary research, policy and decision processes. PM are important in handling system uncertainties, incorporating normative and subjective values and have a significant integrative function in environmental management and research. As chapter 1 indicated much criticism centers on the loss of rigour and the ambiguity of participatory assessment and decision processes. The following chapters may be seen as an endeavour to explore methods and tools to increase rigour and user-friendliness of participatory methods without losing flexibility, transparency and adaptive capacity.

\footnotetext{
${ }^{11}$ For a comprehensive definition and discussion of 'levels' refer to chapter (3)
} 
CHAPTER 3

\section{A methodological structure for participatory water resources \\ management}

\subsection{Introduction}

This chapter provides a methodological basis for practical guidelines that are potentially useful for water managers or other relevant authorities who design, develop and manage projects in or at least at the periphery of common resources and public space. The aim is to increase the effectiveness of a participatory process. In other words, water managers should be enabled to effectively (and efficiently) apply participatory methods that support the achievement of prescribed goals from the design of plans to the implementation of measures.

The method applied here involves the development of a new typology of participatory methods including the classifications by Arnstein (1969) and Mostert (2003a). The approach introduced is the Constraints-Methods-Objectives scheme (CMO), meaning that the range of individual and case-dependent circumstances (constraints, context, problems, limitations) together with the objectives of a project are evaluated against a consistent methodological framework in order to effectively apply participatory methods.

The CMO scheme links the methodological macro level (levels and classes of participation) with the micro level (criteria for the implementation of methods). Furthermore, the connection to goals (via classes of participation) as well as to the constraints of a local project (via implementation criteria) is made.

This is not the first attempt to provide a more systematic and comprehensible overview of participatory methods in resources management. Throughout the last decade a wide variety of guidelines have been published on how to perform participation, and how 
and when to apply participatory methods such as stakeholder analysis, knowledge elicitation, consultation, and social learning.

A literature review in the next section provides an overview of some of the guidelines that are available for environmental and resources management, and discusses their usefulness to practitioners. Subsequently, principle terms and notions in conjunction with participatory processes are defined. This is necessary since definitions vary widely. A consistent terminology is, however, required for the development of a methodological framework. The CMO scheme is introduced with the methodological macro level: levels and classes of participatory methods in conjunction with objectives of a participatory process. Subsequently, the methodological micro level is introduced, and the link to local constraints is made.

\subsection{Literature review}

The number of methods for undertaking or contributing to an environmental decision process is immense. For water managers it is often difficult to select methods that best suit the local constraints as well as the overall objectives, and are thus effective in reaching the goals of a decision process. Participatory methods (see section 3.3.2 for the definition) fall under the category of policy instruments. In public administration these instruments are the means used for effective implementation of a policy (Maarse, 1995). These range from economic incentives and market-based instruments such as taxes and tax exemptions to tools and methods for the interaction of actors in a decision process. For a better understanding of an appropriate application of participatory methods the literature provides a multitude of guidelines.

The following brief review of a selected number of relevant guidebooks and methodological papers is undertaken with the intention of examining compliance with the following criteria: (1) is there an underlying consistent theoretical structure? and (2) are the guidelines operational? In other words, can practitioners easily apply the guidelines to their day-to-day work?

A systematic approach to analysing participatory processes was first attempted by Arnstein (1969) in her groundbreaking article A Ladder of Citizen Participation. The question of who holds the power in decision making is a central question in this article. Arnstein (1969) argues that participation without redistribution of power is not true participation, but rather a token process pretending to involve lay people in a policy process. Sherry Arnstein was seemingly under the impression that fundamental changes were taking place within the societies of the Western industrial world, when civil rights movements and student protests posed categorical questions about democracy, civil rights and domestic and international policies especially in the United States and Western block countries such as France and Germany. The question of power in the sense that it is described by Kondyles (1984) ${ }^{1}$ was omnipresent, and often expressed in form of violent exchanges between protesters and authorities. Even without focussing on the power question, whomever is in charge of policy/decision making, must either

\footnotetext{
${ }^{1}$ Kondyles' notion of power begins with the consciousness of individual identity and perspectives in relationship to a social context. The individual's position in the world plays an increasing role in a (Western) society, where liberalism is ousted by mass democracy.
} 
voluntarily concede power or be forced to do so. This dissertation, however, focuses on participation and related processes not as an attempt to resolve the 'power question', nor as the interaction between power holders and 'have-nots', but views participation as the interaction between experts and lay people. Experts are seen as those institutions/organisations and individuals who have specific knowledge relevant to a policy process, and lay people are those who have no particular expertise related to the project, but are somehow affected or involved in the broadest sense (see section 2.4.3 and 2.5).

The public participation toolbox of the International Association for Public Participation IAP2 (2008) provides a brief overview of participatory methods in tabular form. The four columns refer to: 'technique', 'always think it through'(tips and recommendations), 'what can go right' and 'what can go wrong' for 38 different participatory methods. IAP2 is an association and a network of scientists and practitioners who seek to promote public participation worldwide. The Toolbox is not comprehensive, but an overview highlighting a number of key issues in participation, without reference to levels and phases of participation. The toolbox is aimed at practitioners and provides instant and brief solutions to or advice concerning methodological issues.

Pahl-Wostl (2002) advocates participatory processes in water management as an essential part of the shift towards a polycentric understanding of (environmental) policy making. The European Water Framework directive (EU, 2000) forms a basis for this paradigm shift. Pahl-Wostl (2002) clearly distinguishes between stakeholder and public participation (see section 3.3.2 for definitions).

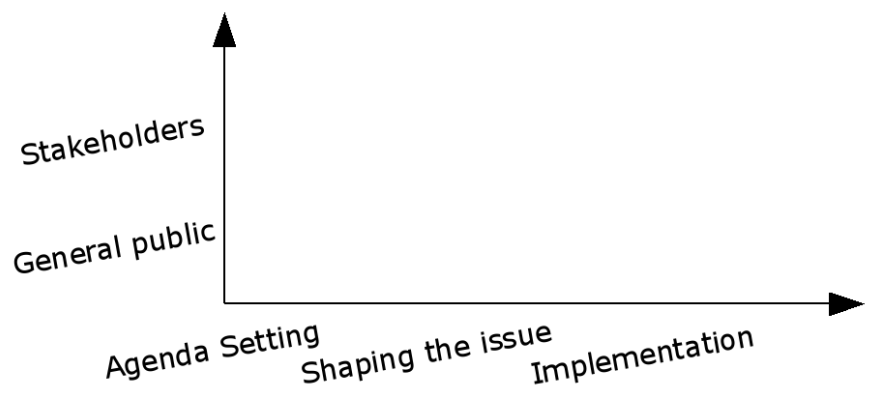

Figure 3.1: Scale of participation in the "life cycle" of an environmental problem (Pahl-Wostl, 2002, p.5)

The two types of participation are plotted against an environmental (policy) 'life cycle' consisting of: (1) agenda setting, (2) shaping the issue and (3) implementation (figure 3.1). In this way the contiguity between participatory process and policy process is revealed. In fact Pahl-Wostl (2002) introduces a simple process-oriented and general framework for stakeholder and public participation. Moreover, a number of participatory approaches are discussed without providing a systematic or comprehensive overview of methods. However a number of examples such as agent-based modelling $(\mathrm{ABM})$, scenario building and multi-criteria analysis (MCA) are presented with some 
emphasis on integrated approaches and the interaction between expert methods (models) and participatory processes. The article demonstrates the role and positive implications of participatory processes in environmental policy, if the predominant management structures permit such an approach.

Mostert (2003a) builds upon the approach of Arnstein (1969) where levels of participation play a prominent role in the analysis of public participation. He is one of the first scholars who assigns particular participatory methods to levels of participation. The levels are: (1) information, (2) consultation, (3) discussion, (4) co-designing, (5) co-decision making and (6) decision making. Table 2 in Mostert (2003a, p.138) suggests that methods may be 're-used', and hence introduces flexibility when applying participatory methods within a decision process. Mostert (2003a) also discusses the political and cultural context of participation related to the assumptions of a local project, and the extent to what participation can be implemented in a policy process.

Mostert (2003a) discusses the design of a participatory process. Issues such as 'actor' analysis, the purpose of a participatory process, roles and rules, policy research and timing are briefly outlined. Another issue highlighted is 'choice of methods', where a number of factors are included: levels of participation, cultural context, phases of a policy process, and public concerns, the level of integration of participatory (sub) processes, and the availability of budget, skills, and resources. However, this article does not provide a more detailed and systematic approach for a 'choice of methods'.

Wates (2000) is a valuable source of practical information on numerous participatory methods that are particularly useful for community planning. Some general advice on how to design and implement a participatory process are provided, and an interesting 'participation matrix' was developed. In this matrix project stages or phases are plotted against levels of community involvement. However, the general principles have no structure, and are rather superficially described. The methods section reveals the sound knowledge and experience of the author, although it is not comprehensive. A number of methods such as group model building and mental mapping are missing. Moreover, there is no setting of methods into an overarching framework.

van Asselt et al. (2001) endeavoured to provide a systematic review of participatory methods as part of an Integrated Assessment approach. The 'goal of application' was in this document already an underlying principle: either participation contributes to the democratisation of citizens or participation is used to improve"... the quality of Integrated Assessments by enriching the knowledge base with contextual knowledge and stakeholder opinions" (van Asselt et al., 2001, p.8). Based upon these two main objectives van Asselt et al. (2001) maps four main goals of participation:

1. mapping out diversity (to reveal the spectrum of opinions and information);

2. reaching consensus (aiming for one solution supported by all in the decision process);

3. democratisation (work out weights that influence a decision process based upon the knowledge of participants;.

4. advising (reveal participant's knowledge that is relevant to a decision process). 
Goal (1) and (2), as well as (3) and (4) are diametrically opposed to each other, and are plotted in a matrix, figure 3.2. However, there is no rationale provided for the choice of goals nor for the evaluation of these goals along a two-dimensional graph. The

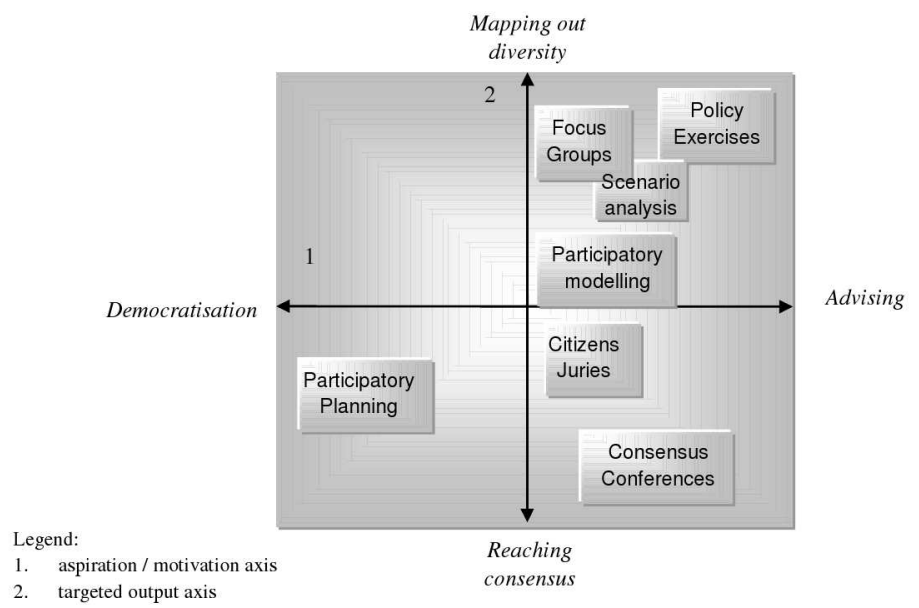

Figure 3.2: Methods-goals matrix (van Asselt et al., 2001, p.9)

methods are grouped into quadrants of goal combinations that can be seen in figure 3.2. Although the approach of categorising methods according to goals is useful, the four goals ultimately constrain rather than support categorisation in this way. On the one hand, participatory methods can support a range of goals, such as interviews which are useful for knowledge elicitation as well as information provision and stakeholder analysis. On the other hand, reaching particular goals may require a combination of methods (e.g. stakeholder analysis can be achieved with document studies, interviews, group model building or any combination of these). Only the summary of methods in (van Asselt et al., 2001, p.43/44) provides more flexibility in terms of the goal-reaching potential of particular methods.

The scope of methods reviewed is limited to focus groups, scenario analysis, envisioning workshop policy exercise, participatory modelling, citizen juries, consensus conference, and participatory planning, and no attempt was made to systematise these methods, for example, by assigning them to levels of participation. Nonetheless, the description of methods is extensive examining the main activity, types and number of participants, tools and techniques, goals, duration and tasks of participants.

Furthermore, van Asselt et al. (2001) lists a number of relevant issues for a participatory process: recruitment of participants, description of tasks and roles of facilitators and participants, planning of meetings, providing material, expected output, and data collection techniques. This approach does not however refer to any of the available theoretical frameworks. Monitoring and evaluation is missing, and the relationship among methods, levels of methods and the applicability of methods within the process in not 
made. In summary it can be said, that the 'building blocks of participation' are well described, but the review of participation lacks consistency, completeness and a relationship between process and the applicability of methods.

Ridder et al. (2005) focus on social learning processes, give practical advice on how to approach stakeholders and the public, and how to communicate with them. They provide water managers with detailed descriptions of chosen participatory methods and provide a number of conflict-resolution approaches. Furthermore, a general structure of participatory processes, a procedural flowchart and an approach to monitoring and evaluating the participatory process are included in their guidebook. Although consistency among methods, structure, monitoring and procedure is rather weak, there is an indication of the phase in which a particular method can be applied. The methods descriptions include functions, examples of use, traps and tricks, costs and criteria for evaluation in a brief overview. However, there is no reference to the 'levels of participation' in which these methods can be applied. For non-experts this might be confusing since, for example, GIS methods are presented together with role playing games, maps, group model building and other methods. The book "Learning together to manage together"provides some valuable advice for those individuals and groups who want to know more about how to implement social learning processes in a planned participatory process.

Elliott et al. (2005) provide the reader with general guidelines for the design and realisation of a participatory process, and an in-depth description of a chosen number of participatory methods. The general guidelines offer valuable advice for participatory managers. However, a systematic approach in terms of levels of participation is missing. Costs and effort are discussed in detail, but oscillate between general remarks and pedantic observations of how much paper, or how many pencils or word processors are required. The description of participatory methods is verbose and detailed, and the choice of methods is limited. Role-playing games, mental mapping, group model building and other methods are missing. A number of elements such as definition, procedure, preparation, budget and pitfalls are discussed. However, the elements are not consistently applied, and thus a comparison is not possible. Arguments for the use of participatory approaches are provided in conjunction with the achievement of particular goals such as enabling democratic governance, strengthening civil capacity, improving efficiency of planning, gaining trust in decisions, achieving greater understanding of public perspectives and interests, increasing social learning, identifying potentially controversial aspects or achieving consensus in a collaborative manner. Criteria for the selection of methods include objectives, topic, participants, time and budget, and are displayed in a comparative chart (Elliott et al., 2005, p.27). The categorisation of objectives of participatory methods is based upon a two-axis chart (axis 1: aspiration/motivation; axis 2: targeted output) adopted from van Asselt et al. (2001, p.9) (figure 3.2), but methods are not assigned to particular quadrants of the chart, and thus there are fewer methodological constraints. In separate section Elliott et al. (2005) provides general guidelines and tips for carrying out participatory methods, particularly with regard to organising the process. However, the link between phases of a process, levels of participation and methods is not made.

The WFD guidelines on participation (European Commission, 2003) translate the principles of the WFD into practical advice for water managers. Integration is a key 
concept of the WFD as well as the guiding documents. Important definitions of public participation, stakeholders, active involvement and others are provided. Furthermore, the rationale for involving the public and stakeholders is discussed. However, there is no clear distinction between stakeholder and public participation including the results of the application of the related participatory methods. In the guidelines, the main elements of information provision, consultation and active involvement are discussed including the relationship among them, but the elements have no connection to a systematic structure and to applicability of participatory methods. In addition, methodological discussions are mingled with practical tips about whom to involve, and what to consider when engaging in stakeholder analysis or consultation.

The elements of context analysis, stakeholder analysis, consultation, access to information reporting and evaluation, developing a learning approach and active involvement are discussed. However, evaluation is seen as an accompanying process that should be integrated in participatory planning. Moreover, stakeholder feedback is valued as an important element of the evaluation process. The document describes a selected number of participatory methods. However, as mentioned previously, there is no connection to an overall methodological framework such as levels or phases of a participatory process, and no concrete advice is offered on how to design a participatory plan. A distinctive feature of this document is an annex with 33 examples of river basin management cases in Europe. The brief case descriptions include the applied methods and tools as well as scale, number of participants and some indication of the success of particular projects.

\subsubsection{Discussion}

Section 3.2 cannot provide a complete overview of guide books and manuals available on the topic of participatory processes. The review reveals that each of the authors has a particular approach, either from a thematic point of view (water-related issues, urban planning or agriculture), or a governance perspective (democratisation, poly-centric versus hierarchical governance style, co-decision processes), or developing a systematic framework for participatory methods in a complex social-environmental context. Either a document assigns a theoretical framework for the combination of participatory methods, or conclusions are drawn from case study-specific experience. The combination of both approaches is missing. The theoretical approaches presented in Arnstein (1969); Mostert (2003a) and van Asselt et al. (2001) may be difficult for practitioners to comprehend. In addition, the case study approaches (partially) miss a systematic theoretical framework and are, moreover, difficult to apply in different local and thematic contexts. In the examples discussed above a water manager who wants to design a participatory process will find a number of best practice tips, occasional comparison of methods and a discussion of values such as sustainability, and democratisation or whom to involve in a process. However, there is no methodological guideline of how to apply participatory methods that is universally valid, systematic, and clearly separates methods from best practice tips. The dualism between using a strict methodological guideline and the required flexibility for any local application is not yet resolved.

The following sections build upon the previous literature, especially the scientific approaches of Arnstein (1969) and Mostert (2003a) as well as the European guidelines for the implementation of the WFD in European river basin management (European 
Commission, 2003), and develop new elements and structures of given methodological approaches. The main objective of this chapter is to provide a taxonomy as well as a methodological structure that serves as a basis for the selection of participatory methods in an endeavour to design a well-structured and effective participatory process. The same methodological structure may be used to apply an monitoring and evaluation process, which will be discussed in the subsequent chapter of this thesis.

\subsection{Fundamental terms and notions}

Before proceeding with the restructuring of the available methodological frameworks, a (re)definition of some key concepts is provided. The literature referred to applies a number of terms and notions intended to facilitate understanding processes that involve concepts such as 'methods' and 'management styles'. However, the array of documents reviewed reveal diverging terms and notions, and moreover, consistent use of the same terms is often lacking.

\subsubsection{Types of participants of a participatory process}

Participatory processes may involve social entities with various backgrounds, functions, knowledge and interests. A categorisation into types of social entities is required, because these types determine the participatory approach used. For water resource management projects four social entity types are relevant:

1. The public are "...one or more natural or legal persons, and, in accordance with national legislation or practice, their associations, organisations or groups" (European Commission, 2003). Usually, the public are those people who live in the vicinity (i.e. in the municipality or the river basin) of project activities, or are otherwise affected by a decision process. The public includes individuals and groups with a general interest as well as stakeholders.

2. Stakeholders are organisations, individuals or their representatives with a particular interest in the course and/or outcome of an investment project. Freeman (1984), within his stakeholder theory, distinguishes stakeholders from shareholders of a company, and emphasises the significant interests and means of influence even though they are not owners of this company. Examples of corporate stakeholders are governmental bodies, political groups, trade unions, communities, associated corporations, employees and customers. Subsequently, stakeholder theory was applied to environmental decision making. Stakeholders, according to Glicken (2000), are those people or organisations either affected by the management process or those who can affect it. These social entities may be interest groups, associations, companies, NGO's, governmental institutions and individuals. Moreover, these individuals and organisations such as land owners may have particular power to influence the course or the outcome of a project. Stakeholders are also more likely to have knowledge of specific aspects of a project. The distinction between the public and stakeholders is not always sharp. However, a number of characteristics may help to separate the general public from stakeholders: 
(a) one or more particular goals that relate (either positively or negatively) to the goals of the project;

(b) a recognisable minimum interest (intention) in achieving these goals within the time frame of the project;

(c) a minimum (cognitive) knowledge of the project plans;

(d) a minimum degree of organisation.

3. The responsible authority in the context of environmental decision processes are (governmental) organisations such as municipalities or water boards who are in charge of a decision concerning water management projects including the organisation and management of a participatory process.

4. Experts are (groups of) individuals who have a (higher level) cognitive knowledge $^{2}$ about (aspects of) the project. Moreover, these experts have the capability to formalise their knowledge, and apply methods in a way that the transition of the planning area from the initial state to a desired state may be described, conceptualised, modelled or prognosticated. Usually, experts are employed by the responsible authorities (or are part of it) to conduct or support planning activities, and evaluate the impact of these activities on the physical and social environment. Experts as well as authorities may be considered as stakeholder, because, according to the definition experts as well as representatives of authorities have an impact on the project.

The distinction between the public and stakeholders may be a grey area, and it may shift throughout the course of a project. In many cases, members of the general public may become stakeholders according to the conditions listed above. Hare and Krywkow (2005) discuss the example of 'farmer Jones' who was simply a member of the public at the outset, and then transformed into an active member of a well-organised community group that is concerned about the loss of arable land for infrastructure development in his river basin. This phenomenon characterises participation as a dynamic process, and demonstrates that stakeholder analysis is not complete with the initial analysis of potential stakeholders. In addition to a sound stakeholder analysis, a high degree of flexibility is required in participatory management Chanan (1999). The distinction between stakeholders and the general public is made because stakeholders have particular interests and goals related to a given project. It is more likely that stakeholders have the capacity and resources to actively participate in a policy process. This might have a significant impact on support for a given project, and even change the power structure of a stakeholder community, and, in turn, may have a significant impact on the course of a participatory process including the application of particular participatory methods.

\subsubsection{Methods}

Participatory methods are a group of techniques for involving social entities (individuals as well as organised or non-organised groups of people) in aspects of a manage-

\footnotetext{
${ }^{2}$ In section 2.1 the this knowledge together with the adequate methodology is referred to as 'regulatory science'
} 
ment process. These methods may have various aims and purposes depending on the clients as well as the objectives of a participatory process. According to van Asselt et al. (2001, p.8) "Participatory methods are methods to structure group processes in which non-experts play an active role and articulate their knowledge, values and preferences for different goals."

Expert methods are approaches that require a high degree of expertise (knowledge and experience) to analyse, model, evaluate and occasionally simulate, reproduce and present within a human-environment system. Usually, lay people are not involved in the development and application of these methods. However, the modification of parameters of or criteria associated with these methods may be based upon interaction with involved lay people. (Rowe and Frewer, 2004) refer to these concepts as elitist model. A typical example of an expert method that requires a participatory process for the generation of parameters is multi-criteria analysis (MCA).

\subsubsection{Processes}

Problem analysis is a diagnosis of the problems identified within a given system. The diagnosis can only be an assessment of system parameters from a subjective point of view. Usually, experts provide this assessment on behalf of the responsible authority. The severity of the issue in question may range from the improvement of life style, the loss of functionality, loss of asset values to a serious disturbance that may threaten the resilience of a system. Apart from the functionality of the (physical) system, a sound problem analysis in conjunction with a stakeholder analysis should indicate their specific interests. These conflicts can also emerge when measures are proposed to overcome the identified problems. Hence, a problem analysis should enable the manager to anticipate conflicts among stakeholders.

Stakeholder analysis consists of (1) identification, (2) categorisation and (3) selection of relevant stakeholder in a given decision process. The goal of this analysis is to establish a basis for cooperation among all involved parties of this process in order to achieve a successful outcome (Hare and Pahl-Wostl, 2002). Instructions for carrying out a stakeholder analysis in environmental decision processes are discussed in Ridder et al. (2005); Hare and Pahl-Wostl (2002).

The identification of stakeholders can be accomplished in a number of ways Hare and Krywkow (2005):

1. Document search: by searching and reviewing existing documents such as newspapers, internal reports etc.;

2. Interviews: by interviewing individuals and organisations who have local knowledge;

3. Participatory stakeholder identification: using group meetings to identify other relevant stakeholders together with the participating representatives (Bryson, 2003);

Stakeholder Categorisation ${ }^{3}$ is not one particular method, but encompasses several approaches depending on the information in which participatory managers are in-

\footnotetext{
${ }^{3}$ Also known as stakeholder mapping
} 
terested. These methods allow managers to group stakeholders in categories depending on the participatory process plans.

In order to identify the level of support for a given project by stakeholders, a powerinterest grid can provide a structured overview of stakeholders including their interests and ability to impact the process. Stakeholders may be assigned to a matrix consisting of the dimensions power in a selected range between weak and strong, and support between opposition and (active) support (Bryson, 2003; Mitchell et al., 1997). This matrix supports the decision process and can hence affect the choice of methods as well as the allocation of resources.

Hare and Krywkow (2005) introduce the policy attractiveness - stakeholder capability grid where stakeholders are evaluated according to their ability to implement a plan (ranging from low to high). The ability is plotted against the attractiveness of the plan from the point of view of stakeholders (ranging from low to high). This method can help to identify which stakeholders might be able to support the implementation of particular policy measures based upon their knowledge and skills.

If the relationship of stakeholders among each other is supposed to be identified, a cross-comparison of stakeholder attitudes to each other can be applied. In this way coalitions as well as conflicts might be detected Hare and Krywkow (2005).

The selection of stakeholders depends on the results of the categorisation. According to the WFD guidance document (European Commission, 2003) all interested members of the public should have access to information about a project and to consultation. Active involvement is encouraged but not prescribed. Stakeholders, however, should be more actively involved in the decision process. The guidance document does not provide detailed instructions about the involvement of stakeholders, so that the stakeholder analysis in the local context is decisive. However, the guidance document refers to the levels of participation when discussing the involvement of stakeholders (see figure 3.3).

Context analysis refers to the analysis of the local context and constraints, and may be seen as a combination of (1) problem analysis, (2) stakeholder analysis and (3) planning and review of the available resources for the participatory process of a project. Ridder et al. (2005) view a context analysis as an extension to the stakeholder analysis in order to be able to develop a 'participation strategy'. The main components are 'political commitment', 'organisational change' and 'capacity building'. Here the notion 'political commitment' refers to the level of activity of a stakeholder. Capacity building on the other hand is seen as part of participatory activities that take place at later in the policy process based upon the context analysis and not part of it.

A participatory process is the interaction of experts such as planners, ecologists, engineers or water managers with lay people throughout a planning procedure with the aim of including the perspectives and views of these lay people to support a decision making process. Participation itself does not necessarily include a decision, but may influence the outcome of a decision by modifying values, goals and knowledge that have previously only been the underlying basis for a formal decision subsequent to an expert evaluation of the transition process including long-term implications. Arnstein (1969, p.216) defines the underlying notion of participation as the "... redistribution of power that enables the have-not citizens, presently excluded from the political and economic processes, to be deliberately included in the future". 
From a methodological point of view a participatory process as a series of participatory methods are linked together to support participatory management. The choice of methods, the design and implementation of the participatory process on the other hand is known as Participatory management. Two types of participatory processes are distinguished:

(1) Public participation is the involvement of the general public in a policy or decision process with a general interest in the outcomes of this process. The guidance document for the implementation of the WFD (European Commission, 2003) provides the following definition: "public participation can generally be defined as allowing people to influence the outcome of plans and working processes.". Furthermore, public refers to a group of individuals and groups no matter whether they are organised or not, and do not need to have predefined goals related to a planned or ongoing policy process. In (local) water resources management projects, however, it is likely that individuals or groups who are considered to be 'the public' in the first instance, may convert to stakeholders given their geographic location close to project activities and the possible positive or negative implications on their current quality of life.

(2) Stakeholder participation is the involvement of stakeholders in a policy process. Based upon the definition of stakeholders these social entities may have a higher impact on the policy process than the general public. As a consequence this can result in a different management strategy (participatory plan) for participatory managers, including the application of different tasks including participatory and expert methods. See also section 3.3.1.

\subsection{Classes of participatory methods - a new category}

The term classes of participatory methods is proposed here as groups of methods that have similar functions, methodology and requirements for expertise and skills. Furthermore, classes summarise methods that may be applied for the achievement of the same goals of a participatory process. The notion of classes was first introduced by Hare and Krywkow (2005) in order to provide a systematic overview of methods, and the first step towards operationalising levels of participation (see section 3.5). Another reason for introducing classes of participation is the fact that participatory methods do not descend from one particular theory, but from various disciplines such as clinical psychology, sociology or environmental case study research (Hare and Pahl-Wostl, 2002). In fact the participatory process methodology as part of an environmental decision process is in itself a multi-disciplinary approach. It is improbable that most water managers know how to handle or predict the impact of each of the methods. This however is a prerequisite for designing and implementing an effective as well as efficient participatory process. Classes are now seen as the key concept that link methods with objectives of a participatory process.

\subsubsection{Matching classes of participatory methods with targeted goals}

Objectives may be seen as management parameters that emerge (1) from the local context and (2) from universal institutional norms that are valid for a policy process (Bressers and Hoogerwerf, 1995). If stakeholder participation is viewed as a process 
that can result in an organisational structure as discussed in chapter (2), than objectives are a preeminent characteristic. Moreover, goal achievement should be the driving force for the design of a participatory strategy, if an effective process has to be designed. For these reasons objectives are separated from local constraints such as the number of stakeholders, the budgeting or the availability of expertise as selection criteria for designing a participatory process

The conjunction between the choice of (participatory) methods and goal achievement has been previously made in van Asselt et al. (2001). However, both the number of methods and the number of goals are limited, and not further discussed in depth.

Participatory methods ${ }^{4}$ can be divided into 9 classes. The notion and description of classes is adapted from (Hare and Krywkow, 2005, p.16-17):

1. Public Information Provision: allows a planner to communicate information about a plan or project to a wide group of people. Methods: websites, flyer, poster, advertisements, media;

2. Education: allows a planner to teach involved individuals the planning and maintenance of a particular project sites. Methods: course work, lectures, workshops, projects;

3. Interviews: allow the planner to elicit knowledge $\mathrm{e}^{5}$. Methods: (semi)structured interviews, card-sorting method, cognitive mapping;

4. Surveys: allow the planner to elicit opinions and data from a large group of individuals. Methods: postal surveys, online surveys, focus groups, mapping, photo survey, Delphi method;

5. Events: allow a planner to set up one-off group events that can draw in a wide range of people to share information about a project in an entertaining or educational manner. Methods: open days, school visit, road show, field trip, ideas competition;

6. Popular Involvement Campaigns: encourage the participation of the public at an individual level in activities that can support the planning process. Methods: tree partnerships, river sponsorship, garden surveys.

7. Fora: allow planners and managers to set up an area for open discussion in which groups of people, over a long period of time, have the ability to voice their opinions about project issues and respond to others viewpoints. Methods: online fora, newsletters, TV/Radio fora;

\footnotetext{
${ }^{4}$ The selection of methods cannot and is not intended to be complete. The aim is to provide examples for each of the classes

${ }^{5}$ Knowledge elicitation tools (KnET) are often seen as an overarching class of methods including interviews and survey approaches (Bharwani, 2006). However, fora, meetings and workshops can be used for eliciting knowledge from lay people. For this reason KnET are considered to be too broad for this classification. In addition, knowledge elicitation may be seen as a goal of a participatory process.
} 
8. Meetings: allow the planner to set up and run moderated large group meetings in order to gather a range of feedback, from a large number of people in a relatively short space of time. Methods: large group response meetings, open public meetings;

9. Workshops: allow the planner to set up and run a moderated workshop with a small number of participants which will provide specific information about a project or even develop plans. Methods: role playing games, scenario building, (computer) simulation, multi-criteria analysis (MCA), citizen juries.

Table 3.1: Matching goals to classes of participatory methods (adapted from Hare and Krywkow (2005, p.18))

\begin{tabular}{|c|c|c|c|c|c|c|c|c|c|}
\hline & 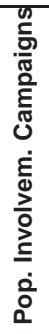 & $\begin{array}{l}\frac{5}{0} \\
\frac{0}{3} \\
\frac{0}{2} \\
\frac{0}{2} \\
\frac{0}{3} \\
\frac{1}{3} \\
\frac{0}{3}\end{array}$ & 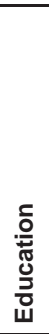 & 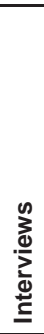 & 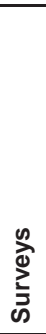 & 岂 & 훈 & 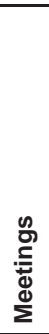 & $\begin{array}{l}\text { n } \\
\text { 응 } \\
\frac{0}{0} \\
\text { 놓 } \\
\vdots\end{array}$ \\
\hline \multicolumn{10}{|c|}{$\begin{array}{l}\text { (1) General normative goals from legal or declar- } \\
\text { ative documents: }\end{array}$} \\
\hline public information & & $\sqrt{ }$ & $\sqrt{ }$ & & & & $\sqrt{ }$ & $\sqrt{ }$ & \\
\hline public consultation & & & $\sqrt{ }$ & $\sqrt{ }$ & $\sqrt{ }$ & $\sqrt{ }$ & $\sqrt{ }$ & $\sqrt{ }$ & $\sqrt{ }$ \\
\hline transparency & $\sqrt{ }$ & $\sqrt{ }$ & & & & & $\sqrt{ }$ & $\sqrt{ }$ & $\sqrt{ }$ \\
\hline identifying constraints & & & & $\sqrt{ }$ & $\sqrt{ }$ & & $\sqrt{ }$ & $\sqrt{ }$ & $\sqrt{ }$ \\
\hline sharing knowledge and experience & $\sqrt{ }$ & $\sqrt{ }$ & $\sqrt{ }$ & & & $\sqrt{ }$ & $\sqrt{ }$ & $\sqrt{ }$ & $\sqrt{ }$ \\
\hline creativity & $\sqrt{ }$ & & $\sqrt{ }$ & & & $\sqrt{ }$ & & & $\sqrt{ }$ \\
\hline acceptance of perspectives & $\sqrt{ }$ & & $\sqrt{ }$ & & & & $\sqrt{ }$ & $\sqrt{ }$ & $\sqrt{ }$ \\
\hline \multicolumn{10}{|l|}{ (2) Goals from case study documents: } \\
\hline identifying all relevant stakeholders & & & & $\sqrt{ }$ & $\sqrt{ }$ & & $\sqrt{ }$ & $\sqrt{ }$ & \\
\hline knowledge elicitation & & & & $\sqrt{ }$ & $\sqrt{ }$ & & $\sqrt{ }$ & $\sqrt{ }$ & $\sqrt{ }$ \\
\hline conflict resolution & $\sqrt{ }$ & & $\sqrt{ }$ & & & $\sqrt{ }$ & $\sqrt{ }$ & $\sqrt{ }$ & $\sqrt{ }$ \\
\hline social learning & $\sqrt{ }$ & & & & & $\sqrt{ }$ & & $\sqrt{ }$ & $\sqrt{ }$ \\
\hline finding consensus & & & & & & & & $\sqrt{ }$ & $\sqrt{ }$ \\
\hline
\end{tabular}

Table 3.1 displays the relationship between classes of methods and goals of a participatory process. The goals in table 3.1 are an arbitrary selection from the literature and include (1) general normative goals: (early) public information and consultation (EU, 2000), transparency, identifying constraints, sharing knowledge and experience, creativity (ISO, 2000), recognition and acceptance of various perspectives (United Nations, 1993) ${ }^{6}$; and (2) specific case study goals: identifying all relevant stakeholders, knowledge elicitation, conflict resolution, social learning (Ridder et al., 2005), finding consensus (van Asselt, 2000). This goal selection does not represent particular case

\footnotetext{
${ }^{6}$ These general normative goals may also be goals that emerged from specific cases
} 
studies, but is supposed to demonstrate the variability in goal setting including the relationship to the classes of participation. The matching of goals with classes of participation is of course only a screening for the selection of appropriate methods. This approach is based upon experience and a literature research as documented in Hare and Krywkow (2005). Goal achievement and methodological structure have a coherent relationship. Moreover, when examining goal achievement in relationship to the applied (classes of) methods, conclusions about the effectiveness of methods may be drawn. If goals are not or only partially achieved, questions concerning the appropriate selection or application may be posed. A controlling approach will be introduced and discussed in chapter 4.

Thus far concepts, notations and relevant definitions with respect to participatory processes in environmental decision efforts are discussed. Furthermore, the relationship between the available tools and methods with project goals is synthesised by introducing the new term classes of participation. As a subsequent step, the overarching (macro) structure of the methodology will be discussed.

\subsection{Levels, classes and methods of participation - the macro struc- ture}

The methodological background for the levels of participation as introduced here is derived from classifications by scientists including, but not limited to Arnstein (1969), Mostert (2003a) and Hare and Krywkow (2005) where public as well as stakeholder participation can reach various consecutive levels of interaction. Additionally, the 'Common implementation strategy for the WFD, guidance document No. 8 European Commission (2003) introduces levels of participation as a principle structure of (public) participation. These levels of interaction may be measured by or reflected in evaluation criteria. They also refer to the application of particular participatory methods.

Table 3.2: The ladder of Citizen Participation Arnstein (1969)

\begin{tabular}{|l|l|}
\hline Citizen control & \multirow{2}{*}{ Citizen power } \\
\cline { 1 - 1 } Delegated power & \\
\cline { 1 - 1 } Partnership & \multirow{2}{*}{ Tokenism } \\
\cline { 1 - 1 } Placation & \\
\hline Consultation & \multirow{2}{*}{ Non-participation } \\
\hline Informing & \\
\cline { 1 - 1 } Therapy &
\end{tabular}

Arnstein's Ladder of Citizen Participation (see table 3.2) focusses on the distribution of power between authorities and the public as an indicator for low (manipulation) or high (citizen control) levels of participation. The notion of power plays a central role for Arnstein.

Mostert (2003a) assigns five levels of participation as depicted in table 3.3 including information, consultation, discussion, co-decision making and decision-making, with 
the latter obviously representing the highest level of participation in terms of involvement in the participatory process.

Table 3.3: Levels of participation according to (Mostert, 2003a)

\begin{tabular}{|l|l|}
\hline Level of Participation & Description \\
\hline Information & $\begin{array}{l}\text { The public is provided with or has access to information (no genuine } \\
\text { public participation, but the basis for all forms of it) } \\
\text { The views of the public are sought }\end{array}$ \\
Consultation & $\begin{array}{l}\text { Real interaction takes place between the public and government } \\
\text { Discussion }\end{array}$ \\
Co-decision making & $\begin{array}{l}\text { The public shares decision-making powers with government } \\
\text { Tecision making }\end{array}$
\end{tabular}

Arnstein's and Mostert's classifications differ from each other in several respects: in reference to the requirements of the European Water Framework Directive (WFD), article 14 (European Commission, 2003) Mostert includes the levels information, consultation, and active involvement, co-decision making and decision making in his analysis. In other words, Mostert classifies activities, and distinguishes a range of activities starting from mere information provision to an interactive decision-making process. However, when analysing (local) water resources management projects, a balance between expert knowledge and lay knowledge, and hence a learning process should be strived for in a decision process. This raises the question of whether or not Mostert's highest level of participation (table 3.3) is the most effective in a decision process concerning local (investment) projects.

The WFD as interpreted by the Guidance Document on Public Participation (European Commission, 2003), states that at the first two levels of participation, both the public and stakeholders (organisations, water professionals, lobby groups) must be involved. At this stage, they must be both informed of management plans and consulted on them. At the level of co-thinking and co-designing (active involvement in developing and designing the plans themselves), the participation of stakeholders only, is encouraged(see figure 3.3).

Building upon the classification systems of Mostert (2003a) and Arnstein (1969), and drawing on the participatory requirements of the WFD Hare and Krywkow (2005) developed a new classification system that includes classes of methods that relate to the levels of participation (see figure 3.4).

However, there is a significant difference between the examples from the literature and the endeavour of this thesis. One of the key objectives of a local water resources project must be the professional implementation of a policy or a set of measures. The effective and efficient use of (in many cases limited) resources and knowledge is another aspect that should be considered. If democratisation is the main objective in a decision process, then Mostert (2003a) and Arnstein (1969) both provide appropriate concepts. If effectiveness and efficiency are the main goals as stated in section 1.4 then 'citizen control' or 'independent performance of public tasks by the public' may not be the most desirable levels of participation, unless this includes expertise that the public possesses or has employed. However, this would be an unusual situation. 


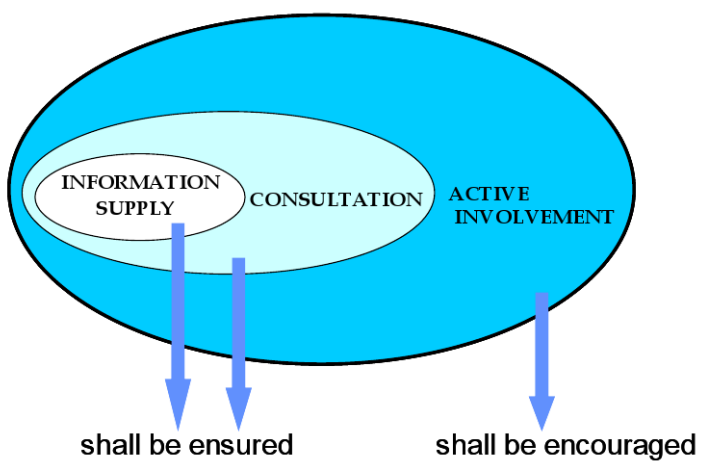

Figure 3.3: Levels of participation according to the guidance document of the WFD (European Commission, 2003, p.(iv))

As discussed in section 2.1 on environmental decision processes, a balance between expertise and lay knowledge is desireable. Examples of the combination of expert methods with participatory methods are provided in section 2.4.3. Consequently, 'citizen control' should not be the highest level of participation for this kind of decision processes. Moreover, following up on section 1.4 it is not only expertise in engineering, ecological assessment, economics or other fields that is required, but also expertise in participatory management that thoughtfully combines different methods and incorporates the various perspectives of the involved actors. According to the definition in section 3.3.3 a participatory process may be seen as an approach to performing a codecision process. Hence, contrary to Mostert (2003a) co-decision making will not be used as a higher level of participation, but as a notion that describes a process where public and stakeholder participation are required. In this way co-decision making itself may have various levels.

The literature frequently applies the notions decision making, decision process and policy process synonymously as a process initiated by investment in the environment of a human-environment system and concluding with a (formal) decision and the implementation of measures. Here a participatory process is seen as being part of a policy process or decision-making process, but not as a synonymous term. A participatory process may be seen as a means of modifying a decision, but not of taking a decision. For this reason the notion decision making as the formal act of taking a decision must be clearly separated from the notion decision making process. In the end, water managers as representatives of the responsible authorities have to take the final decision on how to use the available resources. Section 2.3.1 discusses various governance models that have the capacity to include co-decision and participatory processes. The WFD provides norms that clearly encourage a governance model such as AWM (section 2.3.2).

Mostert (2003a) directly relates methods of participation to levels, which suggests a static use of methods on predetermined levels. Levels may however be viewed as (sub-)goals of a participatory process (i.e. in order to achieve a mutual understanding 


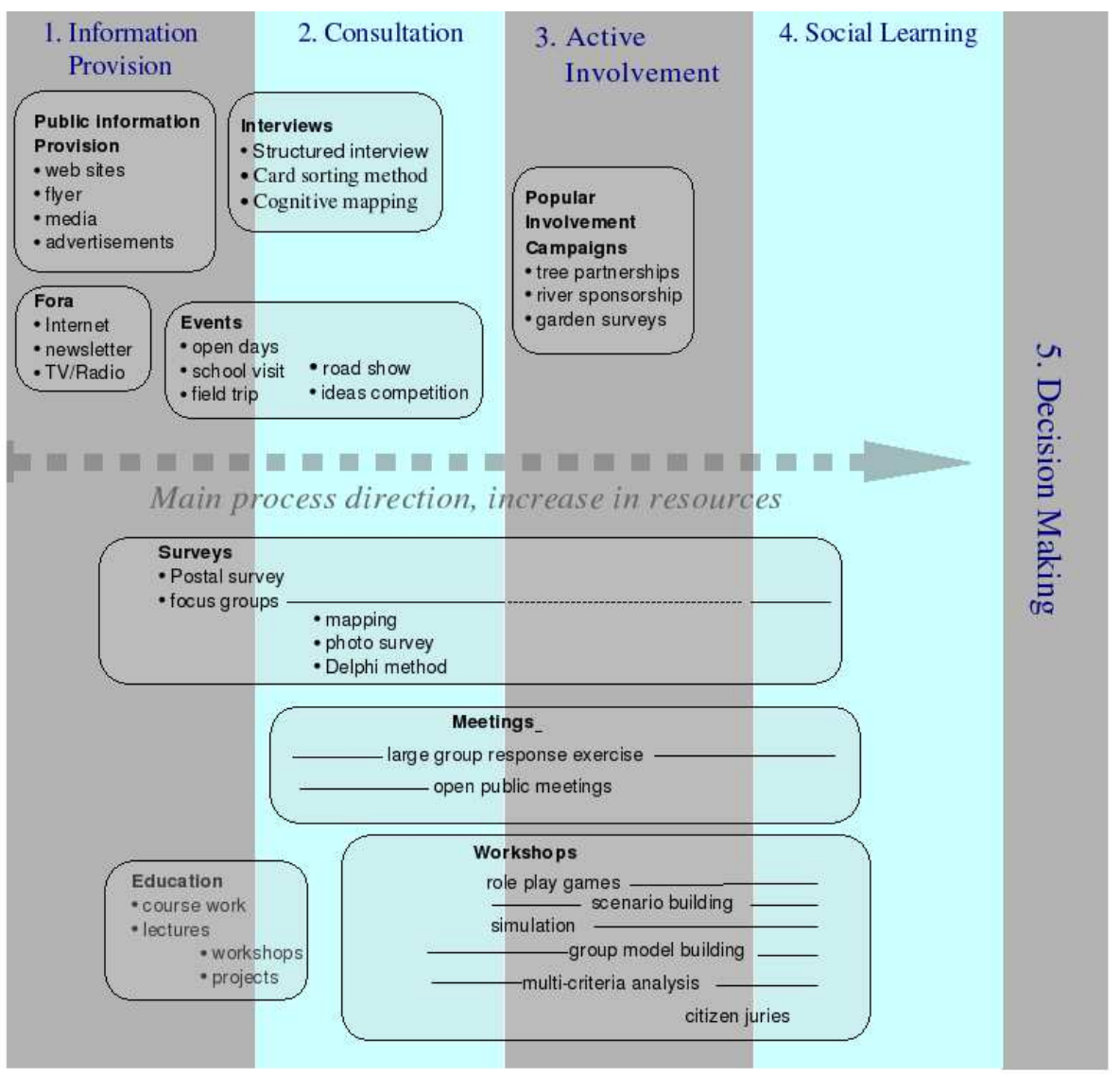

Figure 3.4: Levels and classes of participation (Hare and Krywkow, 2005, p.19)

of stakeholder goals, a social learning process should be initiated, and the level, social learning, should be achieved). These (sub-)goals may also be seen as process goals (Rowe and Frewer, 2004). Table 3.1 is intended to demonstrate that classes of participation may however be employed to achieve several goals. The example of meetings is typical of a multi-purpose use of a method. Meetings can be mere information provision events, but may also reach the consultation level if an exchange of views and perspectives takes place. With this example the significance of thoughtful agenda-setting and goal-oriented work is illustrated.

Following on from the discussion above, the levels co-decision making and decision making are not included in the new classification. Moreover, the level discussion can be assigned to (a) consultation and (b) the newly introduced level social learning (see section 3.5.4 for a definition). This is because discussion has no specific value that can be allocated to a particular level of participation. If the discussion involves only an 
exchange of information then the level consultation can be assigned (see section 3.5.2 for a definition). If the discussion involves an exchange of knowledge and perspectives resulting in modifications of perspectives then the discussion is part of a social learning process.

Another level of participation has been added to Mostert's five categories: active involvement (see section 3.5.3 for a definition). In Hare and Krywkow (2005) Active involvement refers to stakeholder or public activities such as voluntary work. Levels of participation do not indicate a sequence for the application of methods, but the quality of interaction among managers, experts and lay people. The following subsections provide a brief description of each of the four levels of participation (see figure 3.4) that form the new classification.

\subsubsection{Information provision}

Information provision is a mere one-way communication process: planners provide information for the public or stakeholders such as maps, brochures, flyers, TV spots, posters, websites, and newspaper announcements. Strictly speaking, information provision is not a participatory process since participation requires some sort of interaction among the social entities involved. However, it is an essential part of the participatory process and directly contributes to the transparency of the process. (Mostert, 2003a, p.182) includes the "opportunity to comment on plans, discuss issues and develop alternatives"in the level information provision. However, this contradicts the intrinsic definition of information provision as a one way process.

\subsubsection{Consultation}

Consultation is a two-way process where planners introduce the public or stakeholders to the problems at stake as well as to proposed measures to solve these problems. At the same time a response from stakeholders is expected, and should be processed with the help of appropriate participatory methods. The process of consultation enables planners to elicit both local knowledge as well as views and perspectives on several issues. Consultation may be part of an actor analysis as well as problem analysis. In other words, throughout this process, yet unknown stakeholders and, based upon their knowledge and views, unknown problems, side effects and new issues might be identified.

Consultation must be distinguished from active involvement since lay people are strictly speaking not yet involved in the policy process and related activities. Only knowledge and opinions are exchanged that may impact policy processes in form of active involvement or social learning in a later stage of the process.

\subsubsection{Active involvement}

Active involvement is the active cooperation of lay people in a planning process. This may involve: data collection, monitoring, system identification, plan design, voluntary work, implementation and maintenance. Hence members of the public or stakeholders consciously and voluntarily choose for an active role in the design or implementation of project goals. This is not necessarily part of a social learning process, but 
can certainly contribute to such a process. The activities may range from group model building and scenario development to popular involvement campaigns directly at the planning site.

\subsubsection{Social learning}

In brief, social learning may be seen as a process to collectively examine, analyse and modify individual beliefs of all involved social entities with the aim of achieving planning goals with the greatest level of approval among the participants. The result of this collective process should dominate the decision.

Social learning is a popular topic in social science research. It is hardly surprising that there are numerous definitions of social learning available with various views and emphases on the issue. (Bandura, 1977) developed a theory of social learning involving aspects of behavioural and cognitive learning. New behaviour can be achieved as a result of reinforcement (or punishment) or observational learning. The process of social learning includes: close contact, imitation of superiors, understanding of concepts, role model behaviour. Bandura's theory connotes a hierarchical structure of the involved social entities. At least one 'superior' agent carrying particular cognitive knowledge and a predominant position of power participates the process.

(Wenger, 1998, p.5) developed a social theory for learning with the following main components:

1. Meaning: a way of talking about our (changing) ability - individually and collectively - to experience our life in the world as meaningful.

2. Practice: a way of talking about the shared historical and social resources, frameworks, and perspectives that can sustain mutual engagement in action.

3. Community: a way of talking about the social configurations in which our enterprises are defined as worth pursuing and our participation is recognisable as competence.

4. Identity: a way of talking about how learning changes who we are and creates personal histories of becoming in the context or our communities.

According to this definition social learning is collective action introducing individual resources, knowledge and experience that undergo a modification ${ }^{7}$ with the potential to adapt previous goals and intentions. This definition can be applicable to social learning processes in participatory water management.

As an applied example, the European research project HarmoniCop ${ }^{8}$ was exclusively devoted to the issue of social learning in water management. The key message of this project is: Learning together to manage together Ridder et al. (2005). The rationale here is that neither the responsible authorities nor the relevant stakeholders

\footnotetext{
${ }^{7}$ Usually this means yielding more knowledge, experiences and eventually resources - the intrinsic learning process.

${ }^{8}$ http://www.harmonicop.uos.de/
} 
have the resources to individually undergo a complex policy process such as river basin management (RBM). (Ridder et al., 2005) argue that social learning provides RBM with more beneficial results for all involved parties. Significant requirements are: openness and trust, interaction among stakeholders, stakeholder interdependence, critical self-reflection, development of shared world views, critical assessment of potential solutions, joint decision making based upon reciprocity commitment. Hence, (Ridder et al., 2005) associate social learning with a co-decision process. The assumption is that the results of the social learning process at least significantly influence the process. In this approach social learning and co-decision are closely interwoven and difficult to separate.

All of the introduced social learning theories and approaches imply intense activities (possibly) resulting in changing behaviour of the involved social entities including responsible authorities and eventually superior organisations. As a consequence social learning requires extra resources and time as well as sophisticated methodological knowledge and skills. Many examples of participatory water management indicate that the level of social learning is not always reached.

\subsubsection{Decision making}

In water resources management projects competent authorities hold legal and administrative responsibility for decisions. For this reason (formal) decision is deliberately segregated from social learning in this research. Involvement and social learning may influence the final decision for the design and implementation of a planning effort, and the participatory process including information provision, consultation, involvement and social learning maybe seen as a decision making process or policy process. However, the responsibility ultimately remains in the hands of the authorities. This is especially important because of the expertise required in the process of modifying the physical and social environment of the administrative district.

Strictly speaking the organisational structure of a policy process in a local investment project is generally hierarchical, if the authority retains the right and to make and hold responsibility for the resulting decision. Only if the authority delegates the decision making process entirely or partly to a community of stakeholders including experts and lay people, is the management style truly a co-decision. For this reason (formal) decision making is separated from the levels of participation, and is seen as a final point in the decision making process based upon various levels of participation.

\subsubsection{Discussion - levels of participation}

The concepts information provision, consultation, active involvement and social learning are the levels of participation in this approach. These represent levels of activities or intensities of interaction among involved social entities within a co-decision process. Although it may be debated whether or not the lowest level information provision is real participation, it is essential for a fair and open exchange of information, knowledge and opinions within a decision process. It is the basis for an interactive policy process. The levels of participation increase not only with the mere quantity of activities, but also with the intensity. 
Social learning is seen as the highest level because of the more intense interaction in comparison to consultation. Whereas consultation implies an interactive exchange of information, goals and perspectives, social learning exceeds that level, since social learning activities refer not only to an enhancement of knowledge, but also a modification of individual goals. The implications are more significant for the decision process, since primary planning goals may be modified or even discarded. On the other hand, if planning goals are a result of a social learning process, the support for the project among stakeholders might be much higher than without this process. In section 2.2.1 the concept of complex adaptive systems (CAS) is discussed with capacity for learning as an indicator for the adaptive capacity of a system. If a water management project including all physical and social entities and their relationships are viewed as a CAS, then social learning is a key concept for a resilient water management system. The concept of CAS is adopted in the governance model of adaptive water management as discussed in section 2.3.2 where learning plays a similar role as in the concept of CAS. As a consequence, the levels of participation may only be reached with an appropriate governance model.

\subsection{Implementation criteria of participatory methods - the micro structure}

Thus far the overarching methodological structure of participatory processes has been discussed, and the link to policy objectives made. A clear understanding of the conjunction between the methodological macro structure and goal achievement is essential for utilising the most effective (participatory) methods in a decision process. However, the macro structure would be to coarse to identify the appropriate participatory tools and methods for a given policy process. Once the overall goals are identified, the matching classes of methods can be selected and the levels of participation identified. The selection of methods should be the next step. For this reason, the methods that enable the water managers to match local constraints such as the number and types of stakeholders, budgeting or available expertise, must be examined more closely.

One of the repeatedly observed phenomena associated with the application of participatory methods in water management is the use of 'approved' criteria for the selection of appropriate participatory methods without adequate reflection. Approved however often means the responsible managers and experts are not aware of a broader range of methods, do not have the time or the budget, or the legally prescribed procedures are narrowly interpreted.

A classification of participatory methods as demonstrated in section 3.4.1 will undoubtedly help to detect similarities in methods, thus enabling users to systematically browse for other participatory methods that have not yet been applied in order to be goaloriented, and hence more effective. On the other hand potential users of participatory methods may want to know the requirements of the methods in order to manage available resources over the entire period of the participatory process for the same reasons. The context analysis (see section 3.3.2) should result in limitations for the selection of participatory methods. 
Participatory methods tend to originate from the social sciences such as sociology, policy science and psychology. A minimum of expertise is required to apply these methods in a controllable manner, and to yield valid results. On the other hand, the effect and the quality of results depend not only on the sophistication of methods, but also more significantly on the financial resources and time required. For example, a survey may promise more valid results than random interviews or questionnaires. The downside is higher costs and and a higher expenditure of time. In their entirety relevant participatory methods stem from a variety of disciplines that participatory experts cannot oversee. Water managers and planners however may want to have a reliable indication of the applicability of the methods within their participatory processes. Ridder et al. (2005) analyse a number of participatory methods according to their applicability. This is a simple system including three levels of applicability (high, medium, low) in three phases (initiating, managing, improving) of a participatory process. However, a coherent and systematic relationship between the applicability of methods and the local constraints such as availability of resources and number of stakeholders is missing.

\subsubsection{Grouping and description of implementation criteria}

This section introduces a new method that is adopted from Hare and Krywkow (2005) for examining the applicability of participatory methods in light of local constraints. A more elaborate set of uniform implementation criteria that enable users to select participatory methods, and employ them according to their available resources is developed. Uniform criteria can be applied to any existing participatory method independent of the specific context of a case study or project. Based upon these criteria a catalogue of classes and methods was compiled in Hare and Krywkow (2005, p.23-49) enabling users to examine potentially applicable methods.

Since tangible costs (e.g. costs of personnel and material) and intangible requirements (moderation, level of education and experience) are both included in the set of criteria, no absolute costs can be calculated. Although this framework might be used to 'optimise' the use of available resources, the lack of tangible parameters or, in other words, the necessity for including intangible parameters for a valid assessment prevents the application of mathematical, welfare-economic or product optimisation methods. In this way, residual subjective and normative assessment criteria cannot be avoided. However, the categorical and comparable composition of implementation criteria itself minimises the range of uncertainty accompanying the search for the set of methods that promise effective and efficient planning and design of a participatory process. Whereas, the matching of goals with classes of participatory methods supports the identification of effective methods, implementation criteria generally help to identify an efficient use of methods.

A semi-quantitative classification is employed that simply indicates requirements of a criterion. However, with respect to the criteria resources share and level of application skills ${ }^{9}$ the quality of the criterion is distributed over preparation (p), implementation (i) and analysis (a).

${ }^{9}$ This refers to the level of expertise associated with a specific method ranging from common sense to special training. 
The implementation criterion Levels of participation is already discussed in subsection3.5. This criterion refers to the intensity of the method, and is definitely a effectiveness criterion.

\section{Resources share (Cost-effort share)}

The criterion resources share refers to and summarises the required resources in terms of staff, time, tools and additional costs for preparation, implementation (execution) and analysis in relative terms (estimated percentage). Hare and Krywkow (2005) only provided and estimated this share based upon experience, since no relevant evaluation is available in the literature. However, resources share is a significant criterion for the planning of a participatory process. In the catalogue of participatory methods a Resource breakdown table (table3.5) provides a closer look at the components of resources.

\section{Level of application skills}

The criterion Level of application skills indicates the degree to which expertise is required in order to apply a particular method. As with resources share the three phases preparation, implementation (execution) and analysis are distinguished. This is relevant since (classes of) methods such as interviews, surveys, meetings, workshops, group model building, multi-criteria analysis (MCA) and cognitive mapping require particular knowledge, experience and skills. Moreover, the required expertise can differ throughout the phases of a method. For example, surveys must be prepared and analysed with care and thought, since the design of questions has a significant impact on the results. In addition, the analysis method, especially when sophisticated statistical methods are employed, may have a significant impact on the results, not to mention the interpretation of results. The development and implementation of a survey however requires resources and time, but relatively less expertise. Whereas, a workshop involving such activities as role playing games can require considerable expertise in its preparation and during the performance. Levels of application skills are divided in three categories (Hare and Krywkow, 2005, p.21,22):

- Experience and common sense [E]: general understanding of methods, data collection, organising events, communication with stakeholders and the general public;

- Scientific knowledge [S]: analytical capability including induction and deduction among case study issues and results and general methodology, desktop research and (scientific) literature research and analysis, applying scientific methods and tools such as computer models, understanding of complex problems and uncertainty;

- Technical expertise [T]: applying and eventually designing or modifying technical equipment and computer models.

\section{Moderator skills}

Skills in moderation play a significant role in the successful application of participatory methods. The classes of methods, meetings, workshops, several survey methods 
(e.g. Delphi method) and education, require soft skills, especially moderator skills. Hare and Krywkow $(2005$, p.21,22) simply distinguish among normal, high and none. Normal skills are needed for organising and conducting meetings or workshops without specific moderation skills. A number of methods such as scenario building, role playing games or policy exercises may differ in their effectiveness based upon the experience, preparation and performance of a moderator.

\section{User mode}

User mode refers to the number of individuals per activity, and indicates the type of participation. This can be single users, small or large groups. Many participatory methods have an optimal or maximum number of participants. If it is expected that this number will be exceeded, the method may be excluded or resources (time, staff, budget) must be increased.

\section{Special software}

In some cases, Special software, such as computer models or web interfaces for surveys, is required. Software can be both expensive and require expertise for its use.

\section{Summarising the indicators and criteria}

All of the implementation criteria are summarised in table 3.4 and form part of the method description in the catalogue of participatory methods as documented in Hare and Krywkow (2005, p.23-49). See Appendix B for an examples of this catalogue.

Table 3.4: Summary of implementation criteria (Hare and Krywkow, 2005)

\begin{tabular}{|c|c|c|c|c|c|c|c|c|c|}
\hline \multirow{2}{*}{$\begin{array}{l}\text { Level of } \\
\text { participa- } \\
\text { tion }\end{array}$} & \multicolumn{3}{|c|}{ Cost-effort share } & \multicolumn{3}{|c|}{ Level of appl. skills } & \multirow{2}{*}{$\begin{array}{l}\text { Moderator } \\
\text { skills }\end{array}$} & \multirow{2}{*}{$\begin{array}{l}\text { User } \\
\text { mode }\end{array}$} & \multirow{2}{*}{$\begin{array}{l}\text { Special } \\
\text { software }\end{array}$} \\
\hline & (p) & (i) & (a) & (p) & (i) & (a) & & & \\
\hline $1-4$ & $\mathrm{x} \%$ & $y \%$ & $Z \%$ & $\overline{\mathrm{E} / \mathrm{S} / \mathrm{T}}$ & $E / S / T$ & $\overline{\mathrm{E} / \mathrm{S} / \mathrm{T}}$ & none-high & [n] pers. & yes/no \\
\hline
\end{tabular}

\section{Types of resources - resources breakdown table}

Table 5 provides a closer look at the buildup of the cost-effort share as displayed in table 3.4, column 2. The resources types staff, time, tools and additional costs are plotted against the phases of an activity (preparation, implementation and analysis) (table 3.5 .

Table 3.5: Resources breakdown (Hare and Krywkow, 2005)

\begin{tabular}{|c|c|c|c|}
\hline Phases: & Preparation & Implementation & Analysis \\
\hline$\overline{\text { Staff }}$ & \multicolumn{3}{|c|}{ Skills and tasks for each phase } \\
\hline Time [h] & \multicolumn{3}{|c|}{ Duration of activities for each phase } \\
\hline Tools & \multicolumn{3}{|c|}{ Type of tools for each phase } \\
\hline Additional costs & \multicolumn{3}{|c|}{ Costs such as printing, web hosting and room rental for each phase } \\
\hline
\end{tabular}




\subsubsection{Discussion of implementation criteria}

The innovation of implementation criteria is the fact that a uniform set of criteria characterises the usefulness of a participatory method for water managers regardless of the methods to be employed and the specific local context. On the one hand, it represents a more elaborate search for effectiveness, that is introduced with matching goals and classes of participation (levels of participation and user mode). On the other hand, an efficient application of methods is aspired to (as shown in table 4). The latter component enables the manager to balance available resources, time and expertise with the designated goals. It is the CMO approach from the methodological micro-structure perspective.

\subsection{Summary and conclusions}

This chapter describes the development of a structured typology that may serve as a basis for the analysis and design of participatory processes in (local) water resources management projects. The omnium gatherum of available social-science-based participatory methods makes the selection of appropriate methods for planners and water managers difficult. Participatory river basin management and even local planning projects, are in most cases too complex to be managed with simple methods and guidelines.

A multitude of criteria such as the planning context, specific local and cultural problems, the diversity of stakeholders including their individual perspectives, available resources and the diversity of planning goals have to be considered in the management of a participatory process. The literature overview highlights this challenge. There is no generally applicable guideline available. Authors repeatedly point out the case-specific uncertainty and diversity that rightly brings into question the validity of a generally applicable guidebook. Such a book would contradict the attempt of many water managers, scholars and decision makers to cope with the complexity of water management in an adaptive, integrated way.

Nevertheless, some guidance is required, especially since most planners and water managers have at best limited knowledge of and experience with participatory methods. The documents discussed in this chapter do provide a level of guidance and advice in how to design and conduct a participatory process. Some of the documents strive for methodological clarity, but are not consistent or do not attempt to associate levels of participation and methods with objectives and resource limitations. Other documents provide specific information on particular issues such as social learning or are only applicable under certain conditions or comparable case-specific situations. Specific descriptions and discussions of methods are not associated with an overarching framework such as levels or phases of participation.

In order to address this dilemma and overcome ambiguity, an attempt is made to clearly define terms and notions that are relevant for participatory water management. As an example, the WFD guidelines European Commission (2003) have no clear distinction between stakeholder and public participation. The difference between stakeholders and the public is defined, but with no reference to possible consequences or benefits of their respective participation on the process. Stakeholder or public participation, however, may be a significant criteria for the choice of methods, since the two 
types of participatory processes imply different numbers of individuals with different knowledge, interest and the capability of influencing a decision process.

The CMO scheme is realised in the following manner: (1) The concept of levels of participation was enhanced with the introduction of classes of participatory methods. This involves more structure, and at the same time refers to the objectives and goals of a participatory process as displayed in the classes-objective matrix (table 3.1). (2) Methods received a standardised set of implementation criteria that refer to the specific requirements of practitioners. A catalogue of methods that are described with these criteria was published (Hare and Krywkow, 2005). An examination of methods is now possible without reviewing a large number of guidebooks.

In this way, a well-defined set of parameters for each known method can be related to the specific requirements of a water resources management project, without decreasing the necessary flexibility in the design and planning of participatory processes. This CMO scheme provides a basis for controlling activities that will be discussed in chapter 4 , and planning support for participatory management (chapter 6). 
CHAPTER 4

Monitoring and evaluation of participatory processes - the

COPIR approach

\subsection{Introduction}

Monitoring and evaluation in participatory water management is demanded in the legislation of the European Union (European Commission, 2003; EU, 2000). This legislation requires adequate guidance, transparency, reporting and the early recognition of problems. These criteria should support an effective process, and help to improve conditions for future processes by allowing water managers to learn from experience. Apart from institutional norms, the scientific literature argues for monitoring and evaluation.

In a comparative analysis Rowe and Frewer (2004) present arguments for monitoring and evaluation such as improving the effectiveness of the process, reviewing the use of financial resources and learning from past mistakes. Furthermore, Ridder et al. (2005) point to the fact that managers have an opportunity to increase their knowledge of participatory processes.

When examining local applications of participatory processes as accomplished in Rowe and Frewer (2004), many of these processes have included evaluation as an expost activity, and the benefits of evaluation can only be exploited in subsequent projects. Consequently, the application of mid-term evaluations is appropriate but remains cumbersome, and the benefits are not always obvious to water managers.

Moreover, previous evaluation approaches employ specific local values (goals) as criteria, which inhibits a comparison between case studies in terms of their effectiveness. Under those circumstances, trans-boundary ${ }^{1}$ learning has to rely on local experience without the opportunity to fall back on generally applicable criteria. At this point the

\footnotetext{
${ }^{1}$ The term 'trans-boundary' is applicable here from the 'village-project' scale over river basin to international
} 
sustainability/IEA issues of ambiguity and subjectivity, as discussed in section 2.2.1 recur like a déjà vu. There is no standard method, applicable guideline or framework to guide one through an evaluation procedure.

However, this is the challenge for this chapter. Whereas chapter 3 develops and discusses a structured scheme (CMO) that provides more rigour in the structure of participatory process management, the evaluation approach as introduced in this chapter endeavours to operationalise this new methodological scheme, and provide a general approach for the evaluation of participatory processes in environmental decision efforts.

As a basis for the operationalisation of the CMO scheme and the introduction of a generally applicable evaluation framework, introduced here as COPIR ${ }^{2}$ approach, the 'six dimensions of process intensity' that was for the first time introduced by Rasche (2005) are applied. An initial discussion and review of this approach was published in Rasche et al. (2006). This chapter here is a new critical discussion of Rasche's six dimensions of process intensity, as well as an attempt to integrate this evaluation approach with the CMO scheme.

For this reason, the rationale for evaluation processes is examined by discussing basic aspects of organisational theory. Furthermore, the evaluation criteria as found in Rowe and Frewer (2004) are compared with Rasche's six dimensions of process intensity, in order to examine whether or not the new criteria can cover the entirety of all found local criteria. Finally, the definitions for the intensity criteria are provided, and types of participatory processes based upon the combination of the new criteria as developed by Rasche are newly discussed with references to the scientific literature.

Whereas the evaluation efforts as found in Rowe and Frewer (2004) do not clearly distinguish between the evaluation of a local project as a whole and the effectiveness of the related participatory process, the evaluation approach as introduced in this chapter, strictly focusses on participatory processes.

\subsection{Evaluating, monitoring - controlling}

In their 'five components' Bressers and Kuks (2001) consider governance as a policy network of actors (see section 2.3.1). This does not stringently exclude a hierarchical structure of governance, however, it connotes a higher degree of equality among participating actors. Ostrom (1998) and Pahl-Wostl (2002) go a step further and require a polycentric policy approach where hierarchical (command and control) structures are not sufficiently effective anymore. This increases the chance to effectively incorporate the perspectives of lay people, detect unknown problems, and introduce more equality to the involved actors. However, the 'control' part of the 'command and control' system has to be replaced by an adequate approach. The main theme of this chapter is to discuss a new control approach, that is more appropriate in a polycentric government style than previous control mechanisms. The rationale for such a new approach will be discussed next.

Looking beyond the issue of participatory water resources management, there are many sectors in which monitoring and evaluation are daily activities incorporated into

\footnotetext{
${ }^{2}$ COPIR $=$ Constraints, Objectives, Process, Intensities, Reporting
} 
the management process. They play an essential role in providing feedback and adjustment. This may be referred to as controlling.

Controlling is an essential part of management processes in most economies, in industry, information technology, in public and business administration and the service sector. It is needed to evaluate the performance of a system in order to identify errors and increase efficiency and effectiveness.

When examining the process of environmental decision making, especially the involvement of stakeholders and the public, the question may be posed as to what extent the involved social entities form an organisational structure. This could be important for the design and implementation of the participatory management including any monitoring and evaluation efforts. From the point of view of a local project that is limited in time, the societal component of a target system cannot be assumed to possess organisational structure. However, when modifying the (environmental component of the) system, concerns, connectivity, interests or objectives of affected individuals and groups can change. Moreover, these interests and objectives may focus to such an extent, that significant similarities in the belief and goal structure of the affected actors may emerge. Hence, within the time frame of a participatory process social action may evoke attributes similar to those of an organisation. However, what are the principle characteristics of an organisation?

There is no uniform definition of the term organisation. However, scholars such as Parsons (1970); Elliot (1980); Galbraith (1977); Pugh and Hickson (1973); Etzioni (1964); Rowe and Frewer (2004) and Schaad (2003) introduced a number of criteria to characterise organisations:

- the most ubiquitous attribute is goal attainment. The performance, structure and effectiveness of an organisation as a whole is geared towards the achievement of one or multiple goals;

- the individuals of an organisation have a collective belief or a set of beliefs ${ }^{3}$;

- an organisational structure such as task allocation, division of labour and coordination;

- supervision, incentives and restrictions to ensure that all individuals pursue the organisational goals independent of their own individual beliefs;

- information-based decision process communication, rules and output controls are efforts to optimise the final 'product' such as a decision;

- commitment, individuals of the organisation either voluntarily or indentured commit to the goals of the organisation.

The underlying structure of a participatory process in a water management context can be seen as a complex system comprising social entities such as experts, policy makers and lay people (the public and stakeholders) as well as the physical environment (water

${ }^{3}$ only those beliefs should be factored in that are oriented towards goal achievement 
bodies, infrastructure, housing, economic assets, technical artifacts, etc.). The participatory process may be seen as an attempt to achieve a new state of the system. This system at the beginning of a participatory process has no or only weak organisational structures ${ }^{4}$. Although, the entirety of social entities is undoubtedly part of a complex phenomenon undergoing a decision process, in the beginning of a process that 'human part' of the system cannot entirely be considered as an organisation for the following reasons:

- the entirety of social entities as described above has no uniform set of goals;

- there is not a consistent organisational structure including division of labour, coordination and task allocation;

- there is not an overall and collective belief or knowledge of how to pursue the goals of the announced policy process;

- supervision is (in the outset of the policy process) only possible within the "professional' arena (including experts, managers and policy makers) of the 'participatory system';

- lay people cannot be forced into commitment. Typically, the phenomenon of ignorance must be incorporated.

If such a group of social entities cannot be seen as an organisation in the beginning of a participatory process, why should participatory management include elements of organisational control? Initiated by a pronounced decision process intended to modify the existing system, a participatory process may be seen as a transition from an inconsistent complex system including professionals and lay people with diverse goals and beliefs to a more consistent structure that has emerged as a result of communication, consultation and possibly educational or even social learning processes with adjusted goals and beliefs in the form of a compromise, agreement or consensus. If a participatory process is seen as a policy instrument to 'optimise' the process of achieving a given set of goals, effective participatory management also requires monitoring, feedback and evaluation. Hence, monitoring and evaluation is not only relevant for experts, managers and policy making, but also for the stakeholders wishing to know if their specific interests have been addressed. This is in line with the requirements for poly-centric governance as proposed by Bressers and Kuks (2001), Ostrom (1998) and Pahl-Wostl (2002).

As a first step to improving monitoring and evaluation activities: instead of employing criteria such as case-specific goal achievement or stakeholder satisfaction, simply the degree to which the criteria of an organisational structure are fulfilled at the end of a participatory process should be applied. The advantages are: (1) a uniform and comparable set of evaluation criteria; (2) reduction of the subjectivity and ambiguousness of the criteria. However, this is not the entire objective of the approach as introduced here.

\footnotetext{
${ }^{4}$ in this context a participatory process is defined as a local or regional short-dated policy process. This definition is not applicable for global assessments or a long-term strategic discourse
} 
Weber (1920) was one of the first scholars to elaborate on controlling activity within organisations. He emphasised rationalisation as an inevitable step towards greater efficiency within a system. Subsequently, scholars such as Fayol (1949); Schaad (2003) distinguished between systems design (i.e. organisational control) and its daily operations (i.e operational control). Evaluation procedures such as those introduced here are definitely equivalent to organisational control. If an evaluation effort detects errors, either methods must be replaced or the the application of a method must be significantly improved or repeated. That goes beyond adjustments of daily operations, which is a matter of monitoring (section 5.2.2).

Throughout their endeavour to review contemporary evaluation and monitoring methods (from case studies between 1981 - 2004) Rowe and Frewer (2004) distinguish between informal and rigorous evaluation, advocating for the latter approach. Informal evaluation uses observations such as the number of participants at meetings or workshops to indicate the intensity of participation. This, however, does not result in any conclusions about the effectiveness and efficiency of the examined participatory method, nor does it provide data or information sufficient for a tangible analysis employing accepted empirical methods. The authors compared 30 documents that contain evaluation procedures based upon real-world processes. In this document the notion of effectiveness played a central role, and the ultimate goal of an evaluation process is to identify the most appropriate methods throughout a participatory process. Most of the criteria of these documents reviewed are normative, and moreover case-specific or methodoriented. Examples include: representativeness, early involvement of stakeholders, independence, cost-effectiveness, transparency, resource accessibility and availability, incorporation of values/beliefs, convenience, satisfaction, fairness, competence, reduced time for decision making, knowledge achieved, process flexibility. As a consequence of the case-specific dependency the above mentioned evaluation criteria are not generally applicable. The combination of specific local constraints and goals of the investment project repeatedly impede the reuse of evaluation criteria in other projects or case studies, nor do they permit a comparison between various cases or local projects.

In order to overcome the difficulty to reuse normative (both general and local) evaluation criteria of traditional evaluation approaches, an obfuscated comparability between various local cases and projects in terms of efficiency and effectiveness, a novel approach was developed. This novel method, developed by Rasche (2005), introduces the concept of evaluating process intensities in the context of well-separated local constraints and specific project goals. In this chapter the CMO principle as introduced in chapter (3) is elaborated, and a generally applicable evaluation methodology is developed. The following sections outline this monitoring and evaluation method, termed the COPIR approach, including its elements and implications.

\subsection{The COPIR approach}

As indicated in section 4.2, previous monitoring and evaluation approaches have a number of downsides that make it difficult to carry out an effective, comprehensible and comparable analysis of participatory processes. One central problem in these efforts 
is the lack of differentiation between local constraints and case-specific objectives of monitoring and evaluation criteria.

Since in general a comparison between local projects is at least problematic if not impossible, the validity of these monitoring efforts may be matter for discussion. Furthermore, the plurality of world views of all involved social entities does not necessarily provide a generally accepted ranking of all values, apart from a relatively small number of categorical (western) normative values such as access to clean water, freedom of speech, the protection of private property and equality before the law. If a participatory process is defined as an interaction of experts with lay people throughout a planning procedure with the aim to include the perspectives and views of these lay people in order to support a decision making process, imposing values by some authorities cannot be a solution.

Another limitation is that monitoring and evaluation is often only applied after a participatory process is completed. In many cases the results can only be used as lessons learned, and at best applied in subsequent projects. However, controlling according to Weber (1920); Fayol (1949); Schaad (2003) and others is supposed to be an accompanying activity with the aim of analysing and occasionally modifying (effectiveness) or 'optimising' ${ }^{5}$ (efficiency) ongoing processes.

\subsubsection{Determining intensity criteria}

Whereas normative as well as context goals emerge(d) from societal development, institutional changes and local requirements, intensity criteria are concepts that have been entirely developed by scientists. Although Rasche (2005) as well as Rasche et al. (2006) underpin the origin of particular criteria with examples from the literature, a rationale for the choice of exactly these and no other criteria is missing, and probably impossible to yield. The intensity criteria are a result of experience and a deliberation process. Furthermore, Rasche claims that the intensity criteria are non-normative. This however appears to be a rash conclusion, since the incorporation of participatory methods in environmental decision processes rests on mode 2 or post-normal science as well as sustainability presumptions, where normative aspects are inevitably integrated. Moreover, since goal achievement is a cornerstone of this research, some normative value is required to determine what the desirable goals are, and more importantly to what extent the goals are achieved.

However, the 'non-normative' assumption can be adjusted such that values that are exclusively case-specific and thus impede a comparison with other water management projects, are not directly evaluated. Hence, to reach the objective of developing an evaluation method that can be applied to any case using universal criteria, some type of 'meta values' are required that serve as an interface between the underlying taxonomy of methods (CMO) and the varying applicability in the specific local context.

In the exploration to detect universal indicators, a top-down approach appears most suitable. Top-down in this case refers to the structure as introduced in chapter 3 with the

\footnotetext{
${ }^{5} \mathrm{As}$ in the previous chapters the notation optimisation is applied in the sense that as few resources as possible are used to achieve as many goals as possible. The lack of quantitative data, or positively expressed, the intention to include intangible data and indicators in the evaluation procedure impedes the application of optimisation methods known from mathematics, economy or business.
} 
macro and micro level of methodology. Thus deriving criteria starts from the 'levels' of participation. Furthermore general institutional values as introduced in section 1.3 are employed to synthesise intensity criteria.

\subsubsection{Intensity criteria derived from levels of participation}

Levels of participation, as discussed in chapter 3 indicate an intensity of the interaction between authorities and lay people. There are two approaches:

1. power sharing (Arnstein, 1969): The intensity of interaction is being measured with a degree of power sharing between authorities and the public/stakeholders;

2. activity (Mostert, 2003a; Hare and Krywkow, 2005): the degree of interaction including the number of activities and between authorities and the public/stakeholders is measured.

These two criteria can indicate a great deal about how effective the overall participatory effort can be, and the criterion power sharing may already be applied to specify the level of activity. If the authorities schedule and conduct many activities but remain on a, for example, tokenistic level of power sharing, thus alibi participation, the overall assessment may score low, since important goals (of the public and stakeholders) may remain unmatched. Furthermore, if vice versa much responsibility is ceded to stakeholders, the overall assessment may score low, if little or no activities are scheduled or poorly attended, and public perspectives remain unheard, and have thus no chance to be implemented in the planning and execution. These two criteria or two dimensions of intensity are complementary and add validity to each other. However, a complete picture of intensity more dimensions are required.

\subsubsection{Intensity criteria derived from general normative values}

In addition to the criteria power sharing, and activity (also emphasised in the WFD and Ridder et al. (2005)) four additional criteria for the evaluation of participatory processes can be extracted from the relevant literature as well as institutional norms:

3. Renn et al. (1995) discuss the issue of fairness - referred to as equality which focusses on the extent to which stakeholders have equal opportunities to impact the policy process based upon individual world views, interests and objectives. Equality is also a main subject in Enserink et al. (2003) and Lawrence and Daniels (1996);

4. The Aarhus Convention (UNECE, 1998) is devoted to the issue of transparency as a fundamental human right in Western societies;

5. Rasche (2005) refers to the early involvement of the public and stakeholders in planning efforts before any decision is taken as flexibility. This criteria is discussed in Lawrence and Daniels (1996); ÖGUT (2003); Ridder et al. (2005), and is a significant issue in the WFD (EU, 2000). 
6. Finally, the criteria reach refers to the completeness or inclusiveness of potential stakeholders in a policy process (Lawrence and Daniels, 1996; Ridder et al., 2005; Hare and Krywkow, 2005).

Yet, six dimensions or criteria of the intensity of participation have been found: power sharing, activity, (equality, transparency, flexibility and reach. Prior to definition and discussion of these generally applicable terms (see section 4.3.5), a brief discussion of these dimensions that represent evaluation criteria is provided.

\subsubsection{Can six intensity criteria represent multiple goals?}

Based upon the analysis of Rowe and Frewer (2004) the compatibility of evaluation criteria out of the chosen sample of relevant publications with the Rasche's six dimensions is listed in table 4.1.

Table 4.1: Evaluation criteria (Rowe and Frewer, 2004) in relationship to the six dimensions of intensity

\begin{tabular}{|c|c|c|}
\hline Criteria & Frequency $^{a}$ & $\begin{array}{l}\text { Dimension of } \\
\text { intensity }\end{array}$ \\
\hline structured decision making & 2 & \multirow[b]{2}{*}{ Transparency } \\
\hline $\begin{array}{l}\text { transparency; restoring trust in public agencies; subjective assessment of } \\
\text { previous evaluator; access to higher authority }\end{array}$ & 1 (each) & \\
\hline representativeness & 3 & \multirow{2}{*}{ Reach } \\
\hline inclusivity; participation rate; public awareness & 1 (each) & \\
\hline substantive impact on public debate and political decisions & 9 & \multirow[b]{3}{*}{ Power sharing } \\
\hline influence & 5 & \\
\hline $\begin{array}{l}\text { conflicting expectations; inter-jurisdictional strife, power over internal de- } \\
\text { cision making; compatibility with participants' objectives; high likelihood } \\
\text { that recommendations are followed; improve the responsiveness of the } \\
\text { planning process to citizens' values; resolving conflict among competing } \\
\text { interests; incorporating public views into decision making; responsiveness } \\
\text { of agency to policy demands of participants }\end{array}$ & 1 (each) & \\
\hline (early) involvement & 3 & \multirow{3}{*}{ Flexibility } \\
\hline obtain input early in planning & 2 & \\
\hline $\begin{array}{l}\text { decrease time to develop regulations; process flexibility; involve public } \\
\text { throughout planning process }\end{array}$ & 1 (each) & \\
\hline fairness & 3 & \multirow{3}{*}{ Equality } \\
\hline identification of common goals & 3 & \\
\hline $\begin{array}{l}\text { independence; incorporation of values/beliefs into discussion; intended } \\
\text { role of citizens; public and policy maker opinions implied to be important; } \\
\text { obtain representative input; selection of independent membership; spon- } \\
\text { sor perceptions; participant perceptions }\end{array}$ & 1 (each) & \\
\hline Interaction & 2 & \multirow[b]{2}{*}{ Activity } \\
\hline $\begin{array}{l}\text { did values change?; did the participants learn anything?; knowledge } \\
\text { achieved; consensus reached; continuity; frequency of meetings; delib- } \\
\text { eration; use input in development and evaluation of alternatives; level of } \\
\text { community partnership; use personal and interactive methods }\end{array}$ & 1 (each) & \\
\hline
\end{tabular}

${ }^{a}$ Frequency refers to the recurrence of a criterion in Rowe and Frewer (2004)

For the sake of a straight-foreword comparison and classification all evaluation criteria found in Rowe and Frewer (2004) are summarised and assigned to Rasche's six 
dimensions of intensity. This comparison and classification reveals a number of general problems that emerge when designing evaluation criteria and applying them to the related project:

1. All criteria found in Rowe and Frewer (2004) are closely linked to the specific objectives of the related case study or planning effort. This impedes or at least aggravates a comparison of the effectiveness and efficiency of the various participatory processes;

2. Most of the evaluation criteria found in Rowe and Frewer (2004) can be easily assigned to Rasche's six dimensions without a significant loss of validity;

3. The evaluation of the participatory processes is in many cases confused with the evaluation of the related planning effort. In this way a refined analysis whether or not a participatory process has a positive or negative effect on the planning effort is difficult. Examples are 'resource accessibility', 'cost-effectiveness' or 'delays in accomplishments' which cannot unambiguously be assigned to the evaluation of participatory processes;

4. Straight effectiveness parameters such as 'effectiveness of method process', effective decision making or perceived success are direct indicators for effectiveness. However, conclusions about the reasons for particular levels of efficiency and effectiveness can hardly be drawn, since there is no other indication about efficiency and effectiveness than some positive or negative indication, that has been previously collected from empirical work.

\subsubsection{Definition and application of intensity criteria}

The six dimensions of intensity including a brief definition of each criterion are depicted in figure 4.1. The definitions appear as a question, that may serve as a basis for the development of questionnaires or interviews (see table 4.3 in section 4.3.6). The hexagonal depiction of the intensity definition indicates the representation of results by means of radial charts (see section 4.3.6) on the one hand. On the other hand a completeness of intensity characteristics of a participatory process is connoted. The intention of the six intensity dimensions ${ }^{6}$ is to cover all required aspects of process intensity, and more importantly, this is an attempt to provide a complete set of evaluation criteria that are independent of case-specific issues.

Based upon evaluation criteria in the literature such as Arnstein (1969) and Mostert (2003a) the following definition of low, medium or high levels of intensity dimension has been elaborated in table 4.2 .

The three levels of intensity provide an explicit differentiation, that may be a basis for an assessment, resulting in values that enable experts who conduct an evaluation to precisely identify particular strengths and weaknesses of a participatory process.

Scholars such as Feindt (2001); Renn et al. (1995); Chanan (1999); ÖGUT (2003); Oels (2003); Beierle and Cayford (2002); Rowe and Frewer (2004) argue that "good" participation depends on high levels of one ore more evaluation criteria. Although this

\footnotetext{
${ }^{6}$ intensity dimensions and intensity criteria are used synonymously in this document
} 


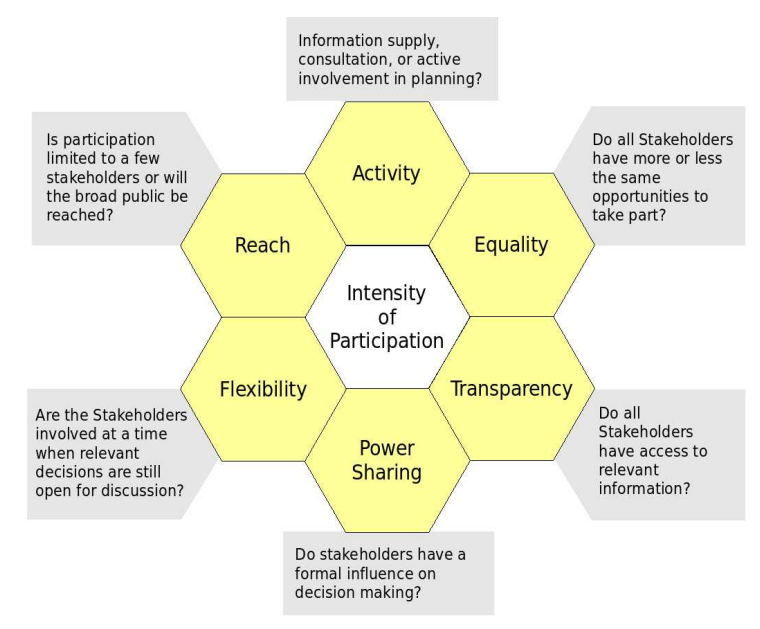

Figure 4.1: The six dimensions of the intensity of participation (Krywkow et al., 2007, p.30)

is certainly true in many cases, it is not always desirable. For instance, high level of equality or activity can be inefficient or even counter-productive such as procrastinating an entire policy process resulting in a delay of implementing measures, possibly in conjunction with unwanted additional costs. Therefore the assessment of a participatory process (stage) should only be accomplished with the complete set of criteria.

Figure 4.2 depicts the relationship among intensity criteria, objectives and classes of participatory methods. Moreover, it displays the inter-linkage between the CMO scheme, especially the objectives/classes relationship, with the relationship between intensity criteria with goals of a participatory processes as listed in table 4.1 and discussed in section 4.3.4.

Objectives of a participatory process are the link between the intensities and classes of participation, and must be preliminary defined at the beginning of a participatory process. There are several types of objectives: (1) objectives of the managers and experts; (2) objectives of the stakeholders; (3) objectives of decision makers and moreover, (4) each of the involved actors has perspectives on each others objects. As a consequence, the primary specified (expert) objectives must be subject to an assessment with other stakeholders, and eventually revised in the consultation phase of a participatory process. The selection of objectives in figure 4.2 is a random choice to demonstrate the inter-linkage of intensities, goals and classes of participatory methods.

If in an evaluation process particular intensities score low, which is an indication of low effectiveness, the corresponding goals will not be achieved. As depicted in figure 4.2 the goals can be related to both the intensity criteria as well as the classes of methods. As a consequence a low intensity score can be related to a corresponding set of goals (that are not sufficiently achieved) and linked to classes of methods. Each class holds a set of participatory methods that are potentially appropriate for achieving the corresponding goals. Yet the current participatory strategy or participatory plan can be 
Table 4.2: Definition of values of intensity dimensions (Rasche et al., 2006, p.5)

\begin{tabular}{|c|c|c|c|}
\hline $\begin{array}{l}\text { Intensity } \\
\text { dimension } \backslash \text { level }\end{array}$ & low & medium & high \\
\hline Activity & $\begin{array}{l}\text { Stakeholders are } \\
\text { only informed }\end{array}$ & $\begin{array}{l}\text { Consultation: Stakeholders } \\
\text { are asked to give their view } \\
\text { on the plans }\end{array}$ & $\begin{array}{l}\text { Active involvement takes place. } \\
\text { Stakeholders with different in- } \\
\text { terests meet to discuss plans. }\end{array}$ \\
\hline Equality & $\begin{array}{l}\text { Some affected } \\
\text { stakeholders or } \\
\text { groups are ex- } \\
\text { cluded from the } \\
\text { process }\end{array}$ & $\begin{array}{l}\text { All stakeholders are involved } \\
\text { personally or represented by } \\
\text { an appropriate person, but } \\
\text { with a different degree of in- } \\
\text { fluence on the outcome }\end{array}$ & $\begin{array}{l}\text { All stakeholders have a similar } \\
\text { influence on the outcome of the } \\
\text { process. They are either tak- } \\
\text { ing part personally or are rep- } \\
\text { resented by an appropriate per- } \\
\text { son. Generally, all participants } \\
\text { have access to the same infor- } \\
\text { mation, and their voices have } \\
\text { the same weight }\end{array}$ \\
\hline Transparency & $\begin{array}{l}\text { Relevant informa- } \\
\text { tion is withheld } \\
\text { from stakeholders } \\
\text { on purpose }\end{array}$ & $\begin{array}{l}\text { Stakeholders are well in- } \\
\text { formed, although there are } \\
\text { some minor deficits. For } \\
\text { example, some information } \\
\text { is not delivered at an early } \\
\text { stage, is not neutral or not } \\
\text { easily understandable }\end{array}$ & $\begin{array}{l}\text { Internal: Stakeholders are at an } \\
\text { early stage informed about all } \\
\text { relevant aspects of the project } \\
\text { and the process in a way that } \\
\text { they can effectively advocate } \\
\text { their own interests. External: } \\
\text { The public is comprehensively } \\
\text { informed about progress and } \\
\text { result of the participatory pro- } \\
\text { cess }\end{array}$ \\
\hline Power sharing & $\begin{array}{l}\text { Stakeholder opin- } \\
\text { ions can possibly } \\
\text { be ignored by the } \\
\text { authority }\end{array}$ & $\begin{array}{l}\text { Stakeholder opinions have } \\
\text { an official status, and have a } \\
\text { pre-defined weight in the de- } \\
\text { cision making process. The } \\
\text { authority will explain the rea- } \\
\text { sons if the decision deviates } \\
\text { from the stakeholder sugges- } \\
\text { tions }\end{array}$ & $\begin{array}{l}\text { All suggestions will similarity in- } \\
\text { corporated in the decision }\end{array}$ \\
\hline Flexibility & $\begin{array}{l}\text { Stakeholders are } \\
\text { involved only after } \\
\text { all relevant deci- } \\
\text { sions have been } \\
\text { made }\end{array}$ & $\begin{array}{l}\text { Stakeholders are involved } \\
\text { early enough to influence } \\
\text { some significant questions of } \\
\text { the project design }\end{array}$ & $\begin{array}{l}\text { Stakeholders are involved at an } \\
\text { early stage and can influence } \\
\text { major questions like the site lo- } \\
\text { cation, whether the measure } \\
\text { planned is necessary at all, etc. }\end{array}$ \\
\hline Reach & $\begin{array}{l}\text { Only a small } \\
\text { group of stake- } \\
\text { holders is in- } \\
\text { volved }\end{array}$ & $\begin{array}{l}\text { A number of stakeholders } \\
\text { cannot take part personally }\end{array}$ & $\begin{array}{l}\text { All known relevant stakeholders } \\
\text { - in public participation including } \\
\text { members of the broad public - } \\
\text { have got an opportunity to take } \\
\text { part personally }\end{array}$ \\
\hline
\end{tabular}

reviewed either for substituting methods that have been applied but are not effective or for improving the application of methods that have had little effect up to this point.

For the review of methods the implementation criteria for participatory methods as introduced in section 3.6 must be applied. In this way local constraints such as budget limitations, institutional regulations, available expertise, limited time or the number of stakeholders can be factored in. Yet the CMO method as introduced in the taxonomy of chapter 3 becomes operationalised. 


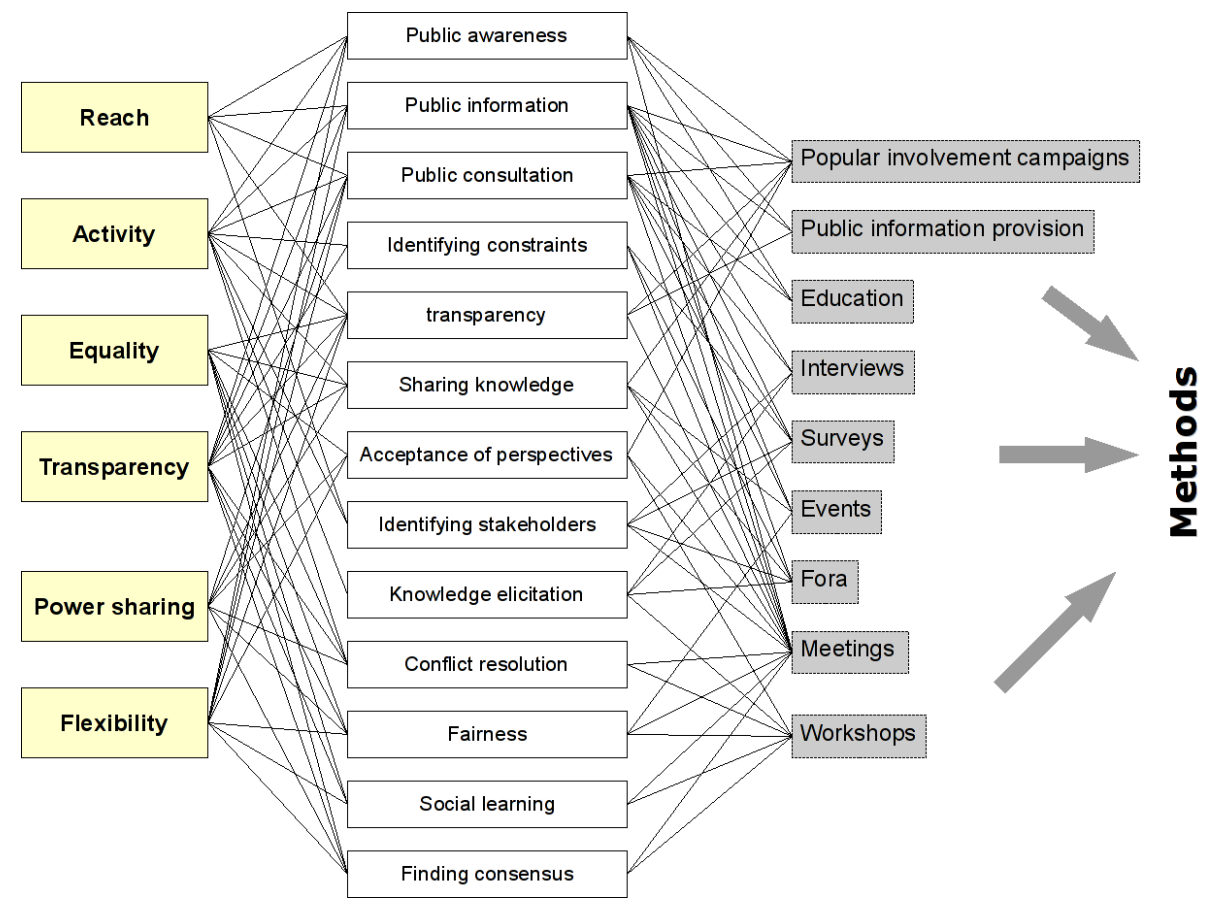

Figure 4.2: The relationship among Intensities, objectives and classes of participation

In figure 4.2 the abundance of connections between intensities and objectives and between objectives and classes can be explained by the random choice of objectives. However, the figure demonstrates that not all classes of methods nor all intensity criteria can serve all goals of a participatory process.

At this point the role of the evaluation of a participatory process as a tool to improve efficiency becomes explicit:

1. The evaluation procedure reveals if applied methods are effective. In other words, are goals (emerging from the objectives) likely to be achieved?

2. With the available resources (constraints), the process goals should be achieved to the greatest possible extent.

The evaluation enables managers to instantly modify a participatory process by altering applied methods or even apply new methods, if required and affordable. In this way the evaluation can reveal weaknesses or errors of the ongoing process. The conjunction between goal achievement and appropriate methodology (classes) is discussed in chapter 3.4.1.

Rasche et al. (2006) provides the example of 'developing win-win plans' as an objective, that depends primarily on the level of activity, since such plans can only be developed with the involved stakeholders. Furthermore, a higher level of flexibility and 


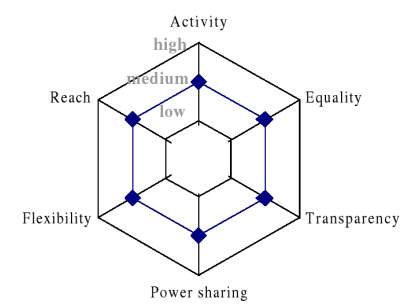

Figure 4.3: Levels of intensities in a radial chart

transparency is required. If, for instance, the objectives (e.g. developing win-win plans) require a high level of activity as determined in the early phase of the project, and an evaluation procedures results in low levels of activity, then counter measures must be taken. Reasons for this type of failure might be attributed to limited financial and human resources, stakeholder fatigue (constraints) or simply in management failure such as the application of inappropriate participatory methods.

This example appears simple, and identifying structural or organisational errors seems to be obvious, and could be recognised without an evaluation effort such as a survey. However, in most cases participatory processes have a multitude of (more or less cohesive) objectives as well as constraints. Therefore, the application of intensities as evaluation criteria help to untangle this complexity, and support the identification of reasons for a particular quality of performance. Other examples that illustrate the relationship between objectives and intensity are: public awareness which requires a high reach of the process; building up trust which requires a high level of transparency; and social learning which requires high activity and high transparency.

\subsubsection{Obtaining, classifying and presenting process intensity values}

The values for the levels of intensity can be collected with the help of social science methods such as interviews or questionnaires. A standard questionnaire in reference to the intensity dimensions is listed in table 4.3. Scale levels (1-3) for every question can be chosen by the interviewee. Statistical analysis may be interposed if required ${ }^{7}$.

The intensity levels are an ordinal classification (low, medium, high) as listed in table 4.2.

The classification of the six dimensions can be visualised in radial charts (figure 4.3). Yet, the combination of the levels of intensities are displayed in diagrams that represent characteristic types of participatory processes ${ }^{8}$. These types are the operationalised counterparts of types of participatory processes that have been described in articles such as Arnstein (1969); Mostert (2003b); Ridder et al. (2005) and others.

\footnotetext{
${ }^{7}$ In the TRUST case study the two answers per question were avaraged, and rounded off according to a qualitative analysis of the Interim Evaluation Report.

${ }^{8}$ Rasche et al. (2006) denotes it "classes of participation", however, in order to avoid confusion with classes of participatory methods as developed in Hare and Krywkow (2005) and discussed in chapter (3), these combinations of intensity levels are here labelled as types
} 
Table 4.3: Interview questions in relationship to the intensity criteria (Rasche et al., 2006; Krywkow et al., 2007)

\begin{tabular}{|l|l|}
\hline Intensity Dimension & Question \\
\hline Activity & $\begin{array}{l}\text { 1) Do/Did stakeholders meet each other and discuss about each others' point of } \\
\text { view on the design of the plans? } \\
\text { 2) Do/Did stakeholders provide their opinion to the plans? }\end{array}$ \\
\hline Equality & $\begin{array}{l}\text { 3) Were all relevant stakeholders identified at the beginning of the participatory } \\
\text { process? } \\
\text { 4) Do/Did all stakeholders have equal access to information and equal opportuni- } \\
\text { ties to influence the plans? }\end{array}$ \\
\hline Transparency & $\begin{array}{l}\text { 5) Are participants in the participatory process well-informed about the issue? } \\
\text { Was enough information provided, could all access the information available and } \\
\text { was it understandable for all? } \\
\text { 6) Do/Did participants know from the beginning of their involvement what will be } \\
\text { done with their input? }\end{array}$ \\
\hline Fower sharing & $\begin{array}{l}\text { 7) Were the stakeholders part of the actual decision-making process? } \\
\text { 8) Were the stakeholders' interests taken into account in the decision-making and } \\
\text { were any deviations from their recommendations explained to them? }\end{array}$ \\
\hline Reach & $\begin{array}{l}\text { 9) Are/Were stakeholders involved at a time when relevant decisions about the } \\
\text { project design are/were still open for discussion? } \\
\text { 10) Was it under the existing constraints (e.g. technical requirements, budget } \\
\text { limitations) possible to implement stakeholders' suggestions? }\end{array}$ \\
\hline $\begin{array}{l}\text { 11) Has the broad public in the area been invited to take part in a participatory } \\
\text { activity (e.g. public meeting, survey, etc.) and was it well responded to? } \\
\text { 12) Do/Did mass media report about the participatory process or is a broad range } \\
\text { of stakeholders provided with information via flyers, newsletters or other means? }\end{array}$ \\
\hline
\end{tabular}

Figure 4.4 displays six typical combinations of process intensities. The dashed lines indicate possible alterations of particular intensity levels that would still fall in the same type.In the following the six types of participation are discussed, and adequate examples from the literature are indicated.

\section{Horizontal participation}

This type characterises the consultation of many stakeholders or the involvement of the broad public, for instance, when it comes to issues related to public goods as main issue. Methods such as public meetings (with many participants) or surveys are usually applied. In Arnstein (1969) horizontal participation would fall in the category tokism.

\section{Vertical participation}

Vertical participation stands for the involvement of a chosen group of stakeholders who interact in an intense way. Transparency, power sharing and flexibility is only granted for the chosen group. The outsiders are at best informed about the results.

\section{Focussed consultation}

This type is highly efficient. Only a small number of chosen stakeholders is involved. Usually bilateral meetings are typical activities of this process. As in the previous type the reach is minimised and transparency, power sharing and flexibility only applies to the chosen stakeholders. 

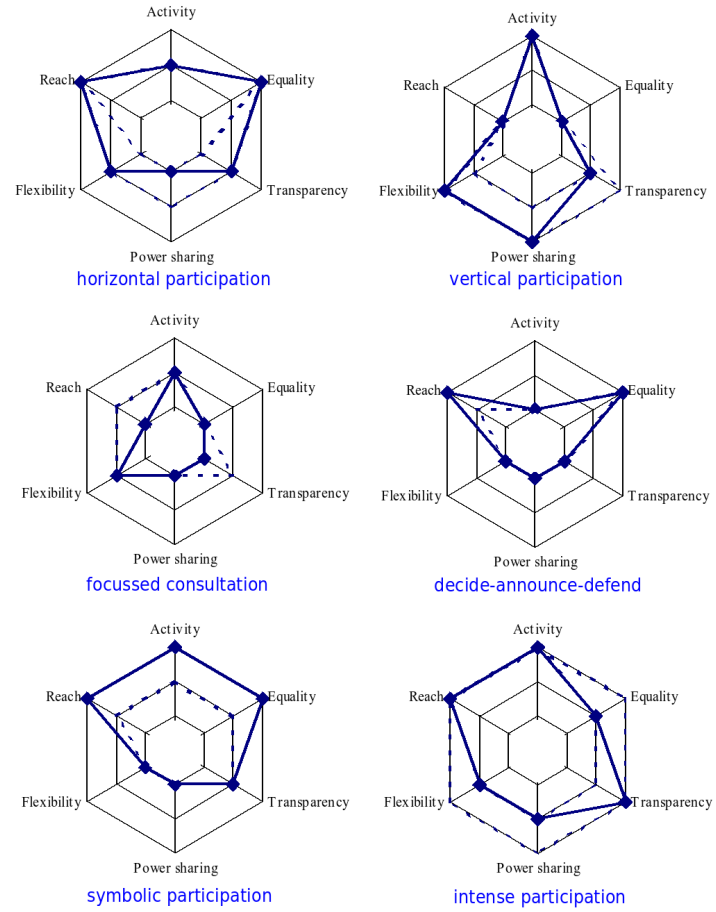

Figure 4.4: Types of participatory processes (Rasche et al., 2006, p.6)

\section{Decide-announce-defend}

A decision has already been taken by the responsible authorities. The participatory process has the only purpose to collect support for a decision that wont be modified (Enserink et al., 2003). In Arnstein's ladder this would be considered as non-participation.

\section{Symbolic participation}

This type connotes an intense participatory process providing a lot of information (often information overload), however, in fact the activities have no influence on the decision process (Newig, 2003).

\section{Intense participation}

Intense participation fulfils all requirements of an effective participatory process: All relevant stakeholders are reached. Each of them has the chance to play a part in the policy process, and advocate for own interests. Available information is unrestrictedly available. The process is transparent with equal impact on the decision process.

\subsubsection{Reporting}

The intensity criteria as represented in radial charts provide a straight-forward overview of the evaluation and make it comparable between various projects or case studies. How- 
ever, this is not sufficient. Every evaluation requires an attached record of the procedure. This way comments of interrogated individuals can be processed, and the evaluation criteria are associated with local issues, which supports an overall assessment, and drawing the appropriate conclusions for an eventually required course correction of the process.

\subsection{Summary and Conclusions}

With respect to the aforementioned problems a new evaluation methodology is discussed here which is based upon 'standardised' intensity criteria instead of case-specific values. The methodological background for this approach is based upon the new typology of participatory methods as introduced in chapter 3 . The relationship between local constraints, the applied participatory methods and overall objectives (CMO) plays a central role as in the typology presented in chapter 3 . In this way a consistency between the typology and the evaluation approach develops, and the evaluation approach discussed in this chapter may be seen as an integral component of the framework for participatory management introduced in this thesis.

This chapter has evolved from the intensity criteria as developed by Rasche (2005); Rasche et al. (2006). The following have been adopted from her work: (1) the definition of the intensity criteria; (2) the definition of types of participation; (3) the definitions of values of intensity dimensions; (4) the standard questionnaire for obtaining intensity values, and (5) the graphical representation of intensities of participation in radial charts.

In addition, Rasche's work is now enhanced with: (1) an in depth discussion about the rationale of evaluating participatory processes; (2) relevant literature on governance and to basic aspects of organisational theory; (3) a further discussion on why these six dimensions have been defined (and not others) as well as a reference to the relevant literature; (4) a comparison of the six criteria with evaluation criteria that have been collected and analysed by Rowe and Frewer (2004); and (5) a discussion on the role of evaluation criteria in reference to constraints and objectives; (7) a description of the relationship among intensities, objectives and classes of methods, and thus the relationship between CMO and COPIR.

The COPIR approach is a method that supports monitoring and evaluation activities of participatory processes in local investment projects. The application of intensities may be seen as a predictive tool: the highest intensity (of a particular parameter) indicates an optimal use of a set of methods for goals that can be related to this particular parameter. Previous approaches have been studied, and the pitfalls of the predominantly goal-oriented approaches analysed. Outstanding features of COPIR are:

- the controlling character of the approach: monitoring is initiated at the outset of the participatory process, and evaluation is a repetitive process identifying process failures and encouraging modifications of the process during ongoing project activities, if required. The aim is to anticipate and avoid undesirable developments, not only from the point of view of policy makers and experts, but also from the point of view of stakeholders; 
- analysing intensities that represent a set of goals of a participatory process provides managers with a generally applicable, well-defined and tangible set of evaluation criteria;

- the well-defined criteria enable scientists and managers to apply approved social science methods. Moreover, a standardised set of interview questions may be applied;

- the intensity criteria facilitate comparability ammong various investment projects, even if the project objectives as well as constraints differ to a significant extent, and in this way support transboundary learning.

Whereas Rowe and Frewer (2004) aim to identify the most appropriate methods of a participatory process in their evaluation approach, the COPIR approach goes a step further: goals of the participatory process, and planning goals may be achieved. Effectiveness in the sense of 'what works best when' is merely a stage in the entire process. Moreover, the initial combination of methods (participatory plan) to be applied to a local investment project may be adjusted based upon the evaluation. Consistency and structure of the process is provided through monitoring (planning sheets) as well as the goal-oriented character of this approach.

Whereas many previous evaluation efforts aimed to provide an ex-post evaluation that at most yields a type of lessons-learned assessment, COPIR is an approach similar to controlling systems in organisations with reproducible methods as well as comparable values and results. Moreover, iterative evaluation enables managers to apply control loops with an opportunity to make adjustments throughout an process.

The application of the COPIR approach in the TRUST project revealed process failures in the various case studies. Special features of the TRUST project were the transboundary exchange of experience between the water managers and capacity building guided by the consultancy. Furthermore, the development of common goals for all five participatory processes enhanced comparability, and facilitated focussed work on problems within the various case studies, based upon discussions within the international group of water managers.

Of course, the COPIR approach has a few disadvantages, most notably the increased effort involved in collecting and analysing data and information for an evaluation procedure. However, throughout the course of the TRUST project, evaluation and monitoring was budgeted at the outset of the project and bundled with regular meeting and workshop activities. This helps to reduce additional costs such as extra travel. In many sectors evaluation questionnaires became a regular part of the interaction between, for example, service providers and customers.

The COPIR approach has the potential to provide a theoretical basis for a standardised evaluation procedure in participatory processes. However, it needs acceptance by the responsible authorities, which assumes that the positive effect of participatory process in the context of local investment projects is taken seriously. The following chapter demonstrates how the COPIR framework was implemented 'in the field'. 
CHAPTER 5

The case studies

\subsection{Introduction}

The case study used for this thesis consists of five different sub case studies that have been pooled within the EU INTERREG IIIb project 'TRUST', , which was carried out between September 2004 and November 2007. It was a collaboration of five partners who combine spatial planning with water management to create water storage facilities: British Waterways (BW), Glasgow City Council (GCC), Provincie NoordHolland (PNH), Hoogheemraadschap van Schieland en de Krimpenerwaard (HHSK) and Provinciale Ontwikkelingsmaatschappij West-Vlaanderen (POM) (see figure 5.1).

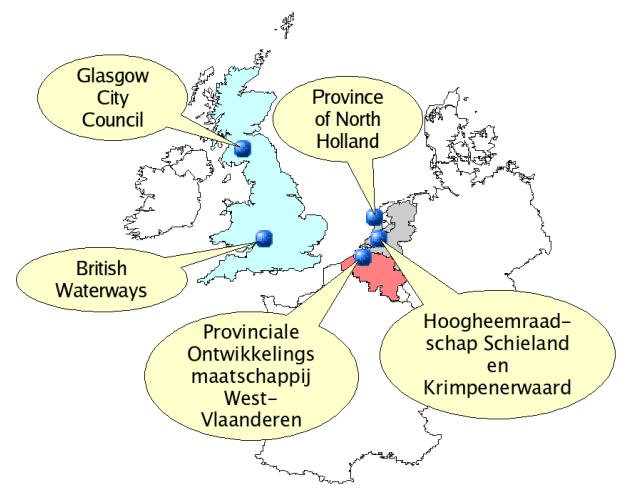

Figure 5.1: Location of the five case studies

\footnotetext{
${ }^{1}$ TRUST $=$ Transformation of Rural and Urban Spatial sTructures
} 
Each partner's project aimed to employ a multi-functional use of water-space as well as innovative and improved water management including public and stakeholder participation. The objective was to deliver strategic, practical and innovative solutions that add value to existing initiatives in water management and spatial planning across Europe. Within the TRUST effort the theme group III (TGIII) focused on issues of public and stakeholder participation. Moreover, TRUST/TGIII was an experiment in how to implement the WFD (EU, 2000) 'in the field'. The five water management partners were supported by a group of scientists and consultants for methodological support in the management of public and stakeholder participation.

Despite new insights in Adaptive Water Management (AWM) (Pahl-Wostl, 2008), Integrated Water Resources Management (IWRM) and spatial planning (Loucks and van Beek, 2005; Rahaman and Varis, 2005), innovative knowledge disseminates slowly outside academia, and the everyday problems of both stakeholders and water managers require operational solutions. This is particularly crucial since the European Water Framework Directive (WFD) (EU, 2000) requires that public and stakeholder participation be implemented in the legislation of every single EU country.

Participatory managers will face two additional challenges: (1) a general tendency toward a more individualised post-industrial society resulting in higher demands for quality of life, and (2) a general awareness of and regard for common pool resources among citizens. The latter may result in a demand for more voice and responsibility. However, once committed to a participatory process, water managers cannot rely on mere top-down decision processes, but must incorporate a variety of perspectives and interests with the consequence of greater complexity and uncertainty in the policy process. A variety of methods for managing multi-actor policy processes is available, but is not always easy to access and apply for practitioners. The gap between science and practice remains tentative. Yet, the five case studies are an opportunity to try out new bridges, and test the applicability of methodological innovations that have been discussed in chapter 3 and 4 . The variability of the five case studies is expected to be an extraordinary challenge. In particular, the implementation of midterm evaluation was new to the research team, and the prospects of success unpredictable. In addition, pooled case studies provide a common ground for capacity building in a transboundary learning environment.

The following sections contain an overview of the methodology applied, a brief description of each of the case studies including an overview of stakeholders and their activities that is structured according to the methodological framework described in chapter 3. Each project presented includes a brief 'lessons learned' section, and the results of the evaluation process.

All names of and relationships between water managers and stakeholders as well as the results in the five projects have been previously published in the final report of the TRUST TGIII group (Krywkow et al., 2007) with explicit approval of all partners. Some of the documents such as the interim evaluation reports (IER) as well as the participatory plans are not published, and the evaluation of the individual performance of the partners' organisations in their goal achievement have to be kept confidential. 


\subsection{Applied methods and capacity building activities}

Apart from capacity building as a significant part of the TRUST duties, the testing of the newly developed methodology was the main task. The underlying idea was to introduce the methodology, test it in the field and review it together with water managers. The case-study constellation was a unique opportunity to conduct a comparative study.

The programme of supporting water managers throughout the TRUST effort consisted of the following parts:

1. biannual meetings of the case study partners under scientific guidance. These meetings provided the participants with the opportunity to report back from current activities, exchange experiences and engage in capacity building;

2. Inception report (IR). The report provided the water managers with guidance on how to prepare, plan and implement a participatory process in water resource management. Moreover, a structured overview of available participatory methods (catalogue) was developed (Hare and Krywkow, 2005). This report was the basis for chapter 3;

3. Participatory plans: the scientists together with the water managers developed a plan that indicated how chosen participatory methods should be implemented in the planning process individually suited to the specific local project;

4. Training: throughout a number of meetings the research team provided training in participatory methods and moderator skills;

5. Monitoring and evaluation: a first version of the COPIR approach (chapter 4) to monitoring and evaluating the participatory processes including the application of interviews, planning sheets, newly developed intensity charts and stakeholder feedback was tested with each of the case studies.

A detailed list of activities is provided in appendix A of this document as well as in Krywkow et al. (2007, p.13). The following sub-sections discuss the applied methods in more detail.

\subsubsection{Participatory plans}

Participatory plans as designed throughout the TRUST project constituted the implementation of the guidelines developed in the IR and discussed in chapter 3, put in the relevant local context including the specific constraints as well as the goals of the process. Furthermore, these plans determined a sequence of participatory activities including the anticipation of uncertainty that might result from stakeholder interaction. In the three case studies for which a participatory plan was designed the scientists visited the site, interviewed the responsible water managers and studied available documents. Moreover, in the case of GCC the consultants participated in a workshop with water managers and stakeholders. Once the constraints as well as the objectives of each of the local projects had been studied and understood, a plan was designed according to the following structure: 
1. ex-post stakeholder analysis, identify all relevant stakeholders from a neutral perspective $^{2}$, especially those who have not yet been contacted;

2. detecting methodological gaps, and proposing a consistent sequence of participatory methods depending on the phase of the ongoing project (information provision, consultation) as well as the targeted objectives;

3. drafting a plan of activities based upon the proposed methods, the available resources and the targeted objectives.

At times of the TRUST effort, the design of the plans was not a systematic approach as it will be introduced in chapter 6 , but it was a best practise exercise based upon the experience of the research team. Their knowledge about the implications of methods on a participatory process in combination with the water managers' knowledge about goals and constraints (especially limited resources) of the case studies resulted in a planning document that proposed a sequence of participatory activities.

The participatory plan for BW focussed on on-site activities such as involvement of school students and on-site information campaigns, guided walks and similar. The purpose of these activities was to increase the acceptance of the project, stop vandalism, ensure long-term use and maintenance of the site and avoid conflicts between the users of the canal site and adjacent residents.

The participatory plan for POM included a number of issues such as improving the stakeholder analysis, starting a dialogue with the person who objected to the plan ${ }^{3}$, intensifying the collaboration with NGOs, introducing measures for capacity building within the organisation POM, and intensifying communication with local farmers.

The main advice in the participatory plan for GCC was to identify commonalities and differences in goals of the involved individuals and organisations that are responsible for planning and implementing the project. The significance of the participatory process did not seem to be completely realised by planners and engineers of the Ruchill Park project. Furthermore, a well organised meeting of all stakeholders and authorities was recommended in order to achieve a structured overview of the most relevant problems, and to have a clear strategy for the development and the maintenance of the site.

PNH received a review of their own communication plan that included a checklist of a generic communication plan. Main issues identified in the review were the consistency of the communication plan with other documents, a clear structure for the plan and the involvement of parties outside the planning consortium. With the requirement to review their own communication plan, PNH raised the issue of communication as part and parcel of an overall participatory process. Internal and external communication that is not clearly structured and efficient can decrease the quality of the participatory process.

HHSK preferred to not have a participatory plan, because the representatives indicated that the participatory process of their project was already too advanced to have significant impact with a participatory plan. Instead a 'generic participatory plan' was required including lessons learned from the TRUST process and previous experience

\footnotetext{
${ }^{2}$ This means the perspective of the scientists

${ }^{3}$ See section 5.3.3
} 
with other projects of HHSK. The generic participatory plan (Krywkow, 2007) builds on insights that are documented in the Inception Report, and points out requirements that are more specific for water managing organisations such as the water board (Waterschap) HHSK. This document is the basis for chapter 6 . The plans as developed for the three case studies are not based on a systmatic approach, but a result of the experience and knowledge of the involved scientists.

\subsubsection{Evaluation and monitoring: the implementation of the COPIR approach}

The methodology of the evaluation has been documented and discussed as COPIR in chapter 4. Basically, the evaluation procedure consists of the elements: (1) Intensity of participation (initial and final); (2) Planning sheets (PS); (3) Interim evaluation reporting (IER). During the field work the following activities for monitoring and evaluation were undertaken:

- Conducting interviews with all water managers to detect the intensity of the participatory processes at the beginning of their projects. See table 4.3 for the design of the interviews ;

- Calculating and presenting results of the intensity interviews, first published in Rasche (2005) and Rasche et al. (2006);

- Designing planning sheets;

- Conducting interviews and field visits for the interim evaluation reports (IER). See table 4.3 for the design of the interviews;

- Reviewing the IER with partners, and subsequent delivery;

- Conducting interviews for the final report, and detecting mutations in the intensity of the participatory processes. The complete interview template can be found in table 4.3;

- Compiling the final evaluation report as part of the final TGIII report (Krywkow, 2007, p. $54-69)$.

\section{Monitoring participatory activities: planning sheets}

For the management effort in all case studies a planning sheet was developed to monitor participatory activities, and co-ordinate those with other activities throughout the entire planning process. This planning sheet is adapted from the Synthetic Process Chart which was developed in the European project HarmoniCOP as a "... graphical representation of the collaborative decision-making process, including the use of various Information and Communication Tools (IC-tools) and the evolution of Social Learning..."(Craps and Maurel, 2003, p.49). In the context of the five case studies the project planner is a simple spreadsheet that indicates participatory activities synchronously with other project activities on a monthly resolution (figure 5.2). Furthermore, the spreadsheet includes evaluation points ${ }^{4}$, involved stakeholders and their activities, outputs and

${ }^{4}$ Dates when an evaluation was planned 


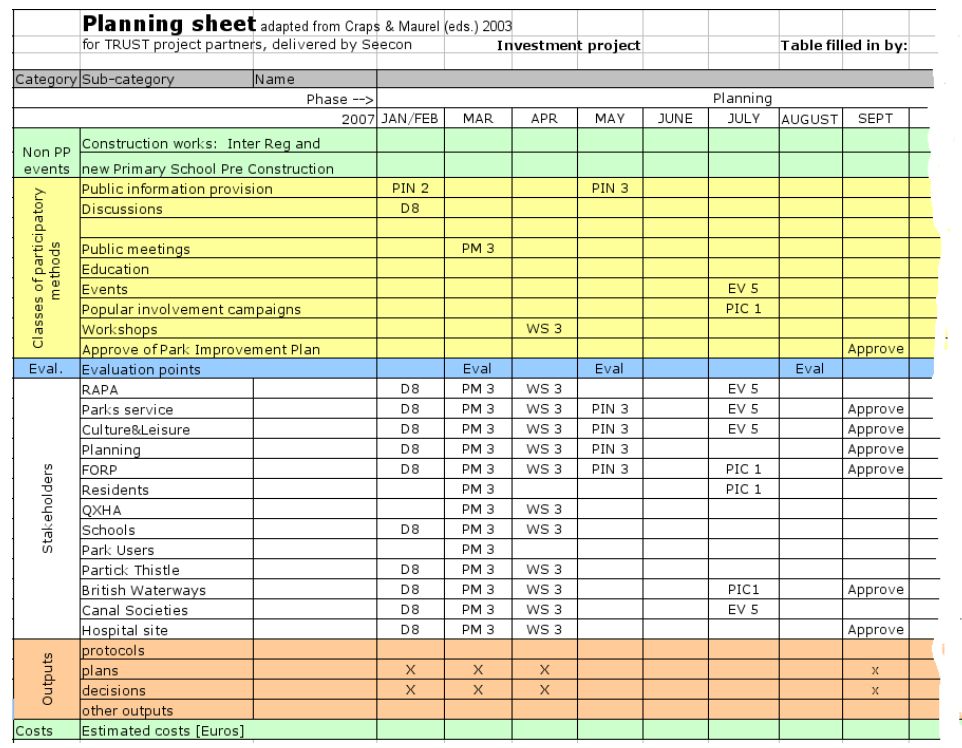

Figure 5.2: Example of a planning sheet: GCC 2007

(estimated) costs. Whereas (Craps and Maurel, 2003) try to visualise and document a policy process with emphasis on social learning activities, the planning sheet here may be seen as a support to handle the complexity of an entire participatory planning process including its evaluation. This planning sheet is thus a tool to plan, communicate, review and, of course, to monitor a participatory process in a (local) project planning effort. The planning sheet may be considered as evidence of the importance of the contiguity between project activities and participatory processes on the one hand, and the significance of an early planning of participatory activities on the other.

Implementation and results of the monitoring and evaluation methods in TRUST TG III

The evaluation of the participatory processes in TG III was carried out in three stages. Timing, methods and outputs of each stage are summarised in table 5.1. The research team visited partners to carry out evaluation interviews, and based upon the interviews, compiled intensity charts and evaluation reports. Based upon the findings and definitions of chapter 3 and 4, especially the CMO framework and the strict separation of goals and constraints, the evaluation of the participatory efforts in each of the case studies was based upon three main criteria:

1. Context/constraints of a particular case study;

2. Process intensity, and its mutations;

3. Goal achievement.

The outcomes of the evaluation are individually presented in section 5.3. 
Table 5.1: Evaluation points within the TGIII process

\begin{tabular}{|c|l|l|l|}
\hline Year & $\begin{array}{l}\text { Name of eval. } \\
\text { point }\end{array}$ & Methods & Outputs \\
\hline 2005 & $\begin{array}{l}\text { Inception eval- } \\
\text { uation }\end{array}$ & $\begin{array}{l}\text { Brief interview with partners on } \\
\text { planned process intensity, and ques- } \\
\text { tionnaire on process and constrains }\end{array}$ & $\begin{array}{l}\text { Intensity charts and recommenda- } \\
\text { tions for participatory plans }\end{array}$ \\
\hline 2006 & $\begin{array}{l}\text { Interim evalu- } \\
\text { ation }\end{array}$ & $\begin{array}{l}\text { Evaluation interview with each partner } \\
\text { and observation of participatory activi- } \\
\text { ties of selected partners. Documenta- } \\
\text { tion planning sheet }\end{array}$ & $\begin{array}{l}\text { Interim evaluation report with partner } \\
\text { feedback on current goal achievement } \\
\text { and lessons learned. Seecon gives } \\
\text { recommendations for the next phases } \\
\text { of the process }\end{array}$ \\
\hline 2007 & $\begin{array}{l}\text { Final evalua- } \\
\text { tion }\end{array}$ & $\begin{array}{l}\text { A questionnaire was sent to each part- } \\
\text { ner including stakeholder feedback. } \\
\text { Documentation: planning sheet up- } \\
\text { date }\end{array}$ & $\begin{array}{l}\text { Process (intensity) and output (goal } \\
\text { achievement); lessons learned for fu- } \\
\text { ture processes }\end{array}$ \\
\hline
\end{tabular}

\section{Interim evaluation reports (IER)}

The IER are assessment reports of the work of each partner provided by the research team. The purpose is to evaluate the ongoing participatory processes, and make suggestions for modifications for an improvement of the process. Consequently, the IER is the implementation of mid-term evaluation as required in chapter 4: The structure of the report consisted of:

- The description of the participatory processes including all applied methods;

- Current and future process objectives;

- Evaluation of the preliminary goal achievement;

- The radial charts typifying the participatory process ${ }^{5}$;

- Identification of sources of problems;

- Lessons learned in relation to each of the goals;

- Recommendations for further work.

Each of the water managers received an individual assessment from the point of view of the scientists. Additionally, capacity-building meetings were used to exchange opinions and perspectives on the particular issues of each of the projects, with focus on goal reaching and suggested modifications of the ongoing process. In this way every partner had the opportunity to discuss their own activities in an international forum.

\footnotetext{
${ }^{5}$ The data for the intensity charts were retrieved directly from the interviews, where the scale was predetermined. This was because only the water managers were interviewed. As indicated in chapter 4 statistical methods as well as divergent scales may be applied if the sample data set is larger.
} 


\section{Final report}

Upon completion of the case study work a final report (FR) was compiled in collaboration of all partners (Krywkow et al., 2007). Apart from case study and process description the results of the evaluation process have been documented. Furthermore, not only the involved scientists reported, but also every partner gave an assessment about their work including lessons learned from their own work as well as about their transboundary learning experience.

\subsubsection{Goal achievement}

As discussed in section 3.4.1 goal achievement may be seen as a driving force and the determining factor for the entire participatory process. In the same section the interrelationship between classes of participatory methods with the objectives of a participatory process are discussed. Table 3.1 displays goals that have been drawn from the literature, but will not be used anymore in this document. Instead, goals from the TRUST case studies will be applied. For an efficient evaluation of the five participatory processes including a better comparability all TRUST partners have elaborated a list of common goals to be achieved throughout the course of the TRUST project: 1) knowledge for decision-making; 2) development of win-win plans; 3) co-financing; 4) long-term use and maintenance; 5) public awareness; 6) satisfaction of stakeholders; 7) increased involvement; 8) empowerment; 9) social learning. All of the goals were relevant to every partner, except empowerment and social learning in the case of POM (table 5.2). The results of the goal achievement are a self-assessment by the water

Table 5.2: Goal achievement of each partner

\begin{tabular}{|l||l|l|l|l|l|}
\hline objective & BW & GCC & POM & HHSK & PNH \\
\hline knowledge for decision-making & yes & yes & no & yes & yes \\
development of win-win plans & yes & yes & yes & yes & yes \\
co-financing & yes & yes & no & no & yes \\
long term use and maintenance & yes & yes & yes & no & yes \\
public awareness & yes & yes & yes & yes & yes \\
satisfaction of stakeholders & n/a & yes & yes & yes & no \\
increased involvement & yes & yes & yes & yes & no \\
empowerment & yes & yes & n/t ${ }^{b}$ & yes & yes \\
social learning & n/a & yes & n/t & no & no \\
\hline
\end{tabular}

${ }^{a}$ not evaluated or no information available

${ }^{b}$ not targeted

managers, collected in the final interviews (see table 5.1). All partners provided an assessment, whether or not the targeted goals were reached. The results are displayed in table 5.2. At the time of the inception evaluation only one partner intended to enforce an intense participatory process. A number of goals were not reached, which is commented upon the relevant sections of the partner descriptions. 


\subsection{Case study description and results}

The TRUST project with the five partners and the group of scientists was organised in three theme groups (TG): TG(I) - engineering, TG(II) - environmental impact assessment, and TG(III) - participatory process. Whereas the collaboration of TG(I) and (II) was based upon well-known issues and expertise, TG(III) water managers were confronted with - what was for them - new approaches of interacting with the public and stakeholders.

\subsubsection{British Waterways (BW): Stroud canal restoration}

The project is based in the South-West of England, close to the centre of the town of Stroud, at the edge of the Cotswolds region. British Waterways is the lead partner on behalf of the Cotswolds Canals Partnership, and is responsible for delivering the restoration through design and consultation with local stakeholders and the public. The project involved:

1. Restoration and mitigation works to a former ornamental pond carrying a rivulet which runs into the canal. The rivulet Ruscombe Brook is prone to pollution from up-stream flooding, which consequently flows into the canal;

2. Excavation of 650 metres of canal incorporating new emergent habitats, reconstruction of a 1.6 metre-wide towpath with vegetated verges, tree management and the creation of reptile hibernacula ${ }^{6}$;

3. Interpretation of the canal.

The development of the designs for the restoration of the bridge at the Oil Mills location, has been guided by conservation and wide public consultation. Environment, heritage, landscape and access appraisals have been carried out. Options for the design were developed by a heritage consultation group, consisting of Gloucestershire County Council, Stroud District Council, Cotswold Canal Trust, Company of Proprietors of the Stroudwater Navigation, English Heritage, Gloucestershire Society for Industrial Archaeology, and British Waterways. The local community and various interest groups, such as Stroud Access Forum, were also consulted, and their comments and recommendations were built into or taken into consideration within the application. Environmental considerations were identified through consultation with conservation groups, such as Gloucestershire Wildlife Trust, the Environment Agency and English Nature. Existing habitats and species will be protected and enhanced. The work around The Lawns, a small park adjacent to the canal, has aimed to manage any polluted water flowing into the canal.

The rivulet flows through a pond on the site, which is overgrown and silted up. The work involves managing the trees around the edge of the pond to increase the amount of light getting to the water. The pond will also be re-profiled to increase the depth of the water, and hazel fagots will be installed as bank protection. This will all encourage increased reed growth around the pond which will act as a filter, managing pollutants that come down the stream.

\footnotetext{
${ }^{6}$ location chosen by an animal for hibernation
} 


\section{Relevant stakeholders}

Table 5.3 presents the relevant BW stakeholders including their scale of activity and their goals. The BW case holds a variety of locally and regionally acting stakeholder organisations each of them with distinctive interests in the Stroud restoration activities.

Table 5.3: Relevant stakeholders of the BW project

\begin{tabular}{|c|c|c|}
\hline Stakeholder & Scale of activities & Description, individual goals \\
\hline $\begin{array}{l}\text { Cotsworlds } \\
\text { partnership }\end{array}$ & $\begin{array}{l}\text { regional, the entire } \\
\text { Cotswold region }\end{array}$ & $\begin{array}{l}\text { an overarching association of several organisations (includ- } \\
\text { ing BW) who care about heterogeneous issues such as } \\
\text { nature protection, tourism, navigation, but also land devel- } \\
\text { opment in conjunction with the maintenance and develop- } \\
\text { ment of Cotswold canals }\end{array}$ \\
\hline $\begin{array}{l}\text { The Lawns core } \\
\text { group }\end{array}$ & local & $\begin{array}{l}\text { consisting of four regional organisations founded espe- } \\
\text { cially for this project }\end{array}$ \\
\hline $\begin{array}{l}\text { Cainscross } \\
\text { Council }\end{array}$ & local & $\begin{array}{l}\text { (governmental) organisation with interest to improve the } \\
\text { amenity value to local residents }\end{array}$ \\
\hline $\begin{array}{l}\text { Company of Propri- } \\
\text { etors of the Stroud- } \\
\text { water Navigation }\end{array}$ & regional & freeholders of the canal \\
\hline $\begin{array}{l}\text { Environment } \\
\text { Agency }\end{array}$ & England and Wales & regulatory body for pollution and flooding \\
\hline $\begin{array}{l}\text { Western Canal Con- } \\
\text { sultative Group }\end{array}$ & regional & group of parish councils in the region \\
\hline $\begin{array}{l}\text { Cotswold Canals } \\
\text { Trust }\end{array}$ & regional & $\begin{array}{l}\text { organised group of volunteers who have promoted the } \\
\text { restoration of the canals for over } 30 \text { years }\end{array}$ \\
\hline $\begin{array}{l}\text { Rushcombe Brook } \\
\text { Action Group }\end{array}$ & local & $\begin{array}{l}\text { campaigning group, focused on eliminating the pollution is- } \\
\text { sues in the Ruscombe Brook }\end{array}$ \\
\hline $\begin{array}{l}\text { School (next to } \\
\text { canal) }\end{array}$ & local & $\begin{array}{l}\text { interested in educating their students about environmental } \\
\text { issues nearby }\end{array}$ \\
\hline $\begin{array}{l}\text { Residents (next to } \\
\text { canal) }\end{array}$ & local & $\begin{array}{l}\text { interested in maintaining the amenity value of their houses } \\
\text { next to the canal }\end{array}$ \\
\hline $\begin{array}{l}\text { Push bikers (adja- } \\
\text { cent to canal) }\end{array}$ & local & $\begin{array}{l}\text { pursue their hobby on ground that is planned to be reno- } \\
\text { vated }\end{array}$ \\
\hline
\end{tabular}

\section{Main participatory activities}

Table 5.4 displays both the variety in classes as well of types of activities. This complies with the variety of stakeholder groups, and indicates a customised application of methods.

\section{Context and constraints}

BW had limited resources both in staff and financial budget for participatory activities. In a later stage of the project this was improved with two new voluntary staff for the co-ordination of participatory activities.

Although most stakeholders, especially the organised groups (see table 5.3), had a sound knowledge base (about regional Cotswold canal issues) as well as willingness and experience to co-operate with $\mathrm{BW}$ in an investment project in relationship to the Cotswold canals, there was one group - the push bikers - difficult to approach. Moreover, intentions and co-operativeness were entirely unknown, with the consequence of much uncertainty about the group's awareness, acceptance and in this way uncertainty 
Table 5.4: Main participatory activities of the BW project

\begin{tabular}{|c|c|c|}
\hline Class of method & Goals & Specific activities (methods) \\
\hline \multirow{5}{*}{ Information provision } & \multirow{5}{*}{$\begin{array}{l}\text { public awareness } \\
\text { increased involvement } \\
\text { recruiting volunteers }\end{array}$} & partnership website \\
\hline & & project atlas for all involved stakeholders \\
\hline & & a display of the works in Cairnscross \\
\hline & & press release \\
\hline & & letters sent out to local residents \\
\hline \multirow[b]{2}{*}{ Meeting } & \multirow{2}{*}{$\begin{array}{l}\text { knowledge for decision-making } \\
\text { increased involvement } \\
\text { development of win-win plans } \\
\text { co-financing } \\
\text { long-term use and mainte- } \\
\text { nance }\end{array}$} & several discussions with the core group \\
\hline & & $\begin{array}{l}\text { several discussions with other stakeholder } \\
\text { groups such as Ruscombe Brook Action } \\
\text { Group and local residents }\end{array}$ \\
\hline \multirow{2}{*}{ Survey } & \multirow{2}{*}{$\begin{array}{l}\text { public awareness } \\
\text { recruiting volunteers } \\
\text { knowledge for decision making } \\
\text { development of win-win plans }\end{array}$} & $\begin{array}{l}\text { questionnaire sent to several hundred } \\
\text { households }\end{array}$ \\
\hline & & $\begin{array}{l}\text { school children collected views of } 64 \\
\text { passers-by at a street stall }\end{array}$ \\
\hline education & $\begin{array}{l}\text { public awareness } \\
\text { increased involvement } \\
\text { long term use and maintenance } \\
\text { education }\end{array}$ & $\begin{array}{l}\text { two educational events each in summer } 2005 \\
\text { and } 2006\end{array}$ \\
\hline \multirow[t]{2}{*}{$\begin{array}{l}\text { Popular involvement } \\
\text { campaigns }\end{array}$} & \multirow{2}{*}{$\begin{array}{l}\text { increased involvement } \\
\text { education } \\
\text { long-term use and mainte- } \\
\text { nance }\end{array}$} & $\begin{array}{l}\text { volunteers have been involved in archaeolog- } \\
\text { ical activities, in combination with training for } \\
\text { college students }\end{array}$ \\
\hline & & $\begin{array}{l}\text { volunteers have been involved in side clear- } \\
\text { ance of the vegetation around the pond, and } \\
\text { clearance (litter) along the canal }\end{array}$ \\
\hline
\end{tabular}

about the maintenance of the site. Furthermore, legal land-purchase issues have delayed the process. Additionally, limited resources of one of the main stakeholder groups hampered the process of combining local stakeholder knowledge with educational activities.

\section{Evaluation results}

The main constraint of this partner was the lack of knowledgeable staff, both with the responsible authorities and among stakeholders, who would be able to train volunteers.

BW started with the intention of conducting a type of horizontal participation (see figure 4.4 for types) involving as much as possible stakeholders and the broad public with, however, little discussion about the design of the plans. The high reach was significant for the recruitment of volunteers.

As depicted in figure 5.3 volunteers were involved, and the process reached a high level of activity. Furthermore as the decision process became more particular, higher impact on decisions was assigned to some of the stakeholders such as land owners. BW and a number of significant stakeholders formed up a core group with high activity and information exchange. However, non of the public or less significant stakeholders was entirely excluded from the policy process. A sufficient number of public activities was organised with interaction as required. This may be seen as an example for an effective process. The increase of power sharing as a result of the transference of decision 

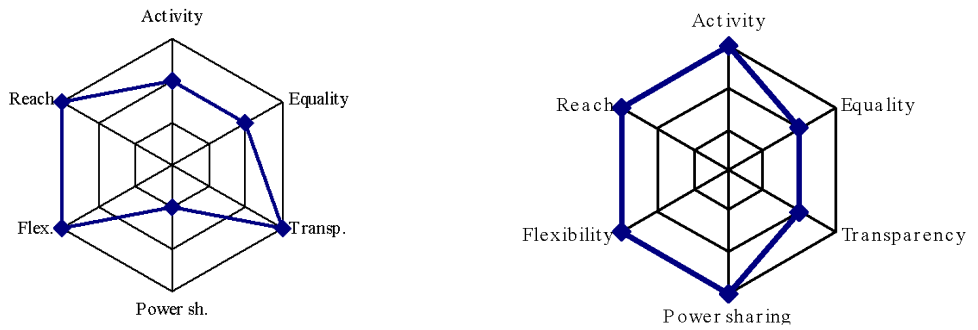

Figure 5.3: Mutations in the intensity of participation 2005 and 2007 (BW)

competence from BW to the Lawns core group, however, resulted in a delay in the decision process, since one of the stakeholders did not provide the partners with required documents on time. On the other hand, as a result of the delay a new and important stakeholder was discovered. With a better stakeholder analysis such as proposed in section 3.3.3 this could have been avoided.

\section{Lessons learned}

BW experiences can be summarised as following:

- Better involvement of stakeholders in the planning of participatory activities;

- Communication with stakeholders must be more efficient;

- Better stakeholder analysis, and as a consequence earlier involvement of relevant stakeholders;

- More effective information and consultation activities including education about aims and available means of the canal restoration activities;

- Better manage the expectations of stakeholders and the public.

\subsubsection{Glasgow City Council (GCC): the regeneration of Ruchill Park}

The TRUST project has created a valuable opportunity to direct funds to the regeneration of a large local park, enabling green space regeneration to become part of a much bigger programme including new housing, new schools and a new commercial centre.

Glasgow's water storage planning activity is based on a series of attenuation ponds situated in a park, on a hillside above, and overlooking a stretch of the Clyde canal. The objectives of the project's design are:

1. Remove surface water run-off from existing combined sewers;

2. Reduce risks of flooding and pollution of adjacent watercourses;

3. Enhance the quality of the environment and biodiversity;

4. Improve water quality prior to final discharge. 
The Ruchill district of the city is largely residential, and the final phase of the regeneration of previous industrial and redundant hospital sites started in the second half of the year 2007. The area features two hills, and it is on one of these hills that the study side is situated. The hill occupies about 60 hectares, of which 30 hectares is a redundant hospital ground, situated on the eastern part of the hill. This site was sold to a private house builder in the summer 2007. The remaining 30 hectares form a local park.

The focus of the case study is three ponds with the highest pond to the east of the park. Each pond feeds the adjacent lower pond and eventually discharges via a pipe through a local street into the canal. The three ponds flow by gravity; they are planted with aquatic and marginal plantings. They will permanently contain water. The ponds can be accessed by a footpath network linked to the park footpath network.

\section{Relevant stakeholders}

The composition of stakeholders (table 5.5) indicates the attempt of GCC to integrate spatially adjacent planning issues: the park regeneration including the new ponds, developing land for housing and building a new school.

Table 5.5: Relevant stakeholders of the GCC project (Krywkow, 2007)

\begin{tabular}{|c|c|c|}
\hline Stakeholder & Scale of activities & Description, individual goals \\
\hline $\begin{array}{l}\text { The Councils } \\
\text { Parks Service }\end{array}$ & local & $\begin{array}{l}\text { governmental organisation, responsible for the maintenance } \\
\text { of the park }\end{array}$ \\
\hline British Waterways & Great Britain & maintain and manage the waterways \\
\hline Scottish Water & Scotland & $\begin{array}{l}\text { water supplier (drinking water and sewage water supply, } \\
\text { maintenance and planning) }\end{array}$ \\
\hline $\begin{array}{l}\text { Local community } \\
\text { groups }\end{array}$ & local & $\begin{array}{l}\text { citizen groups caring about public and community issues in } \\
\text { the neighbourhood around the park }\end{array}$ \\
\hline $\begin{array}{l}\text { local social hous- } \\
\text { ing landlords }\end{array}$ & local & house owners \\
\hline $\begin{array}{l}\text { The four primary } \\
\text { schools }\end{array}$ & local & $\begin{array}{l}\text { will be relocated to a new primary school adjacent to the } \\
\text { TRUST project site }\end{array}$ \\
\hline
\end{tabular}

\section{Main participatory activities}

Participatory activities (table 5.6) are prevailingly targeted to increase public involvement and acceptance of the newly arranged park facilities.

\section{Context and constraints}

A significant challenge for the GCC managers was to create win-win situations among the three spatially adjacent, topical investment projects: (1) the ponds; (2) school building and (3) development of a residential site on a former hospital ground. This resulted in a difficult planning situation for the participatory process. Later on GCC decided to focus on the SUDS with the TRUST resources, and create a win-win situation in conjunction with the other projects.

Furthermore, GCC had no appropriately trained staff to handle a participatory process with such a complex context including various groups of interest. In addition, the allocation of a financial budget turned out to be a long-winded process within the organisation of GCC. 
Table 5.6: Main participatory activities of the GCC project

\begin{tabular}{|c|c|c|}
\hline Class of method & Goals & Specific activities (methods) \\
\hline \multirow{3}{*}{ Information provision } & \multirow{3}{*}{$\begin{array}{l}\text { public awareness } \\
\text { increased involvement }\end{array}$} & newspaper advertisements \\
\hline & & a display in the park \\
\hline & & flyers \\
\hline \multirow{2}{*}{ Survey } & \multirow{2}{*}{$\begin{array}{l}\text { public awareness } \\
\text { knowledge for decision-making }\end{array}$} & customer (park users) survey in the park \\
\hline & & $\begin{array}{l}\text { survey among } 4000 \text { households in the vicinity } \\
\text { of the park }\end{array}$ \\
\hline \multirow{3}{*}{ Meetings } & \multirow{3}{*}{$\begin{array}{l}\text { knowledge for decision-making } \\
\text { development of win-win plans }\end{array}$} & meeting with friends of Ruchill Park \\
\hline & & $\begin{array}{l}\text { liaising with elected members of the park } \\
\text { comity }\end{array}$ \\
\hline & & $\begin{array}{l}\text { meeting with park service staff and planning } \\
\text { service staff of GCC }\end{array}$ \\
\hline Workshop & $\begin{array}{l}\text { public awareness } \\
\text { long-term use and mainte- } \\
\text { nance } \\
\text { increased involvement }\end{array}$ & place-making workshop \\
\hline \multirow{2}{*}{$\begin{array}{l}\text { Popular involvement } \\
\text { campaigns }\end{array}$} & \multirow{2}{*}{$\begin{array}{l}\text { public awareness } \\
\text { increased involvement } \\
\text { development of win-win plans }\end{array}$} & $\begin{array}{l}\text { co-funding (with GCC planning department) } \\
\text { a 'Fun Run' through the park }\end{array}$ \\
\hline & & $\begin{array}{l}\text { development of an arts project linking school } \\
\text { activities with park activities }\end{array}$ \\
\hline
\end{tabular}

The involved organised citizen groups had little experience with campaigning activities and handling issues within a more complex planning situation. A capacity-building workshop together with the research team, however, initiated a learning process among individuals of the citizen groups. Moreover, many residents (public), although interested, had difficulty in comprehending the planning situation including the functionality and consequences of implementing the SUDS.

\section{Evaluation results}

The lack of acceptance of the application of participatory methods among the technical staff of GCC was a significant constraint. Better co-ordination between planning, engineering and participatory management could have improved efficiency. However, in comparison to the other TRUST partners, GCC had sufficient and trained staff to organise participatory activities. Furthermore, financial resources were adequately available. In co-operation with a committed community group case-specific problems were detected and processed in a larger context of the surrounding urban area. The communication with the public was partially problematic, since a significant number of individuals had difficulty to comprehend relevance as well as implications for the environment and the residents. GCC planed a series of workshops involving local community groups for an inter-active and intense discussion about the planning, design and implementation of the ponds within the park. Very soon throughout the course of the project the implications of the project to other public issues and concerns became obvious. This resulted in an increase of activities that involved the public, especially local residents and park users. The high level of activity remained consistent during all project phases. Only a limited number of stakeholders participated decision processes such as the design of the ponds. The highlight of these activities was a 'market place' with commu- 

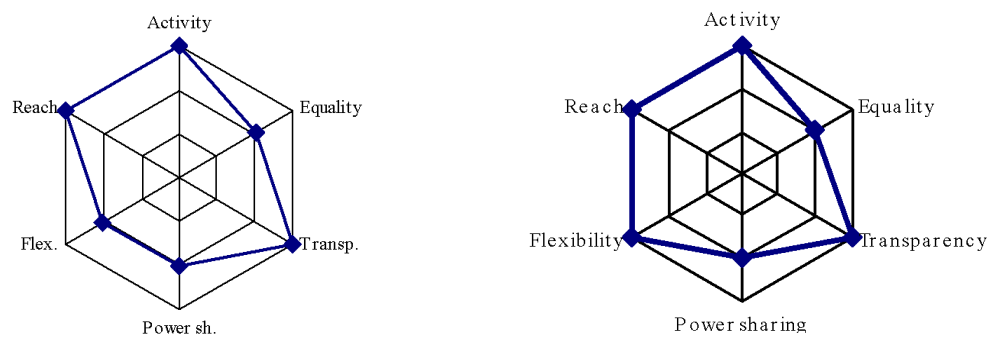

Figure 5.4: Mutations in the intensity of participation 2005 and 2007 (GCC)

nity groups. The outcomes of this event resulted in a 'short term action plan' for the park management. Although the location and functionality of the ponds was in fact determined prior to the participatory process, authorities accepted modifications that resulted from the interaction with interest groups. The entire participatory process relevant for the TRUST-related project was embedded in previous activities concerning the park. The reach of the process, its acceptance and the improvement of the quality of the park facilities indicated a vital and successful participatory process, of the type known as intense participation (see figure 4.4 for types).

\section{Lessons learned}

Lessons learned can be summarised with the following items:

- The benefit of a well-prepared and organised participatory process was recognised including the fact that knowledgeable staff is required for an appropriate participatory management;

- The participatory plan co-developed with the consultants improved the participatory process, and enabled the GCC staff to include all relevant stakeholders, to handle complex planning issues and anticipate emergent situations;

- Time expenditure especially for the preparation of a participatory process was underestimated before the TRUST experience;

- A participatory process requires a thoughtful allocation of budget that should be an integral part of the entire plan budgeting;

\subsubsection{POM West-Vlaanderen: constructing a new fresh water basin}

The majority of the farmers in the region Roeselare-Tielt of West Flanders produce vegetables that are processed by a local manufacturer of frozen vegetables. During the last decades this region has suffered from both increasing rainfall intensities with subsequent flooding, as well as from extended periods of drought. POM assumes that these are phenomena of climate change impact, and believe that these types of extreme situations are likely to occur more frequently in the future. Throughout the prevailingly dry summer season farmers increasingly need irrigation water. However, drought periods 
significantly decrease the irrigation capacity of the regional river basins. In addition, the surface water quality deteriorates remarkably.

To date, the frozen vegetables manufacturers use deep groundwater as process water to a great extent. Since the amount as well as the quality of deep groundwater layers decline rapidly, there will be limitations on this water source. In order to maintain the water supply for both the farmers and the frozen vegetable manufacturers, an alternative water supply must be found.

The Province of West Flanders authorities decided to plan for the development of a detention basin for the storage of superfluous water throughout the wet season. The basin is designed in a way that provides sufficient irrigation capacity, and has, moreover, potential as an industrial process water supply. As a second function ecologically valuable embankments are laid out to improve local biodiversity. The following tasks were part of case study activities:

- A feasibility study to determine whether or not the water quality meets the requirements of the frozen vegetable manufacturer;

- The design of a hydraulic model of the rivulet downstream of the water storage basin;

- A water storage basin plus upstream structural works. Not only the construction of the water storage area of $3 \mathrm{ha}$ (app. $1.5 \mathrm{ha}$ basin and $65.000 \mathrm{~m}^{3}$ earthworks) but also the construction works will result in improved water management (supply in balance with demand) in the area;

- An estimation of the guaranteed flow that can be supplied to the industry;

\section{Relevant stakeholders}

The POM case combines public and stakeholder participation (table 5.7). The main interests of the stakeholders focus on the water use of the new basin.

\section{Main participatory activities}

A focus of participatory activities (table 5.8) is the acceptance among farmers of the pond as a source of irrigation water

\section{Context and constraints}

The province of Ardooie decided not to communicate with stakeholders before the land to be developed was allocated and the building permit was granted. This made an early involvement of stakeholders impossible. During the objection period one neighbour was able to delay the planning and implementing process for several months. The regional nature conservation group refused a collaboration with the water managers, because they did not believe in a sustainable use of the water basin for irrigation. The communication and collaboration between responsible authorities from the provincial level to POM as the planning body was legally prescribed for this project. However, this was not always efficient and caused some delay in the process. There was very little experience with participatory methods among the responsible authorities. Moreover, as repeatedly stated in the TRUST meetings, there was little belief in the effectiveness and benefit of an appropriate participatory management among higher-ranking POM staff. 
Table 5.7: Relevant stakeholders of the POM project

\begin{tabular}{|l|l|l|}
\hline Stakeholder & Scale of activities & Description, individual goals \\
\hline \hline $\begin{array}{l}\text { Farmers unions } \\
\text { (Boerenbond, BB } \\
\text { en Algemen Boeren } \\
\text { Syndicat, ABS) }\end{array}$ & $\begin{array}{l}\text { regional } \\
\text { Vlaanderen) }\end{array}$ & $\begin{array}{l}\text { represent the interests of the regional farmers. Are fur- } \\
\text { thermore interested in good water quality for the irriga- } \\
\text { tion of crops during the dry season }\end{array}$ \\
\hline $\begin{array}{l}\text { Frozen vegetables } \\
\text { manufacturers }\end{array}$ & $\begin{array}{l}\text { regional (produc- } \\
\text { tion) and Europe } \\
\text { (marketing) }\end{array}$ & $\begin{array}{l}\text { trying to identify alternative fresh water resources since } \\
\text { the groundwater supply declines significantly }\end{array}$ \\
\hline $\begin{array}{l}\text { neighbouring land own- } \\
\text { ers next to the project } \\
\text { site }\end{array}$ & local & $\begin{array}{l}\text { were suspicious about the (negative) consequences of } \\
\text { a fresh water basin next to their property }\end{array}$ \\
\hline $\begin{array}{l}\text { Municipality of Ardooie } \\
\text { Provincial government } \\
\text { of West Vlaanderen }\end{array}$ & regional & $\begin{array}{l}\text { local } \\
\text { well as the industry }\end{array}$ \\
\hline $\begin{array}{l}\text { Environmental conser- } \\
\text { vation group (Toren- } \\
\text { valk) }\end{array}$ & regional & $\begin{array}{l}\text { interested in a sustainable water supply for irrigation as } \\
\text { well as the industry }\end{array}$ \\
\hline $\begin{array}{l}\text { Residents of Ardooie } \\
\text { able water source for irrigation }\end{array}$ \\
\hline
\end{tabular}

\section{Evaluation results}

The partner was inexperienced with the design and management of a participatory process. Moreover, the lack of support from superior authorities as well as scarce financial and human resources limited the prospects of successful public and stakeholder participation activities.
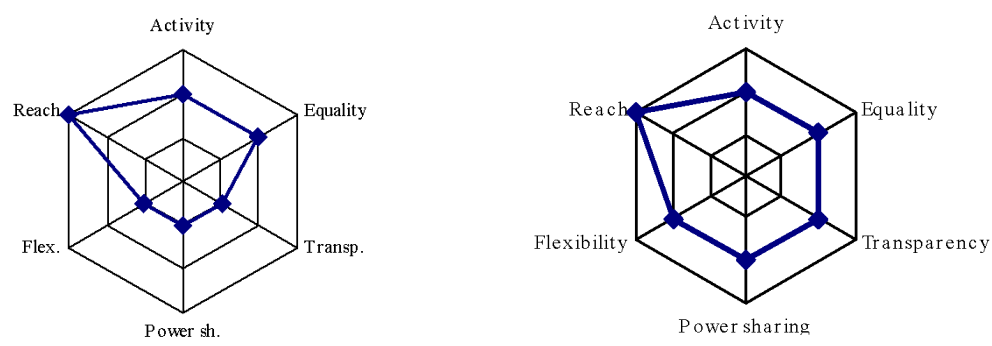

Figure 5.5: Mutations in the intensity of participation 2005 and 2007 (POM)

POM planned a participatory process that may be classified as type focussed consultation (see figure 4.4 for types). Subsequent to a brief stakeholder analysis, a public information meeting was scheduled to present the plans to interested individuals and groups. Only a selective group of potential users of the water basin (farmers and the vegetable processing industry) was approached, and a survey was conducted. This resulted in a legal procedure initiated by a neighbour of the water basin including a delay in the planning procedure. Whereas a non-governmental nature organisation refused 
Table 5.8: Main participatory activities of the POM project

\begin{tabular}{|l|l|l|}
\hline Class of method & Goals & Specific activities (methods) \\
\hline \hline \multirow{3}{*}{ Information provision } & \multirow{3}{*}{ public awareness } & article in a newsletter of the municipality \\
\cline { 3 - 3 } & $\begin{array}{l}\text { website about the project linked to the municipal website } \\
\text { as well as the POM website }\end{array}$ \\
\cline { 3 - 3 } Survey & $\begin{array}{l}\text { press conference subsequent to the completion of the } \\
\text { construction works }\end{array}$ \\
\hline \multirow{2}{*}{ Meeting } & $\begin{array}{l}\text { public awareness } \\
\text { increased involvement } \\
\text { satisfaction of stake- } \\
\text { holders }\end{array}$ & $\begin{array}{l}\text { mailing of a leaflet including an invitation to a public } \\
\text { meeting and a brief questionnaire for all residents and } \\
\text { stakeholders within 5km surrounding area }\end{array}$ \\
\hline $\begin{array}{l}\text { long-term use and } \\
\text { maintenance } \\
\text { satisfaction of stake- } \\
\text { holders } \\
\text { public awareness }\end{array}$ & $\begin{array}{l}\text { meeting with the council of Ardooie, presentation of the } \\
\text { project and discussion }\end{array}$ \\
\cline { 3 - 3 } & $\begin{array}{l}\text { public information meeting, presentation of the project } \\
\text { and discussion }\end{array}$ \\
\cline { 2 - 3 } & $\begin{array}{l}\text { bilateral meetings with the frozen vegetables manufactur- } \\
\text { ers }\end{array}$ \\
\hline
\end{tabular}

any collaboration with the planners, although a high potential of creating win-win situations was possible. However, due to capacity-building activities and a trans-boundary exchange of experience within the TRUST TGIII a stakeholder meeting in a later stage of the project was better prepared and successfully conducted.

\section{Lessons learned}

There are a number of important lessons that emerged in this case:

- The internal communication between the responsible authorities must be improved;

- Stakeholders with serious concerns about the management and implementation of water resources projects must be taken seriously, and a dialogue must be pursued;

- As confirmed by a POM representative as well as local residents, a discussion with the neighbour had considerable potential to avoid a legal procedure and hence a delay in the implementation of the project;

- The goal-oriented approach of participation supports the application of appropriate participatory methods;

- Early involvement of stakeholders and the public helps to avoid misunderstandings; and has the potential to encourage more support for a given project.

\subsubsection{Water Board of Schieland and the Krimpenerwaard (HHSK): a new water way}

The Polder ${ }^{7}$ Bleiswijk is a rural area (beneath sea level) that is part of the administrative district of HHSK. A spatial transition due to increased urbanisation and the development of specialised agriculture (glasshouses) is, however, occurring.

\footnotetext{
${ }^{7} \mathrm{~A}$ polder is a low-lying tract of land that forms an artificial hydrological entity, enclosed by embankments referred to as dykes
} 
The area's current water management approach requires a strict system of drainage and water level control with weirs and pumping stations, to pump the surface water to the polder outlet. In the current situation the Polder Bleiswijk suffers severely from excess water during times of intensive rainfall, and there is a lack of fresh water in times of drought. HHSK expects an increasing number of climate-change-driven extreme weather situations such as heavy precipitation as well as droughts. Eventually, this will result in serious economic loss (e.g. loss of crops, damage to infrastructure and houses). The activities of HHSK in the context of TRUST aim to reduce this risk of economic loss, and improve the capacity to cope with excess water.

The planning effort is called Wateropgave 2015 and involves the enlargement of surface water in the Southern part of the polder Bleiswijk, and combining improved aquatic nature with a recreational functions. The project includes:

- The redirection of urban water discharge away from the natural environment;

- The improvement of the availability of water during periods of drought;

- The improvement of the ecological balance in the area.

The TRUST demonstration project includes the realisation of a new, landscapeintegrated, main waterway (earthworks and landscaping), ecological embankments, two canoe-passable culverts, a combined pedestrian and cycle bridge, and two road bridges. The excess soil from the waterway is used to create new ecological embankments, and to reinforce nearby dykes. The new main waterway ends near a new pumping station, called Lansingerland.

Because of this project, the improved drainage of the area will undoubtedly reduce the risk of flooding of the polder. In addition, visitors from the nearby urban areas benefit from the higher ecological quality of the area and the improved recreational facilities. Furthermore, the improved recreational facilities are expected to increase the revenues of the recreational entrepreneurs in the area, while improved access to the area will most likely attract more visitors to the two existing restaurants.

\section{Relevant stakeholders}

HHSK tried to involve as many stakeholders as possible. The stakeholders as listed in table 5.9 represent various land-use preferences in the area.

\section{Main participatory activities}

The majority of activities were bilateral meetings with the stakeholders (table 5.10). Furthermore, some events were organised for the local residents.

\section{Context and constraints}

One of the stakeholders (Rottemeren Recreation Board) refused to take part at any participatory activities beyond the mere legal procedure to provide land for development, despite repeated efforts of HHSK to involve this stakeholder in the process. According to HHSK this partner would have been required to conduct field trips, education activities and additional public involvement campaigns. However, apart from that there was a general public and stakeholder support for the project, or at least no opposition. 
Table 5.9: Relevant stakeholders of the HHSK project

\begin{tabular}{|l|l|l|}
\hline Stakeholder & Scale of activities & Description, individual goals \\
\hline \hline $\begin{array}{l}\text { Rottemeren Recre- } \\
\text { ation Board }\end{array}$ & local & land owner \\
\hline $\begin{array}{l}\text { Golf course De Rotte- } \\
\text { bergen }\end{array}$ & local & land owner \\
\hline Allotment owners & local & land owner \\
\hline $\begin{array}{l}\text { local nature conser- } \\
\text { vation group }\end{array}$ & local & protecting nature in the polder \\
\hline $\begin{array}{l}\text { Department of public } \\
\text { works }\end{array}$ & national & $\begin{array}{l}\text { Department for Traffic and Waterways. Responsible } \\
\text { for the safety of all citizens with focus on flood risk. } \\
\text { Issuing building permits }\end{array}$ \\
\hline $\begin{array}{l}\text { Provincial govern- } \\
\text { ment of Zuid Holland }\end{array}$ & $\begin{array}{l}\text { regional (the entire } \\
\text { province) }\end{array}$ & issuing building permits \\
\hline
\end{tabular}

Table 5.10: Main participatory activities of the HHSK project

\begin{tabular}{|l|l|l|}
\hline Class of method & Goals & Specific activities (methods) \\
\hline \hline \multirow{3}{*}{$\begin{array}{l}\text { Information } \\
\text { provision }\end{array}$} & public awareness & $\begin{array}{l}\text { personal letters, personal visits, telephone calls } \\
\text { and emailing }\end{array}$ \\
\cline { 3 - 3 } & development of win-win plans & $\begin{array}{l}\text { advertisements in local newspapers and newslet- } \\
\text { ters }\end{array}$ \\
\cline { 3 - 3 } & display in the nearby village \\
\hline \multirow{2}{*}{ Consultation } & $\begin{array}{l}\text { knowledge for decision } \\
\text { making }\end{array}$ & $\begin{array}{l}\text { legally prescribed display of the plans with the op- } \\
\text { portunity to comment and object }\end{array}$ \\
\hline Meetings & $\begin{array}{l}\text { knowledge for decision making } \\
\text { development of win-win plans }\end{array}$ & bilateral meetings with all relevant stakeholders \\
\hline \multirow{2}{*}{ Events } & public awareness & $\begin{array}{l}\text { Polder feest', public ground breaking ceremony, } \\
\text { opening the implementation phase }\end{array}$ \\
\cline { 3 - 3 } & increased involvement & $\begin{array}{l}\text { public tape-cutting ceremony for the new pumping } \\
\text { station }\end{array}$ \\
\hline
\end{tabular}

The project in the polder Bleiswijk had already started a significant period of time prior to the start of the TRUST project. The learning effect was hence limited.

\section{Evaluation results}

The water board has a long history and considerable experience in handling surplus water. However, the application of interactive participatory processes only emerged in the most recent transition phase of the water board. Still there is much resistance towards intense public and stakeholder participation within the organisation, which might be viewed as a constraint in the TRUST-related planning effort. The planning issue in the polder Blijswijk involves a number of stakeholders such as land owners, tourists, nature groups and sport clubs with a high potential for conflicts.

The participatory process of HHSK was planned as type focussed consultation (see figure 4.4 for types). only complying with the legally prescribed procedure (information provision, public meeting, objection period). Although a number of stakeholders uttered concerns about the project, the same individuals and groups did not participate at the first public meeting. However, when HHSK became part of the TRUST project, 
they started enhancing the already ongoing participatory process by activities that increase the environmental awareness including school children and site users. However, activities remained limited. Only bilateral meetings with a limited number of stakeholders were held. Furthermore, only the most important stakeholders (from the point of view of HHSK) were partly involved in the decision process. The majority of the stakeholders had not impact on the decision process. Their opinions, suggestions and objectives were heard, but not included in the decisions.
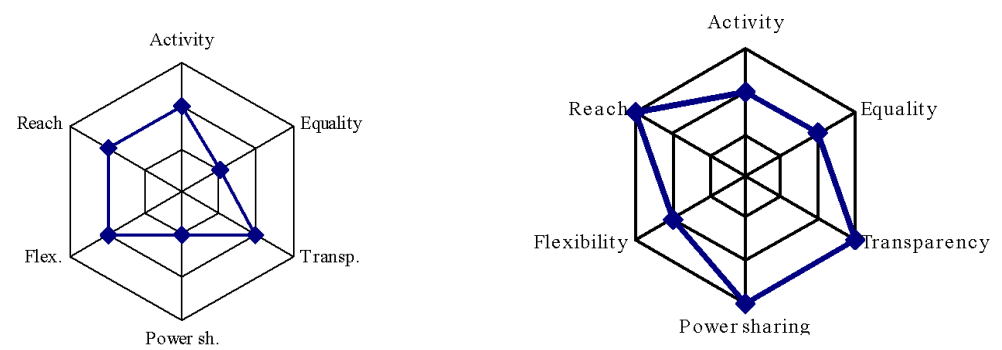

Figure 5.6: Mutations in the intensity of participation 2005 and 2007 (HHSK)

HHSK very efficiently analysed the most relevant stakeholders, identified potential conflicts and took appropriate countermeasures. From the perspective of HHSK the goals of co-financing, long term use and social learning were not achieved, because of the resistance of important stakeholders to collaborating in further activities. HHSK indicated repeatedly that their project managers are not trained to meet the requirements of an intense participatory process as described in Hare and Krywkow (2005). However, the TRUST experience will contribute to an improvement of HHSK's future participatory processes.

\section{Lessons learned}

The following items are of relevance for HHSK:

- A participatory process is more than mere risk assessment ${ }^{8}$.

- The HHSK staff realised the benefits of a participatory process;

- In the latter phase of the project, a sense of ownership and involvement of lay people played an increasing role;

- Participation should be an essential part of every planning procedure;

- A participatory expert (rather than a communications officer) can improve the quality of the participatory management;

- Generally disseminated conventional advertisements have little effect in terms of reaching relevant stakeholders;

\footnotetext{
${ }^{8}$ Risk assessment in the sense of ensuring that no one delays the process (e.g. with a legal procedure).
} 
- Face-to-face contact and personal invitation are more promising than 'anonymous' or remote interaction such as fora;

- A participatory process starts with (or even before) the actual project period and continues until the end;

- Public events are effective to acquaint representatives of stakeholder groups, build up trust and keep in touch. A participatory process can be costly, but the benefits can outweigh the financial effort.

\subsubsection{The Province of North-Holland (PNH): improving and extending a recreation area}

The current state of the recreational area (2007) is a result of building activities started in the late 1960s. The area was developed as part of the structural improvement for the agricultural modification of the region Great Geestmerambacht. Due to suburbanisation processes and population growth a larger recreation area is required. For this reason the three municipalities of Heerhugowaard, Alkmaar and Langedijk decided to enlarge the area Geestmerambacht. The new part of the recreation area The Druppels is at the same time part of the TRUST project. Besides its recreational function The Druppels is developed as a peak retention polder to compensate for the fact that the lake of Zomerdel is cut off from the drainage canal.

Lake Zomerdel will remain the centre of the recreational area. The redevelopment of the lake shores included water sports and daytime recreation. The lake itself may be used for swimming, canoeing, wind surfing and diving. There are several fishing areas, and routes for walking, cycling and horseback riding. Camp grounds, a number of small hotels, cafés and restaurants are associated with the area.

In addition to developing recreational facilities, the water quality of Lake Zomerdel had to be improved. To reduce the risk of blue algae contamination, the lake was cut off from the North Holland Canal. As a result, the water supply has stopped, and the surface level declined by about one metre. The lower water level made it necessary to rebuild the embankments of the lake. Suggestions provided by site visitors were incorporated into the restructuring of the area. The works took place between 2006 and 2007.

When Lake Zomerdel was separated from the canal, the storage capacity of the Schermer drainage canal declined. To compensate for this capacity loss, the recreational area of Geestmerambacht was expanded by approximately $375.000 \mathrm{~m}^{3}$. A new dyke had to be constructed around the entire area of the Druppels. The urban surface water of Alkmaar North will be redirected the new recreational area, which increases the water storage capacity of the urban area of Alkmaar. The water measures ensure that the water system of the entire area (500 ha) will be more flexible and self-containing.

\section{Relevant stakeholders}

Apart from a group of local residents and an NGO, the majority of stakeholders were (local) governmental organisations (table 5.11). 
Table 5.11: Relevant stakeholders of the PNH project

\begin{tabular}{|l|l|l|}
\hline Stakeholder & $\begin{array}{l}\text { Scale of } \\
\text { activities }\end{array}$ & Description, individual goals \\
\hline \hline Province of North Holland & regional & investor, planner and issuing building permissions \\
\hline $\begin{array}{l}\text { Recreation board } \\
\text { Geestmerambacht }\end{array}$ & local & responsible for the realisation of the project \\
\hline $\begin{array}{l}\text { A consortium of munici- } \\
\text { palities of the surrounding } \\
\text { towns Alkmaar, Langedijk } \\
\text { and Heerhugowaard }\end{array}$ & local & investors, issuing planning permissions \\
\hline Group of local residents & local & land owners in the vicinity of the recreational area \\
\hline Nature organisation & regional & nature conservation and protection in the recreational area \\
\hline
\end{tabular}

\section{Main participatory activities}

PNH was very active in terms of advertising the project and increasing the awareness and acceptance among local residents (table 5.12). Meetings were held with a representative of local citizen groups.

Table 5.12: Main participatory activities of the PNH project

\begin{tabular}{|l|l|l|}
\hline Class of method & Goals & Specific activities (methods) \\
\hline \hline \multirow{3}{*}{$\begin{array}{l}\text { Information } \\
\text { provision }\end{array}$} & \multirow{3}{*}{ public awareness } & website of the recreation area including planning activities \\
\cline { 3 - 3 } & & Advertisements in the local newspapers \\
\cline { 3 - 3 } & postal distribution of flyers and leaflets \\
\cline { 3 - 3 } & $\begin{array}{l}\text { knowledge for deci- } \\
\text { sion making }\end{array}$ & $\begin{array}{l}\text { a periodical newsletter } \\
\text { Meetings } \\
\text { dents and board meetings with representatives of local resi- }\end{array}$ \\
\hline
\end{tabular}

\section{Context and constraints}

The number of expected visitors to the recreational site was initially underestimated. TRUST partners suggested conducting an environmental impact study to cope with this problem. Although all relevant government stakeholders were involved in the process, the municipal projects and planning activities such as land development, a new race course or a depot for contaminated soil were planned in the vicinity or on the ground of the recreational area. This resulted in irritation and mistrust among stakeholders, especially the citizens and environmental groups. In general the complexity of the issues of this planning approach in conjunction with the multitude of responsible authorities complicated the course of the project including the participatory process. For this reason the research team was asked to review the communication plan of the consortium rather than design a participatory plan. Furthermore, there are some contradicting interests among stakeholders about the use of the recreational area, especially among residents, site users and the nature conservation group.

\section{Evaluation results}

The main constraint of the project was in the complexity of the project consortium including a significant number of government agencies involved. The consultants de- 
signed a communication plan for the consortium to support a higher efficiency of information exchange.
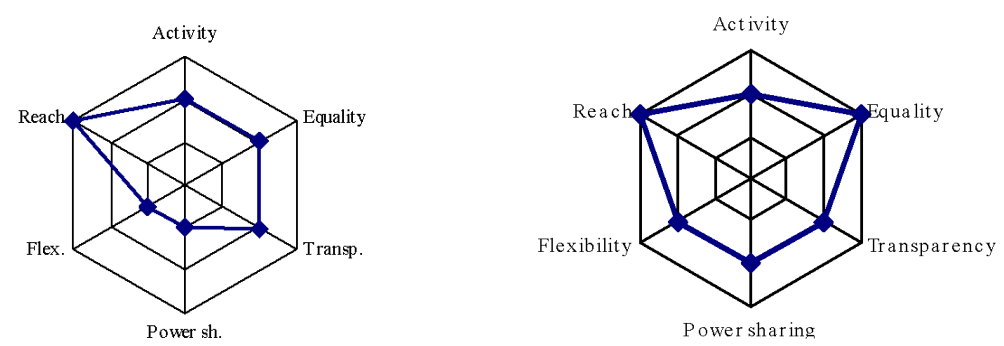

Figure 5.7: Mutations in the intensity of participation 2005 and 2007 (PNH)

However, during the TRUST process the municipality responsible for the area tried to allocate a disposal for excavation ground in the direct vicinity of the recreational site. This resulted in significant annoyance and mistrust among local residents and stakeholders. Symbolic participation (see figure 4.4 for types): In the beginning of their project PNH exerted themselves to inform a broad public in the local press, with flyers and other means of communication about the proposed extension and modification of the recreation area. Meetings were held with stakeholders, residents and local interest groups, but were used largely to present planning options and respond to questions. However, little discussion time was scheduled, and relevant decisions had already been taken prior to any participatory activities. The ideas and suggestions were collected and structured in the form of response cards. However, there was no effort to transparently display how public and stakeholder suggestions were incorporated into the plans. The lack of feedback resulted in an emotional discussion during a meeting in 2006. The failure in goal achievement reflects the lack of transparency and flexibility of this participatory process. The goals of satisfaction of stakeholders, increased involvement and social learning were not achieved.

\section{Lessons learned}

There were two important insights that emerged from the PNH project. The incorporation of an evaluation process is an additional effort, but helped to improve the participatory process including consequences for participatory management in future projects. Furthermore, the PNH representatives believe that a communications advisor can help to improve the communication process among the responsible authorities.

\subsection{The evaluation and monitoring process as a whole}

The first section of each of the case-study descriptions demonstrates the significant differences among the (sub) cases. This holds for all aspects of every local context in terms of the type and goals of the of physical interference in the landscape, the related problems and side effects, the size of the area, the number and types of stakeholders, and the involved authorities including the variety of institutional levels. As an 
example, POM had a 3 ha field with a 1.5 ha basin, whereas PNH worked on a 500 ha recreational area with a whole variety of land use. Moreover, the composition of stakeholders is completely different, such as an active involvement and diverse interests of several instances of local and regional authorities in the process of PNH. In contrast, POM was able to represent all relevant authorities throughout the entire process. With 'conventional' means and methods it would have been a tremendous challenge to achieve comparable results.

Yet, both the CMO methodological scheme as well as the COPIR approach for evaluation and monitoring introduced a generally applicable methodological framework to all cases studies without imposing a mechanistic design and analysis pattern on the case studies. Furthermore, goal-oriented working enabled the water managers to decide for a suite of methods that are most appropriate for their specific requirements. How is this possible? (1) The strict separation of goals/objectives from the local constraints is the primary assumption. In the TRUST project all partners together were able to work out a set of goals that was relevant to each of them (table 5.2.3). (2) Every partner was able to formulate their most significant local and unique constraints. (3) Between yet identified objectives and constraints, each partner together with the research team was able to select an appropriate set of methods to be aligned over the entire course of the project. CMO is simply stated the following principle: water managers are provided with a means of identifying suitable methods with the support of scientists, and scientists do not impose their methods on the case study. This introduces a great deal of flexibility to the case studies, and entirely complies with the requirements of AWM, especially in respect to the adaptive capacity of a system. So much for CMO.

COPIR is identical in design to CMO, except that it works reciprocally: the combination of detected intensity criteria ${ }^{9}$ can help to identify why targeted goals were not achieved or insufficiently achieved. As an example: PNH did not achieve the goal 'satisfaction of stakeholders'. The intensity analysis gained a type 'symbolic participation' with little transparency, activity, power sharing and flexibility. The constraints section, the interfering planning activities of some authorities are easily detected as a main reason for unsatisfied stakeholders. The difficulty in managing the complexity of contemporaneous and spatially adjacent ${ }^{10}$ planning issues is a second reason. Furthermore, table 5.12 manifests the low activity level with only two different participatory efforts: information provision and an array of stakeholder meetings. The underlying reason for this failure in goal achievement was uncoordinated planning activities of the responsible authorities. An institutional analysis might reveal that the self-assessment of 'high equality' might not be quite correct, since the other stakeholders have only very limited opportunities to intervene. A simple problem solving approach, and a first step, would have been to invite the representatives of the source of the problem. The water managers of PNH never tried that. As a first step to find a solution in the long term, the PNH managers requested a 'checklist for a communication plan', which the research team delivered instead of a participatory plan.

\footnotetext{
${ }^{9}$ As equivalent to the 'method' part of CMO

${ }^{10}$ In this case even overlapping
} 
This problem illustrates how the intensity criteria serve as a link between constraints and objectives as well as a first step to identifying modifications in the application of methods. Moreover, it can serve as a point of contact for trans-boundary learning. The selected PNH problem is one example of how CMO as well as COPIR have been implemented in the particular case studies, and a problem analysis of the management approaches was achieved. The complete analysis for every case study is documented in the IER, and according to the TRUST/TGIII agreement not a matter for public discussion. Only the principle approach ( 5.2.2) and a summary of results for each partner is provided as section 'evaluation results' and section 'lessons learned'.

In the end of the TRUST project, all partners were convinced they had reached a relatively high intensity of participatory process, that all relevant stakeholders had been informed, and that the views of the stakeholders were included in the process (figures 5.3 - 5.7). Furthermore, from the partners' perspectives, they succeeded in achieving most of the very ambitious objectives. However, only one partner (GCC) considers the objective of 'social learning' to be achieved in their project (section 5.3.2). Stakeholder feedback on the participatory processes would have been an appropriate way to evaluate the above-mentioned statements of the partners. However, lack of time and the limited resources available for participatory processes averted the collection of stakeholder feedback. The results of the interviews, represented in the intensity charts, are for this reason only the views of the water managers and the consultants. From the researcher's point of view, opportunities were missed:

- Opportunities for active involvement (in planning, implementation and maintenance) and social learning (generating understanding and long-term behavioural changes of users) (HHSK, PNH);

- More effective co-operation within and among planning authorities (through acknowledgement of the importance of participation and clearly defined responsibilities between partner organisations) (GCC, POM, PNH);

- Gathering stakeholder feedback on the process quality and outcomes (e.g. through short informal dialogues or questionnaires) to allocate process errors (all case studies).

However, in comparison to classic planning processes, the partners have moved towards more intense participation as indicated in figures 5.3 - 5.7. In most cases with little resources available for participation, and having to deal with a general lack of acknowledgement of the positive implications of participation ${ }^{11}$, the partners did very well in involving the stakeholders in their projects. The networks that were built with stakeholders, the transboundary experiences gained, and the learning effects of exchange with the researchers and the other partners, will contribute to participation efforts in future projects.

\footnotetext{
${ }^{11}$ in some cases higher ranking staff at the end of TRUST still denied the benefit of a well-managed participatory process for their local investment projects
} 


\subsection{Summary and conclusions}

Not surprisingly, the case study process revealed a number of differences among the various projects based upon the diversity of local context as well as the nation-specific legal and cultural differences. However, the effort of including the evaluation procedure was not a contest of who performed best throughout the time span of the TRUST project. There was plenty of opportunity to exchange transboundary experiences in addition to the capacity building effort guided by the research team. All of the water managers had some experience with public and stakeholder participation. However, there was little knowledge about the range of methods as well as the potential benefits of a participatory process. The TGIII effort had some influence in shaking up the previous approaches of the particular case studies. But some new insights could be collected, and within limitations implemented in the ongoing processes.

The hypothesis about the transboundary comparability as claimed in chapter 2, was entirely confirmed by the case study effort. Although the planning themes of the (sub) case studies differed considerably, the effectiveness of the participatory processes could be measured with the newly developed intensity criteria, and easily compared to one another. Whereas both reports IER and FR provided a detailed analysis and discussion of each partner's performance, the intensity charts permitted an instant overview and comparison of the performance. Moreover, they implied a particular type of participation according to the typology of figure 4.4. Despite limited time and resources throughout the project, mid-term evaluations were implemented, and the conclusions could be fed back to the management process (control loop). All sub case studies were labelled with two intensity charts, that clearly displayed an evolution of participatory activities within each of the cases.

This is a significant step forward in the endeavour to develop a standardised evaluation framework. However, it is not only a result of the uniform set of intensity criteria, but also because of the newly developed CMO framework (chapter 3). CMO enables scientists and managers to use a uniform set of methods and evaluation criteria, that enables its appropriate application. However, the strict separation of the methodology from the local constraints on the one hand, and the objectives of the participatory process on the other, allows for sufficient flexibility in the application and give way for adaptive participatory water management. 
CHAPTER 6

A selection procedure for participatory process design

\subsection{Introduction}

In chapter 3 a new methodological scheme (CMO) for participatory management is developed and discussed. Within this scheme, local constraints, process objectives and methodological requirements are viewed in a holistic way. However, it was necessary to make a clear distinction between these issues. Furthermore, chapter 4 discusses a method to monitor and evaluate participatory processes in order to operationalise the CMO scheme to increase effectiveness and efficiency of a participatory process. Moreover, the newly developed methodology was successfully tested in five different case studies proving the case-independent applicability of the new methods. Incidentally, a great deal of capacity building was accomplished. Water managers acquainted with new participatory methods, as well as scientists had the opportunity to gather practical knowledge in the field. However, how exactly will water managers apply the CMO scheme when they want to implement participatory processes in their work, but are not supported by scientists, and do not have prior knowledge of participatory methods? Indeed, the TRUST/TGIII experience confirmed that the majority of water managers involved in the case studies have limited knowledge and experience in participatory management.

Throughout their field work, water managers repeatedly mentioned the need for a 'cookbook' with tangible guidelines for the management of stakeholder and public participation. This guidance should be implementable without the support of scientists. A 'cookbook' is possible, but this would contradict the concept of adaptive water resources management, since such a guidebook lacks flexibility. For this reason this chapter introduces an approach for narrowing down the choice of methods for a given participatory process, and aligns these methods according in a schedule. The principle elements of this approach are: 
1. the CMO scheme (chapter 3) providing the methodological cornerstones;

2. the COPIR approach (chapter 4), a method to control and review the design of a participatory plan;

3. alignment of methods with a policy process. The terms and notions introduced in chapter 3 are now assigned to a general process scheme; and

4. a decision tree approach, used in operational research, artificial intelligence, data mining and machine learning, in order to select and synthesise participatory methods potentially applicable to the given local constraints and objectives.

A brief introduction to the decision tree method is provided in this chapter. Furthermore, the translation of the CMO approach into a process-oriented scheme is described. Thereafter, the application of a decision tree and the alignment approach for is demonstrated for one case study of the TRUST project.

\subsection{Decision trees}

Decision trees (DT) are both abstract representations and classification algorithms of a decision process that may have several branches (of decisions) under particular conditions. DT may, for instance, be represented as acyclic digraphs (an alignment of nodes and arcs) or a set of contingency tables containing attribute/value pairs of given ontologies. Classification algorithms may, for instance, be mathematical expressions or Boolean classification. The classification along the tree is structured in the form of attribute levels from the 'root attributes' to the required exterior branches (Mitchell, 1997; S.J.Russel and Norvig, 2003; Winston, 1992). The specific goal of a decision tree for participatory management is the generation of an array of methods that are in their composition an appropriate choice to efficiently achieve the desired goals of a given process. In this case the classification attributes are: effectiveness, appropriateness and efficiency (see chapter 3 and 4).

\subsection{The alignment of methods}

Before employing a decision tree for selecting methods, a structure for the methods alignment had to be developed. The CMO scheme provides a structural overview of methods in a hierarchical way. This supports the understanding of the coherence among methodological terms and concepts. However, the CMO scheme does not provide guidance on how methods can be aligned along a timeline. Yet, the goal is to provide an approach for designing a participatory plan as applied in the case studies (chapter 5). Consequently, the next step is to provide a scheme enabling water managers with no particular knowledge of participatory methods to design a participatory plan without the help of experts.

A simplified graphical representation of the CMO scheme is depicted in figure 6.1. In Chapter 3 it was proposed that the methodological structure of participatory methods may be distinguished in two levels: (1) the macro structure (levels and classes of participation) that refer to the objectives of a local project, and (2) the micro structure where 
the context (constraints) of a local project refers to implementation criteria. The entirety of that structure is called the CMO scheme. A simplified graphical representation of the CMO scheme is depicted in figure 6.1, indicating that the identification of objectives as well as constraints provide criteria for the design of a participatory plan.

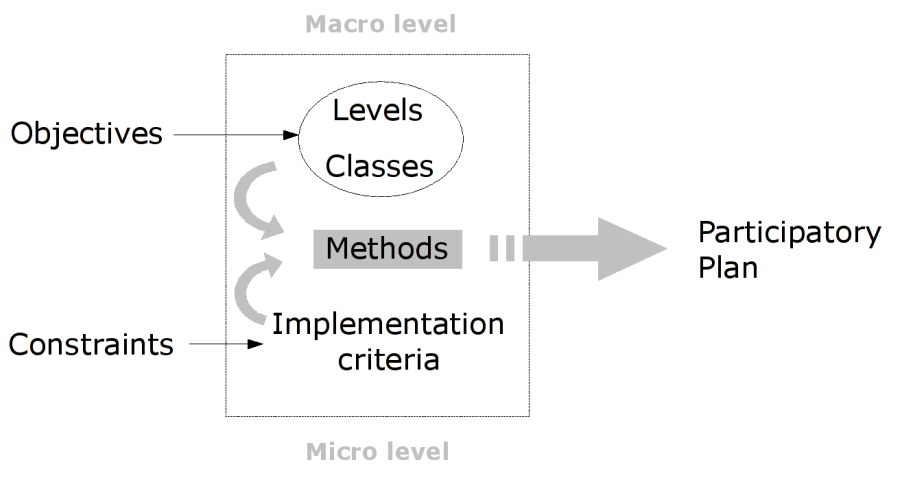

Figure 6.1: The constraints - method - objectives framework (CMO)

Both constraints and objectives of each individual water management project introduce variables that cannot be assigned to any other project. However, with the CMO scheme the variables can be employed in an adaptive and integrated way as required by the WFD (EU, 2000) as well as the guidance documents (European Commission, 2003). The application of this scheme to the design a participatory process is introduced in the following section.

The definition of terms and notions (section 3.3) provides descriptions of the concepts, but does not introduce or only partially (see section 3.5) introduces a consecutive alignment of concepts. This structure is however vital for the application of methods in a local policy process. For the water manager the question remains: what alignment of tools and methods is most effective and efficient for achieving the goals of a participatory process as well as the entire investment project? Therefore, knowledge of the effects of participatory methods in water resource management is important.

\subsubsection{Participatory management}

Although, the methodological structure must be employed throughout a policy process, the requirements for methods are changing throughout a policy process as the composition of the stakeholder group, the available knowledge, the identified problems and stakeholder perspectives of these problems might change. Moreover, it is not only participatory activities that contribute to the policy process, but also the activities of experts. Examples of the combination of participatory methods with expert methods are provided in section 2.4.3. Both examples (MCA and ABM) require sophisticated algorithms to model systems with multiple criteria, problems or processes from the perspective of several actors in the policy process. The parameter 'perspectives' requires empirical data that are usually collected with the help of social science methods such as 
interviews or surveys. However, the interrelationship of analytical modelling methods with participatory methods is more intense, if actors may participate in the selection of criteria, problems or even processes. The highest level of interaction, however, is achieved when model results are discussed between experts and involved lay people, and functions similar to a validation process. The interrelationship of expert with participatory methods on various levels of interaction among actors in a policy process may be seen in parallel to the levels of participation. Whereas survey and interview techniques take place on the consultation level, interactive model validation is active involvement and can reach the level of social learning.

In order to manage all aspects of a policy process a new term participatory management is proposed here as a generic concept comprising all activities that analyse and manage the interaction among the participant types that are involved as defined in section 3.3.1. Participatory management combines participatory methods with expert methods in the management of processes that include human-environment interaction, and normally endeavour to manage the transition from the current state $\left(W_{1}\right)$ of a given situation to a desired state $\left(W_{2}\right)$. Participatory management is considered an approach that is equal in its level of sophistication to that of engineering and environmental impact assessment.

Furthermore, the analysis of technical and environmental (physical) aspects of a given system can rely on comparatively static ${ }^{1}$ and known parameters. The drivers for changes within include new information and consultation throughout the process that may trigger modifications in the individual perspectives of the actors. In other words, the beliefs, and as a consequence, goals of involved individuals and organisations may change. This implies that participatory management involves the iterative interaction of the various participants throughout the course of a water resources management project, and is labelled as core process in section 6.3.2. Consequently, participatory management requires the ongoing processing of new information about the goals and beliefs of the participating social entities, and must respond with appropriate methods until a solution or measures have been developed. A thoughtful selection of methods as well as elaborate participatory planning are therefore essential for effective participatory management.

Assuming the application of adaptive water management including a polycentric approach to policy making (see section 2.3 .2 and 2.3.2), the quality of participatory management is a significant parameter for the adaptive capacity of a policy making system. In other words, the lower the effectiveness and efficiency of a management approach, the higher the vulnerability of the actor-environment system. An example to illustrate this is the stakeholder in the POM case study (see section 5.3.3) who went to court, and delayed the decision process for more than half a year. The case study description demonstrated that a dialogue with that stakeholder would have prevented the delay caused by the judicial process and the associated costs. Hence, a management error was the reason for a delay in the process, with increased costs as a consequence.

${ }^{1}$ Static must be seen as a relative term. Whereas stakeholder perspectives may suddenly change within days or hours, physical parameters of the lithosphere, pedosphere, biosphere, and hydrosphere do not change as quickly except as a result of catastrophic events. 


\subsubsection{First alignment level: phases}

Table 6.1 provides a simplified overview of the relationship between processes and methods throughout a policy process.

Table 6.1: A framework for the design of a participatory process including phases (columns), tasks (bold), methods (normal font) and goals (circled numbers)

\begin{tabular}{|c|c|c|c|}
\hline PREPARATION & Inception & Core phase & Decision \\
\hline $\begin{array}{l}\text { problem analysis: } \\
\text { literature study, field } \\
\text { study, expert methods } \\
\text { (models) (1)(2) } \\
\text { stakeholder analysis: } \\
\text { literature and media } \\
\text { recherche, survey, } \\
\text { interviews (1)(5)6(7) } \\
\text { resource allocation }{ }^{a} \text { : } \\
\text { expert methods } \\
\text { (3) } \\
\text { agenda setting (draft) } \\
\text { communication plan: } \\
\text { survey, interviews } \\
\text { (1)(2)(5) } 7 \text { ) }\end{array}$ & $\begin{array}{l}\text { publication: public } \\
\text { inform. provision, fora, } \\
\text { events, meetings } \\
\text { (1)(2)(5)(6)(7) } \\
\text { stakeholder analysis: } \\
\text { interviews, meetings } \\
\text { (1)(5)(6)(7) } \\
\text { resource allocation: } \\
\text { co-financing } \\
\text { (3) } \\
\text { agenda setting (final) } \\
\text { monitoring and } \\
\text { evaluation: } \\
\text { planning sheet } \\
\text { (1)(5)(6)(8) } \\
\text { participatory plan: } \\
\text { (final) } \\
\text { (1)(2)(4)(5)(7) } \\
\text { knowledge elicitation: } \\
\text { interviews, surveys, } \\
\text { events (1)(2)(4)(6) (7) }\end{array}$ & $\begin{array}{l}\text { monitoring and evalu- } \\
\text { ation: } \\
\text { interviews, intensity } \\
\text { analysis } \\
\text { (1)(5)(6)(8) } \\
\text { recruiting volunteers: } \\
\text { (3)(4)(5)(7) }\end{array}$ & $\begin{array}{l}\text { monitoring and evalu- } \\
\text { ation: } \\
\text { interviews, intensity } \\
\text { analysis } \\
\text { (1)5(6) (8) }\end{array}$ \\
\hline
\end{tabular}

Goals: (1) knowledge for decision-making; (2) development of win-win plans; (3) co-financing; (4) long term use and maintenance; (5) public awareness; (6) satisfaction of stakeholders; (7) increased involvement; (8) empowerment; (9) social learning

${ }^{a}$ The analysis of stakeholders, problems and available resources together is referred to context analysis

The process of participatory management is divided in four phases:

1. Preparation: managers prepare a participatory process, that includes a context analysis, a stakeholder analysis, a problem analysis and the compilation of information. In this phase primarily expert methods such as literature and media review, models and data-driven methods are applied. Stakeholders and the public are not yet involved;

2. Inception: this includes dissemination of information, knowledge elicitation including stakeholder views on existing problems, and detecting new problems. The knowledge of the managers and experts is integrated with stakeholder perspectives and interests. In the end all relevant issues and stakeholders including their individual perspectives should be identified; 
3. Core process: this is the intrinsic participatory process, and at the same time the core of an adaptive water management system, that represents the iterative interaction of authorities, stakeholders and experts in order to develop a solution for implementing a policy. As with all adaptive systems learning is the central notion within this phase (see section 2.3.2 and 2.2.1).

4. Implementation: a decision is made. However, the implementation of measures may include stakeholders.

Phases of a participatory process are discussed in Pahl-Wostl (2002), where the phases agenda setting, shaping the issue and implementation are used, but levels and methods of participation are not consistently assigned to these phases.

\subsubsection{Second alignment level: Tasks}

In table 6.1 participatory management includes expert methods as well as participatory methods throughout the "lifecycle of an environmental problem" (Pahl-Wostl, 2002, 5). Expert methods are required for (1) stakeholder analysis, problem analysis, compiling and presenting information as well as supporting consultation, and (2) supporting social learning processes with methods such as modelling, simulation and scenario building. Examples of the combination of expert methods with participatory methods are provided in section 2.4.3. In order to capture the combination of the two types of methods, phases of participatory management must be further subdivided. For this reason the concept of tasks is introduced. Tasks may be characterised as following:

- Tasks are an operationalisation of the integrative character of participatory methods in integrated assessments (see section 2.4.2).

- From a management point of view, tasks are necessary activities of water managers. Hence, tasks may either consist of a combination of several methods or a single method. Table 6.1 summarises the tasks within phases of participatory management.

- Tasks may be seen as sub-goals of a decision process or steps towards the achievement of one or several goals;

- Tasks (as well as phases) indicate the progress of a decision making process.

The following list above indicates tasks for the water managers as well as participatory methods that are applicable in one or more specific phases of a water management project.

1. preparation phase: all preparation and analysis prior to the interaction with the public and stakeholders must be accomplished in this phase including an analysis of potential problems and conflicts, the allocation of resources, the co-ordination with the overall planning effort, and hence an exchange with engineers, ecologists and other experts who are committed to the project; 
2. inception phase: introducing the public and stakeholders to the planning objectives and problems, envisaged solutions and measures including possible impacts on the social and physical environment, knowledge elicitation;

3. core phase: additional and deeper information provision, education, detecting planning design errors and possible side effects in interaction with stakeholders and the public, education, social learning, scenario building, model validation, finding consensus or compromise, adjusting planning goals.;

4. decision phase: recruiting volunteers

The list above indicates a number of tasks for the water managers as well as participatory methods that are applicable in one or more specific phases of a water management project.

Table 6.1 displays the management scheme as a goal-oriented process indicating what tasks and associated methods may be applied in what phase of the participatory process (table column). The general process direction is presented from left to right, and within the phases (with exceptions) from top to bottom. The circled numbers below tasks and methods indicate which goal can be achieved by applying a particular task. A number of tasks can or must be accomplished within a phase or a given time span: context analysis, resource allocation (planned resources), agenda draft, communication plan and the first draft of a participatory plan must be finalised within the preparation phase; a comprehensive and transparent publication of the planning effort must be started in the inception phase, well before representatives of the planning administration initiate a dialogue with stakeholders and the public. Most tasks such as problem analysis, resource allocation, agenda setting, participatory planning and stakeholder analysis must be reviewed and finalised in the inception phase.

Monitoring and evaluation must be started as early as possible, but at the latest as soon as interaction with stakeholders and the public begins, in order to provide the managers with flexibility and an indication of when to modify a participatory process. Knowledge elicitation must be finalised in the inception phase. This provides participatory managers with the perspectives and views of all involved groups and individuals as a basis for further analysis and application of appropriate methods.

Of course, dialogue with stakeholders and the public may start as early as the initiation of the entire process, and any information should be used to support the planning procedure. A deeper analysis of stakeholder and public opinions, however, cannot be accomplished before a comprehensive dialogue takes place with all involved parties. This analysis is a significant prerequisite for an intense social learning process. Sophisticated methods such as models and scenario building should not be employed before a sound analysis of perspectives and views takes place, and only if the complexity of human-environment interaction requires such models. Furthermore, higher-level methods can only be used in interaction with stakeholders (see section 2.3.2 and 2.4.3). For this reason, dialogue, learning and response (within the core phase) is not a linear process, but iterative (Pahl-Wostl, 2008).

The guidance document of the WFD (European Commission, 2003) advises the compulsory application of information supply and consultation, whereas active involve- 
ment is encouraged (see figure 3.3). The application of phases and tasks builds upon this recommendation. In general, the level of obligation to apply tasks declines with progressing phases of a policy process. Whereas preparation and inception are inevitable, social learning processes are not required if all involved stakeholders agree with the proposed policy. In other cases such as demonstrated in section 5.3.3 simply meeting a stakeholder with a controversial perspective, can resolve a potential conflict. The design of the alignment scheme is consistent with the CMO scheme as well as it is the operationalisation of the principle of goal-oriented management. If controversial discussions involving a heterogeneous group of stakeholders take place, social learning processes and iterative interaction among stakeholders, experts and policy makers are strongly advised prior to implementing a policy. This approach partially contradicts the policy life-cycle of Pahl-Wostl (2008). As figure 2.3.2 indicates, goals setting, policy formulation, policy implementation, monitoring and evaluation, as well as state/policy assessment are part of an iterative policy process that should be repeated until a solution has been found. The alignment scheme modifies this policy cycle:

1. The experience of the TRUST project reveals that monitoring and evaluation at every iteration is barely feasible, if limited resources of (local) water management projects are limited;

2. Goal-setting of a participative process must be finalised prior to an iterative process, which is represented by the core phase of the alignment scheme. In particular, process goals (participatory plan) should be determined before entering an iterative process; and

3. Policy implementation in the alignment scheme (decision) is a step that should result from a policy cycle instead of being part of it.

In water management projects with a high potential for conflicts and a heterogeneous stakeholder structure, redundant process steps result in discontent, and may compromise the entire policy process as demonstrated in the case study of $\mathrm{PH}$ (see section 5.3.5).

\subsection{Selecting participatory methods with the help of a decision tree}

The purpose of the decision tree is to select methods according to both the goals and the constraints of a local project. The aim is to exclude methods that are not suitable for the case in question. Consequently, the remaining set of methods can be assigned to the two alignment levels, tasks and phases of a participatory project management. The decision tree consists of two types of contingency tables:

1. the classes of methods - objectives table based upon the methodological macrostructure of the CMO scheme examines the objectives of a case study or project, and excludes those methods that are not appropriate. The remaining set of methods enters the 'constraints tables'; and

2. 'constraints tables' may be used to exclude more methods that do not comply with 'the number of participants', 'required soft skills' and 'required expertise'. 
The constraints tables are based upon the implementation criteria as discussed in section 3.6.

The selection among the remaining methods may be based upon available financial resources of a project. If this is the case, no more contingency tables should be applied. For this reason an individual assessment must be completed. The water manager has the opportunity at this stage to supply missing soft skills or recruit expertise with financial resources that may be available. In other words, if required and if the financial resources permit, experts such as modellers, moderators or mediators may be employed.

Financial resources may be assessed with the use of look-up tables as introduced in section 3.4. These tables together with short descriptions of the respective participatory method are compiled in a catalogue of participatory methods, based upon a literature search and first published in Hare and Krywkow (2005, 23 - 49). The indicators for number of participants, expertise and moderator skills as applied in this chapter are drawn from this catalogue. An examples of catalogue items are provided in appendix B.

The second function of these look-up tables is to align the remaining methods in table 6.1. Yet, the remaining methods of the decision tree selection can be assigned to tasks in table 6.1. The result is a participatory plan that incorporates the local constraints as well as the objectives of a local project, supported by participatory methods that are a result of an 'optimisation' process. In other words, all known participatory methods have been matched with the local objectives and constraints. The following sections present contingency tables that are based upon the data that have been found throughout the case study effort in this research.

\subsubsection{Contingency table 1: Matching classes of participatory methods with ob- jectives}

Table 6.2 is an adaption of table 3.1 with the set of goals that have been identified throughout the case study collaboration with all involved water managers (see table 5.2). The goals that have been found in the literature, and used in table 3.1 are no longer in use.

Furthermore, the classes that have been applied in each of the case studies are listed in the second part of table 6.2. A simple frequency of occurrence is added to each of the columns. The comparison of both entries results in a significant 'mismatch' of the classes between the potentially applicable methods (first half of the table) and the methods that have actually been applied in the case studies (second half of the table). It is notable that only the British partners used involvement campaigns. Reasons for this were identified in the TGIII workshops where Dutch and Belgium practitioners stated that the use of volunteers is not a standard approach in water management projects. Citizens of these countries rely entirely on the authorities trusting that their tax contribution is invested in these projects. The main reason for the application of education, interviews, fora and workshops is the fact that these classes of methods require both a higher level of expertise and more resources than other classes of methods. The TRUST partners were either not willing or did not have the capacity to employ methods from these classes. The following selection procedure is simulated with the data of the partner PNH (see section 5.3.4) to select from the pool of methods as introduced 
Table 6.2: Matching goals to classes of participatory methods (adapted from table 5.2)

\begin{tabular}{|c|c|c|c|c|c|c|c|c|c|}
\hline & 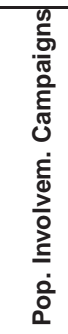 & $\begin{array}{l}\text { 흠 } \\
\frac{0}{3} \\
\text { 은 } \\
\text { 을 } \\
\text { 흘 }\end{array}$ & 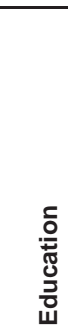 & 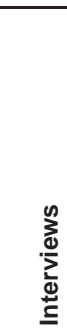 & 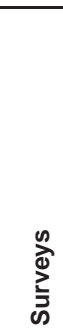 & 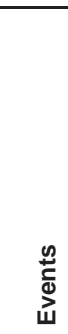 & 뜡 & 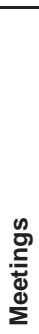 & 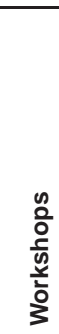 \\
\hline knowledge for decision making & & $\sqrt{ }$ & $\sqrt{ }$ & $\sqrt{ }$ & $\sqrt{ }$ & & $\sqrt{ }$ & $\sqrt{ }$ & $\overline{\sqrt{ }}$ \\
\hline development of win-win plans & & & & $\sqrt{ }$ & $\sqrt{ }$ & & $\sqrt{ }$ & $\sqrt{ }$ & $\sqrt{ }$ \\
\hline co-financing & $\sqrt{ }$ & & & & & $\sqrt{ }$ & $\sqrt{ }$ & $\sqrt{ }$ & \\
\hline long-term use and maintenance & $\sqrt{ }$ & $\sqrt{ }$ & $\sqrt{ }$ & $\sqrt{ }$ & $\sqrt{ }$ & $\sqrt{ }$ & $\sqrt{ }$ & $\sqrt{ }$ & $\sqrt{ }$ \\
\hline public awareness & $\sqrt{ }$ & $\sqrt{ }$ & & & & $\sqrt{ }$ & $\sqrt{ }$ & $\sqrt{ }$ & \\
\hline satisfaction of stakeholders & $\sqrt{ }$ & $\sqrt{ }$ & & & & $\sqrt{ }$ & $\sqrt{ }$ & $\sqrt{ }$ & \\
\hline increased involvement & $\sqrt{ }$ & $\sqrt{ }$ & $\sqrt{ }$ & & & & $\sqrt{ }$ & $\sqrt{ }$ & $\sqrt{ }$ \\
\hline empowerment & $\sqrt{ }$ & & $\sqrt{ }$ & & & & $\sqrt{ }$ & $\sqrt{ }$ & $\sqrt{ }$ \\
\hline social learning & $\sqrt{ }$ & & & & & $\sqrt{ }$ & $\sqrt{ }$ & $\sqrt{ }$ & $\sqrt{ }$ \\
\hline occurrence $[x / 9]$ & 0.77 & 0.55 & 0.55 & 0.33 & 0.33 & 0.55 & 0.33 & 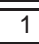 & 0.55 \\
\hline \multicolumn{10}{|l|}{ Applied in the case studies } \\
\hline BW & $\sqrt{ }$ & $\sqrt{ }$ & $\sqrt{ }$ & & $\sqrt{ }$ & $\sqrt{ }$ & & $\sqrt{ }$ & \\
\hline GCC & $\sqrt{ }$ & $\sqrt{ }$ & & & $\sqrt{ }$ & $\sqrt{ }$ & & $\sqrt{ }$ & $\sqrt{ }$ \\
\hline POM & & $\sqrt{ }$ & & & $\sqrt{ }$ & $\sqrt{ }$ & & $\sqrt{ }$ & \\
\hline HHSK & & $\sqrt{ }$ & & & & $\sqrt{ }$ & & $\sqrt{ }$ & \\
\hline $\mathrm{PNH}$ & & $\sqrt{ }$ & & & & & & $\sqrt{ }$ & \\
\hline occurrence $[y / 5]$ & 0.4 & 1 & 0.2 & 0 & 0.6 & 0.8 & 0 & 1 & 0.2 \\
\hline
\end{tabular}

in section 3.4.1. Since all classes of methods are potentially suitable to achieve one or more of the designated goals (table 5.2), the entire pool of methods enters the next contingency table.

\subsubsection{Contingency table 2: Number of participants}

Table 6.3 matches all available participatory methods with the number of participants in a process. Throughout a participatory process, various methods may be used that can have different numbers of participants.

PNH has engaged the public as well as stakeholders. As a consequence, methods for a large group of individuals may be selected in a limited way. However, the representatives of the relevant stakeholders are a group of less than 20 individuals. The following methods might be selected:

- Information provision: websites are standard information provision tools. Flyers and media advertisements can reach the neighbourhood in the vicinity of the recreation site.

- Fora: Internet forum, newsletters, radio forum - all methods have the potential for an exchange of information and perspectives; 
Table 6.3: Contingency table 2: number of participant and appropriate methods, adapted from Hare and Krywkow $(2005,20)$

\begin{tabular}{|c|c|c|c|}
\hline $\begin{array}{l}\text { Classes of meth- } \\
\text { ods }\end{array}$ & Large group $(>50)$ & $\begin{array}{l}\text { Mid-size group }(20- \\
50)\end{array}$ & Small group (>20) \\
\hline $\begin{array}{l}\text { Information pro- } \\
\text { vision }\end{array}$ & $\begin{array}{l}\text { websites, flyers, media ad- } \\
\text { vertisements }\end{array}$ & websites & \\
\hline Fora & $\begin{array}{l}\text { Internet forum, newsletters, } \\
\text { radio forum }\end{array}$ & Internet forum & \\
\hline Interviews & & $\begin{array}{l}\text { cognitive mapping, in- } \\
\text { terviews }\end{array}$ & $\begin{array}{l}\text { card-sorting method, cog- } \\
\text { nitive mapping, interviews }\end{array}$ \\
\hline Events & $\begin{array}{l}\text { open days, road show, } \\
\text { ideas competition }\end{array}$ & $\begin{array}{l}\text { field trips, school visit, } \\
\text { ideas competition }\end{array}$ & \\
\hline $\begin{array}{l}\text { Popular involve- } \\
\text { ment campaigns }\end{array}$ & sponsorship/partnership, & partnership/sponsorship & \\
\hline Education & lectures & lectures, course work & $\begin{array}{l}\text { lectures, course work, } \\
\text { workshops }\end{array}$ \\
\hline Surveys & $\begin{array}{l}\text { postal surveys, photo sur- } \\
\text { vey }\end{array}$ & $\begin{array}{l}\text { telephone/postal sur- } \\
\text { veys, focus groups, } \\
\text { photo survey }\end{array}$ & $\begin{array}{l}\text { focus groups, Delphi } \\
\text { method }\end{array}$ \\
\hline Meetings & $\begin{array}{l}\text { large group response ex- } \\
\text { ercises/open space, open } \\
\text { public meetings }\end{array}$ & & \\
\hline Workshops & $\begin{array}{l}\text { multi-criteria analysis } \\
(\mathrm{MCA}),\end{array}$ & $\begin{array}{l}\text { multi-criteria analysis } \\
\text { (MCA), }\end{array}$ & $\begin{array}{l}\text { multi-criteria analysis } \\
\text { (MCA), group model build- } \\
\text { ing, simulation, role playing } \\
\text { games, co-modelling }\end{array}$ \\
\hline
\end{tabular}

- Interviews: cognitive mapping, interviews and card sorting method may be used for a small group of stakeholders;

- Events: open days, road shows, ideas competitions, field trips, school visits are all appropriate methods. Regular field trips can be especially useful in informing, consulting and educating interested citizens as well as stakeholders.

- Popular involvement campaigns: sponsorship/partnership are appropriate methods;

- Education: lectures, course work, workshops are methods that could be applied;

- Surveys: postal surveys, photo surveys, telephone surveys, focus groups, Delphi method can be applied;

- Meetings: large group response exercises/open space could be used. However, these methods should not be used for the public (local residents as well as users and lobby groups), since the chance of equitably balancing such a large group of people is low. Open public meetings are more appropriate;

- Workshops: multi-criteria analysis (MCA), group model building, simulation, role playing games, co-modelling; all these workshop methods can be used with stakeholders. 
After applying the number of participants as a selection criterion 'large group response exercises/open space' was excluded from the selection.

\subsubsection{Contingency table 3: required moderator skills}

Table 6.4 indicates the degree of moderator skills that methods require to be successfully implemented in a process. Methods such as Internet fora, interviews, ideas competition, and courses, require some degree of moderation. However, these methods are not as influential as, for instance, a workshop or a role playing game.

Table 6.4: Contingency table 3: required moderator skills

\begin{tabular}{|l|l|}
\hline Moderator skills & Methods \\
\hline \hline high & $\begin{array}{l}\text { radio fora, cognitive mapping, card-sorting method, workshops, focus groups, Del- } \\
\text { phi method, large group response exercises/open space, group model building, role } \\
\text { playing games }\end{array}$ \\
\hline low & $\begin{array}{l}\text { Internet forum, interviews, ideas competition, courses, simulation, co-modelling, } \\
\text { public meetings }\end{array}$ \\
\hline not required & $\begin{array}{l}\text { websites, flyers, media advertisements, newsletters, open days, road show, field } \\
\text { trips, school visit, sponsorship/partnership, lectures, mail surveys, photo survey, } \\
\text { multi-criteria analysis (MCA) }\end{array}$ \\
\hline
\end{tabular}

PNH did not have a moderator who was capable of leading workshops requiring high moderator skills. However, the practitioners of PNH have experience with public as well as stakeholder meetings. As a consequence, all methods that require high moderator skills have to be excluded from the selection for all partners. The remaining methods are:

- Information provision: websites, flyers and media advertisements;

- Fora: Internet forum, newsletters;

- Interviews: interviews;

- Events: open days, road shows, ideas competitions, field trips, school visits;

- Popular involvement campaigns: sponsorship/partnership;

- Education: lectures, course work;

- Surveys: postal surveys, telephone surveys, photo surveys;

- Meetings: open public meetings;

- Workshops: multi-criteria analysis (MCA), simulation, co-modelling.

PNH does not have an 'in-house' moderator. However, a professional moderator can be hired, if the financial resources are available. This must be decided when reviewing the financial resources. 


\subsubsection{Contingency table 4: Required expertise}

Expertise is indicated as level of application skills (see table 3.4). This means that particular methods require well-trained experts that are able to appropriately implement those methods in a participatory process. Examples of sophisticated methods are: multicriteria analysis, co-modelling or scenario building (see table 6.5). The advantage of these methods is that they may enable the participants to understand complex interrelationships. However, there is also the possibility that (1) incorrect data are used, (2) correct data are used incorrectly, (3) an inappropriate method is used or (4) results are incorrectly interpreted (see section 2.1). The consequences can be fatal to the process, which has been demonstrated in practice. For this reason, sophisticated methods have been chosen with care and should be applied by those with adequate expertise.

Table 6.5: Contingency table 4: Expertise (application skills)

\begin{tabular}{|l|l|}
\hline $\begin{array}{l}\text { Level of applica- } \\
\text { tion skills }\end{array}$ & Methods \\
\hline \hline high & $\begin{array}{l}\text { cognitive mapping, card-sorting method, workshops, focus groups, Delphi } \\
\text { method, group model-building, simulation, role-playing games, co-modelling, In- } \\
\text { ternet fora, courses, lectures, multi-criteria analysis (MCA) }\end{array}$ \\
\hline \multirow{2}{*}{ low } & $\begin{array}{l}\text { radio fora, large group response exercises/open space, public meetings, inter- } \\
\text { views, ideas competition, websites, flyers, media advertisements, newsletters, } \\
\text { open days, road show, field trips, school visit, sponsorship/partnership, mail sur- } \\
\text { veys, photo survey }\end{array}$ \\
\hline
\end{tabular}

PNH does not have experience with models, simulations and similar expert methods that are applied in conjunction with participatory methods. Hence, a high level of application skills is not available. The remaining methods are:

- Information provision: websites, flyers and media advertisements;

- Fora: Internet forum, newsletters;

- Interviews: interviews;

- Events: open days, road show, ideas competition, field trips, school visits;

- Popular involvement campaigns: sponsorship/partnership;

- Education: lectures, course work;

- Surveys: postal survey, telephone survey, photo survey;

- Meetings: open public meetings;

- Workshops: n/a 


\subsubsection{Cost/effort share}

The number of participants, moderator skills and expertise are constant attributes that can be assigned to any participatory method. It is a relatively straightforward exercise to design contingency tables with these attributes. However, a look-up table as table 3.5 indicates another attribute: cost/effort share. This attribute is not appropriate for inclusion as a contingency table because of its volatility. There are no comparable and fixed prices for staff, equipment and miscellaneous costs. Upon completing a decision tree, the water manager has to refer to the look-up tables and balance the non-monetary estimation and distribution of costs as listed in the relevant tables with the available budget. The remaining methods still have the potential to achieve all goals as indicated in table 5.2. In view of the limited financial resources of PNH, some 'redundant' methods may be removed, such as road show, ideas competition, telephone surveys and photo surveys.

In section 5.3.5, PNH is described as a project with a complex set of issues, a heterogeneous group of stakeholder and a complicated administrative structure. Given that the goals satisfaction of stakeholders, increased involvement and social learning were not achieved, expertise for the realisation of more sophisticated methods in conjunction with stakeholder participation such as MCA or group model building should have been recruited.

\subsection{Synthesis of alignment of methods with the decision tree}

The available methodology to align participatory methods to a management scheme is presented in table 6.1. The remaining methods of PNH may be aligned as follows:

\section{Preparation phase}

- Problem analysis: literature study, field study

- Stakeholder analysis: literature study, media study, field study

- Resource allocation: financial review

- Agenda setting (draft)

- Communication plan: literature study, media study, (telephone) interviews with consortium partners

- Participatory plan (draft)

\section{Inception phase}

- Publication: websites, flyers and media advertisements

- Stakeholder analysis: field study, postal survey, public meeting

- Resource allocation: postal survey, public meeting

- Agenda setting (final)

- Monitoring and evaluation: planning sheet, interviews

- Participatory plan (final) 
- Knowledge elicitation: interviews, postal survey, public meeting

\section{Core phase}

- Education: lecture, field trip

- Social learning: meetings, (MCA)

- Monitoring and evaluation: interviews (stakeholder response), intensity analysis

- Recruiting volunteers: sponsorship/partnership

\section{Decision}

- Monitoring and evaluation: results of intensity analysis

Several tasks may refer to the same methods: interviews may be designed for stakeholder analysis, resource allocation (co-financing), knowledge elicitation and monitoring and evaluation at the same time; a meeting may be used for stakeholder analysis, knowledge elicitation and resource allocation; and surveys can be used for resource allocation, knowledge elicitation, and monitoring and evaluation. The multi-purpose application of methods depends on a well-coordinated planning and preparation of activities resulting in a highly efficient use of methods.

The comparison of the simulated design of a participatory plan for PNH with the methods actually applied as presented in table 5.12 demonstrates that the potential of applicable methods according to the alignment scheme/decision tree was significantly higher than the applied methods. Even with a reduced set of methods, assuming scarce resources for participation, effectiveness could have been greater. The failure in reaching the goals of 'social learning' and 'increased involvement' lies in the shortage of appropriate methods throughout the stakeholder participation process. The dissatisfaction of stakeholders is also an indicator of the poor performance of the applied methods, especially the meetings.

\subsection{Conclusions}

The newly introduced decision procedure, consisting of an alignment scheme and a decision tree, represents a continuation of the methodology that has been developed in chapter 3 and 4 . However, it is not a method that has been tested in the case studies such as CMO and COPIR, but is a result of the case study work. When implementing the example of PNH in the decision scheme, it was only possible to use available material that was developed for testing CMO and COPIR. For a suitable test of the decision procedure some of the interview questions as well as the workshop topics should have been fitted to the requirements of the decision scheme presented in this chapter. For example, the simulated case study result cannot provide a direct answer to the question of whether or not moderators or experts were available and/or were intended to be recruited nor whether sufficient financial resource were available to hire experts.

Nevertheless, the case study material permitted a simple demonstration. Elements of this decision procedure have already been developed in Hare and Krywkow (2005). 
The most innovative part was the 'catalogue of participatory methods' including lookup tables for the estimation of decision attributes. Furthermore, Hare and Krywkow $(2005$, p. 16 - 22) is a first attempt in the development of a procedure for selecting participatory methods. However, it did not apply the two concepts 'alignment' and 'decision tree'.

The development of this decision procedure is a balancing act between strict guidelines as required by the water managers of the case studies, and the variable local context of each particular project. More work must be carried out to: (1) test the robustness of the method in the field, (2) complete the current set of look-up tables, and (3) provide a tool in the form of software for an automated application of the decision framework. The decision framework as discussed in this chapter can provide support for water managers to improve their participatory management, and help to explore new methods without an extended review of the relevant literature including the variety of available guidebooks. This can be a significant step forward to bridge the gap between science and practice by transferring more of the valuable scientific work of many researchers to the practise of water management. 
CHAPTER 7

Conclusions and prospects

Goal-oriented management is a central concept in the research undertaken presented in this thesis. It was driven by the search for effectiveness in participatory management as well as for more rigour in the application of scientific methods. Goal-oriented management is introduced to provide a problem-solving approach that leads to more effective implementation of public and stakeholder participation.

Participatory methods in environmental decision making may be seen as part of the interdisciplinary methodological framework of Integrated Environmental Assessment, that emerged from the need to explore complex and real-world processes in a holistic way. Normativity, uncertainty and subjectivity are deliberately included in the research agenda. These notions enable scientists to model complex interrelationships, and explore large scale phenomena and their effects on small-scale systems and human beings. This is of importance for policy processes and to the policy makers who require reliable and comprehensible results from the scientific world. Participatory methods can play a key role in the discourse among scientists, lay people and policy makers, by translating scientific insights into information that is appropriate for decision processes in the environmental policy arena.

The entire research upon which this thesis is based is characterised by its dualism and a search for balance among phenomena. This includes but is not limited to: science and management, human and environment, rigour and flexibility, large-scale events and small scale impacts, constraints and objectives, expert knowledge and lay knowledge, participatory methods and expert methods, strict guidelines and local contexts, alignment scheme and decision tree, macro methods and micro methods, levels and classes, and phases and tasks. On the one hand, more rigour in the methodology is required to increase scientific validity as well as the reliability of models and results. On the other hand, mechanistic approaches have limited applicability and are difficult to trans- 
fer between case studies. Consequently, Dale (2001) postulates a dualistic thinking to prevent the decoupling of related phenomena and ontologies. Decoupling may result in aberrations that obscure the view of the origin of problems, and moreover the quest for problem solution. The contemporary tendency to employ technical solutions as a panacea for a wide range of (environmental) problems is just one example of this phenomenon.

The drawbacks of this type of research include 'messy problems', inevitable uncertainty, complex interrelationships, wicked causal networks and value-laden concepts. Moreover, the mindset of the average occidental earthling craves instant technical solutions, causal chains, freedom of markets, a bargain, and 'bling-bling mobile phones'. The questions underlying this world of low prices and instant cash are sometimes inconvenient and preferably swept under the carpet. However, the recent credit crisis as well as the ongoing climate change impact debate suggest that the carpet cannot conceal these issues any longer, and it is time for a spring cleaning.

In the last two decades integrative and multi-disciplinary research has evolved to an extent that its protagonists could increasingly get essential themes profiled on the policy agenda at all scale levels from global to local. The rapid development of integrated models in conjunction with the growing availability of bulky data sets, both supported by an exponential growth in computer capacity provide more and improved evidence of phenomena such as the human impact on climate change. However, methodologies are required to improve the understanding of these problems, and more importantly, to translate new scientific insights into policy processes and trendsetting decisions. Unfortunately, better models and bigger computers alone cannot solve the problems of the world. The bridging element between science, policy and management, governance, needs to be reconsidered. The concept of integrated environmental assessment already has a dualistic nature: (1) research methodology and (2) assessment for consultancies, managers and policy makers. Governance may be seen as a member of the multi-disciplinary family, and falls under the umbrella of integrated environmental assessment. A governance style specifies, for example, what and how norms and values are implemented in, and how human interaction is managed throughout a policy process. This has consequences for the extent to which stakeholder and public participation may influence decision processes. It goes beyond the mere ideological perspective of high-level policy makers and managers, and includes the applied methodology of a governance approach. For this reason, expertise and professionalism are required.

The above statement provides the link to the central statement of this thesis, and the argument for expertise in participatory management is made. Another goal of this research was to expedite the emancipation of participatory management so that it becomes an area of expertise alongside engineering, ecological assessment and planning. Hence, it is argued that more research on methodological aspects of stakeholder and public participation must be undertaken.

The first research question of this thesis was:

1. Is there a consistent methodological framework for participatory processes in water resources management that is independent of the local context, but flexible and adaptive enough to handle specific issues, and uncertainty? 
The available methodology for public and stakeholder participation in environmental decision processes, and in particular for water resources management, was reviewed, and a new typology has been added to the existing concepts. The aim is to enable water managers to select the most effective and appropriate methods for designing and implementing their participatory processes. A new consistent structure (CMO) was developed that serves as an underlying concept for the implementation of process planning and design as well as evaluation and monitoring. Goal-oriented management was the determining notion of this approach. First, a selection of guidebooks have been introduced and discussed, and several weaknesses were identified. Based upon the relevant literature, an overview of essential concepts of public and stakeholder participation was provided. The new concept of classes of participatory methods has been introduced to serve as a link between methods and levels of participation. The second function of the new term is to provide a systematic overview of a multitude of methods. At the same time, levels of participation that are based upon various concepts in the literature were related to the requirements of (local) environmental decision processes. The new concepts of (1) macro structure, referring to the levels and classes of participation; and (2) micro structure, referring to the implementation criteria of participatory methods (cost/effort share, expertise, soft skills, number of participants, etc.) were introduced. This new typology is the essential basis for the constraints-methods-objectives scheme, where the macro structure refers to the objectives of a process and the micro structure to the constraints. More specifically, classes of participatory processes may be assigned to particular objectives, that already narrows down the search for effective methods. The second part of this search refers to the local constraints and availability of resources, which is the second level of selection.

The CMO typology as introduced in chapter 3 is not a complete methodological framework but provides structure for a framework. The operationalisation of this typology was accomplished in 1) a controlling approach, and 2) a planning support approach that provides a selection algorithm for the design of a participatory plan.

\section{How can water managers be enabled to select appropriate methods for their work, and if required to adjust the methods throughout the course of a project?}

Throughout the CMO approach as described in chapter 3 was the only underlying methodology that supported water managers in the design and implementation of participatory methods in their projects. The CMO scheme was accompanied only by a list of best-practise tips for the design and planning of a participatory process. A first version of the new (CMO) approach was documented in the TRUST/TGIII inception report and provided to the managers of each of the case studies. In addition, scientists and managers implemented workshops together with the intention of building capacity among the managers. However, it was not only managers who learned from scientists, but also scientists who were able to learn from the day-to-day work of water managers. In this way a combination of lectures and iterative (social) learning was achieved. Another important effect was transboundary learning. The exchange of experience among water managers from three different European countries was a significant aspect of the 
case study effort for both the managers and the scientists. In other words, one uniform methodology was tested in five sub-case studies with distinctive local contexts.

A subsequent step was the development of a participatory plan that follows the (CMO) scheme, but is suited to the requirements of each of the case studies. The scientists and managers collaborated to design the plans that were eventually implemented in their respective case studies. These plans are a result of an effort combining a methodological structure with experiences and knowledge of both the scientists and practitioners.

Thus far, scientists and managers have collaborated fruitfully, and initial results may be considered a success. However, after all the capacity building that took place, managers were still concerned that they are not able to apply the methodology without the support of participatory experts. As a result of this concern, and the field work carried out, a new method for the selection of participatory methods was developed. For this purpose, three approaches were combined: (1) the enhancement of participatory processes to participatory management combining participatory methods with expert methods based upon the new term, tasks. Tasks mark stages along project stages that co-ordinate the application of methods; (2) the alignment of the macro-structure of the CMO scheme into a framework that represents phases of a project. In other words, the time dimension was introduced as an integral part of the methodological framework. Moreover, tasks were aligned with the phases, and both concepts (CMO and alignment) together constitute a strict guideline for the design of a participatory process without violating the local context; and (3) in order to narrow down the selection of participatory methods a decision tree was applied. The tree currently consists of four levels with contingency tables. The levels are: objectives of a process, number of participants, available soft skills, and available expertise. The final level within the decision tree is the cost/effort share attribute that could not be translated into a contingency table because of its variability. However, at this point, after the application of the four contingency tables, a water manager can make a choice by balancing the remaining methods with the available resources.

The decision tree was applied with available data from the case study, and implemented in the alignment scheme. Yet, a sound knowledge or a complete overview of participatory methods is not necessary in order to make an appropriate choice of methods.

\section{Is there a generally applicable method to monitor and evaluate participatory processes independent of the context of a specific project?}

The monitoring and evaluation method is described and discussed in chapter 4. The methodology is the operationalisation of the CMO scheme with the objective to perform a controlling procedure. The effectiveness of the applied methods have been assessed with regard to both objectives and constraints of a local case. Reasons for success or failure of a (sub)process can be derived from either the wrong choice of a particular method or an imperfect implementation of a method. The novelty of this approach is the use of a well-defined set of intensity criteria for the evaluation of participatory processes instead of direct evaluation criteria that are (in many cases) only applicable to a specific local project. In addition to its general applicability, the virtue of this approach 
is the comparability among various applications at a local level, which suggests its value in supporting transboundary learning, which was demonstrated by the five case studies. Furthermore, the evaluation results delivered a surprisingly accurate portrayal of each of the case studies, even without the desired stakeholder response. Together with the planning sheets, the standard interview questions and the reports, a complete set of tools for evaluation and monitoring is now available. In summary, the contribution of this thesis is:

1. a uniform methodological structure that endeavours an better taxonomy of methods in terms of their goal-reaching capacity on the one hand and their applicability in terms of the local constraints on the other;

2. based upon this methodological structure a monitoring and evaluation procedure supports users to control participatory processes, detect and correct undesirable development and significantly improve the comparability of process development and outcomes among various projects;

3. provide a rigorous selection procedure for the design of a participatory strategy, that is capable of incorporating local objectives and constraints, and this way facilitates the required flexibility and adaptive capacity of any human-environment system throughout a decision process.

The newly developed methodological framework $(\mathrm{CMO}+\mathrm{COPIR}+$ alignment/decision tree) gives way for both a scientific discussion and better understanding and systematic access to participatory methods that are potentially available for the application in water resources management.

\section{Prospects}

This thesis is only a snapshot of the current scientific effort. More research must be carried out particularly with a view to improving the selection process for the choice of participatory methods. Thus far, the two new approaches, CMO and COPIR, have been tested, but more field work should be undertaken with new case studies. The five cases of the TRUST project have demonstrated the value of these approaches, but these studies alone are not sufficient evidence of the effectiveness of the method. In new case studies, the applicability of the new selection tools described in chapter 6 must be tested with an appropriate set of field methods.

Furthermore, the catalogue of available participatory methods should be reviewed, completed, and a generally applicable (software) tool should ideally be developed to implement the new methods, and make them available for practitioners and managers of participatory processes worldwide. Initially, this will require an extensive literature review and web search. The review undertaken in this research obviously encompassed only a selection of methods to fit the requirements of the TRUST project. Software in conjunction with a web interface may serve as a planning support tool for practitioners, but can also be a platform for accessing and exchanging already available knowledge that has been gathered throughout years of research. Such a web portal has not only potential as a planning support tool for practitioners, but also as a platform for the 
collection, exchange and improved accessibility of knowledge and experience that has already been gathered in academia as well as in practice over the last decades. In light of the current efforts of many European countries to implement the Water Framework Directive in their national legislation, the methodology introduced in this research may be a valuable support to many European, as well as non-European water managers, once the planning support tool is available. 
Bibliography

Ahmed, E., Elgazzar, A. S., and Hegazi, A. S. (2005). An overview of complex adaptive systems. arXiv:nlin/0506059v1 [nlin.AO]. arXiv.org, Cornell University.

Alcamo, J., Shaw, R., and Hordijk, L., editors (1990). The RAINS Model of Acidification. Science and Strategies in Europe. Kluwer Academic Publishers, Dordrecht.

Arnstein, S. R. (1969). A ladder of citizen participation. Journal of the American Institute of Planners (JAIP), 35(4):215-224.

Axelrod, R. (1997). The Complexity of Cooperation. Princeton University Press, Chichester, West Sussex.

Axtell, R. (2000). Why agents? On the varied motivations for agent computing in the social siences. Number 17 in Social and Economic Dynamics Working Paper. The Brookings Institution.

Bak, P. (1997). How Nature Works: The Science of Self-organized Criticality. Oxford University Press, Oxford.

Bandura, A. (1977). Social Learning Theory. Prentice-Hall Series in Social Learning Theory. Prentice Hall, Inc., Englewood Cliffs, N.J., first edition.

Beierle, T. C. and Cayford, J. (2002). Democracy in practice: public participation in environmental decisions. Resources for the Future. RFF Press, Washington.

Berger, T., Birner, R., McCarthy, N., Díaz, J., and Wittmer, H. (2007). Capturing the complexity of water uses and water users within a multi-agent framework. Water Resources Management, 21(1):129-148. DOI: 10.1007/s11269-006-9045-z.

Bharwani, S. (2006). Understanding complex behavior and decision making using ethnographic knowledge elicitation. Social Science Computer Review, 24(1):78 105. DOI: $10.1177 / 0894439305282346$. 
Bressers, J. T. A. and Hoogerwerf, A. (1995). Inleiding tot de beleidsevaluatie. In Bressers, J. T. A. and Hoogerwerf, A., editors, Beleidsevaluatie, chapter 1, pages 19 - 32. Samson H. D. Tjeenk Willing, Alphen aan den Rijn, 3rd edition.

Bressers, J. T. A. and Klok, P. (1987). Grondslagen voor een instrumententheorie. Beleidswetenschap, 1:77 - 97.

Bressers, J. T. A. and Kuks, S. M. M. (2001). Governance patronen als verbreding van het beleidsbegrip. University of Twente Publications.

Brugnach, M. and Pahl-Wostl, C. (2008). A broadened view on the role fro models in natura resource management: Implications for model development. In C. Pahl-Wostl, P. K. and Möltgen, J., editors, Adaptive and Integrated Water Management, coping with complexity and Uncertainty, chapter 10, pages 187 - 203. Springer-Verlag Berlin Heidelberg.

Brundtland Commission (1987). Our Common Future. Oxford University Press.

Bryson, J. M. (2003). What to do when stakeholders matter? (http://cep.lse.ac.uk/seminarpapers/10-02-03-BRY.pdf). Presentation at the London School of Economics and Political Science, 10-02-03.

Carmichael, J., Tansey, J., and Robinson, J. (2004). An integrated assessment modeling tool. Global Environmental Change, 14(2):171 - 183.

Caswill, C. and Shove, E. (2000). Introducing interactive social science. Science and Public Policy, 27(3):154 - 157.

Chanan, G. (1999). Local community involvement: A Handbook for Good Practice. European Foundation for the Improvement of Living and Working Conditions. Office for Official Publications of the European Communities, Luxemburg.

Coenen, F. H. J. M. (1995). De bijdrage van het beleid aan de doelbereiking. In Bressers, J. T. A. and Hoogerwerf, A., editors, Beleidsevaluatie, chapter 5, pages $86-103$. Samson H. D. Tjeenk Willing, Alphen aan den Rijn, 3rd edition.

Cohen, L., Manion, L., and Morrison, K. (2007). Research Methods In Education. Routledge, 6th edition.

Conzelmann, T. (1998). 'Europeanisation' of Regional Development Policies? Linking the Multi-level Governance Approach with Theories of Policy Learning and Policy Change. European Integration online Papers (EIoP), 2(4).

Craps, M. and Maurel, P. (2003). Social learning pool of questions: an instrument to diagnose social learning and ic-tools in european river basin management. Prepared under contract from the European Commission 3, K.U.Leuven - Centre for Organizational and Personnel Psychology (COPP) and Cemagref, Montpellier. HarmoniCOP combined WP2/WP3 deliverable. 
Dale, A. (2001). At The Edge: Sustainable Development in the 21 st Century. Number 6 in Sustainability And The Environment. UBC Press, Vancouver, Toronto.

De Maaswerken (1997a). Maasvarianten. Technical report, Directoraat-Generaal Rijkswaterstaat.

De Maaswerken (1997b). Maasvarianten: De Reacties. Technical report, DirectoraatGeneraal Rijkswaterstaat.

Drafting Group (2002). Guidance on public participation in relation to the water framework directive; active involvement, consultation, and public access to information, prepared in the framework of the common implementation strategy of the european commission and the eu member states. Technical report, European Union, Brussels.

Elliot, D. (1980). The organization as a system. In Salaman, G. and Thompson, K., editors, Control and Ideology in Organizations, pages 85 - 102. The Open University Press.

Elliott, J., Heesterbeek, S., Lukensmeyer, C. J., and Slocum, N. (2005). Participatory Methods Toolkit. A practitioner's manual. King Baudouin Foundation and the Flemish Institute for Science and Technology Assessment (viWTA).

Enserink, B., Kamps, D., and Mostert, E. (2003). Public participation in river basin management in the netherlands: (not) everybody's concern. Technical report, The Harmonicop project, European Commission,(contract no.: EESD-ENV-2000-02-57).

Epstein, J. M. (1999). Agent-based computational models and generative social science. Complexity, 4(5):41-60.

Etzioni, A. (1964). Modern Organizations. Prentice Hall, Englewood Cliffs, N.J.

EU (2000). Directive 2000/60/EC of the European Parliament And of the Council. Official Journal of the European Communities, OJ L 327:72. WFD.

European Commission (2003). Public Participation in Relation to the Water Framework Directive. Common implementation strategy for the Water Framework Directive 2000/60/EC. Guidance document No. 8. Office for Official Publications of the European Communities, Working Group 2.9 - Public Participation, Luxembourg.

Fayol, H. (1949). General and industrial management. Pitman, London, 18 edition.

Feindt, P. H. (2001). Regierung durch Diskussion?: Diskurs- und Verhandlungsverfahren im Kontext von Demokratietheorie und Steuerungsdiskussion. PhD thesis, Universität der Bundeswehr Hamburg, Lang, Frankfurt/Main.

Freeman, R. E. (1984). Strategic Management: A stakeholder approach. Pitman, Boston.

Funtowicz, S. O. and Ravetz, J. R. (1993). Science for the post-normal age. Futures, 25(7):739- 755 . 
Galbraith, J. (1977). Organizational Design. Addison-Wesley, Reading, MA.

Geldof, G. (2002). Omgaan met complexiteit bij integraal waterbeheer. PhD thesis, Universiteit Twente, Deventer.

Gibbons, M., Limoges, C., Nowotny, H., Schwartzman, S., Scott, P., and Trow, M. (1994). The new production of knowledge: the dynamics of science and research in contemporary societies. Sage, London.

Gleick, P. (2003). Global freshwater resources: Soft-path solutions for the 21st century. Science, 302:1524 - 1528 .

Glicken, J. (2000). Getting stakeholder participation 'right': a discussion of participatory processes and possible pitfalls. Environmental Science and Policy, 3(6):305310 .

Godin, B. (1998). Writing Performative History:: The New New Atlantis? Social Studies of Science, 28(3):465 - 483.

Greenwald, B. and Stiglitz, J. (1986). Externalities in economies with imperfect information and incomplete markets. Quarterly Journal of Economics, 101:229 - 264.

Großkurth, J. A. (2008). Regional sustainability. PhD thesis, ISIS, Maastricht University, Maastricht.

Harding, R. (1998). Environmental Decision-making: The Role of Scientists, Engineers and the Public. Federation Press.

Hare, M. and Pahl-Wostl, C. (2002). Stakeholder Categorisation in Participatory Integrated Assessment Processes. Integrated Assessment, 03(1):50 - 62.

Hare, M. P. and Krywkow, J. (2005). Participatory processes for the design of water storage areas. Technical report, Seecon Deutschland GmbH, Osnabrück. Seecon TR no. 01/2005 for the TRUST project.

Heckhausen, H. (1987). Interdisziplinäre Forschung: Zwischen intra-, multi- und chimären-disziplinarität. In Kocka, J., editor, Interdisziplinarität: Praxis, Herausforderung, Ideologie, pages 129 - 145. Suhrkamp, Frankfurt am Main.

Hicks, J. (1939). The foundations of welfare economics. Economic Journal, 49(196):696-712. doi:10.2307/2225023.

Hinkel, J. (2008). Transdisciplinary Knowledge Integration. PhD thesis, Wageningen University, Wageningen, The Netherlands.

Hirsch, D., Schlueter, M., and Borovikovskaya, S. (2007). Stakeholder participation process in the Amudarya river basin. Mid term report (2006-2007), Integrated NeWater Project in PRIORITY 6.3 Global Change and Ecosystems in the 6th EU framework programme, contract no 511179 (GOCE). 
Holland, J. H. (1992). Adaptation in Natural and Artificial Systems: An Introductory Analysis with Applications to Biology, Control, and Artificial Intelligence. MIT press.

Holling, C. S., editor (1975). Adaptive Environmental Assessment and Management. Blackburn Press. Reprinted 2005.

Holling, C. S. (1986). The resilience of terrestrial ecosystems; local surprise and global change. In Clark, W. C. and Munn, R. E., editors, Sustainable Development of the Biosphere, pages 292-317. Cambridge University Press, Cambridge, U.K.

Hommes, S., Hulscher, S., Mulder, J., Otter, H., and Bressers, H. (2009). Role of perceptions and knowledge in the impact assessment for the extension of Mainport Rotterdam. Marine Policy, 33:146 - 155.

Hoogerwerf (1998). Beleid, processen en effecten. In Hoogerwerf, A. and Herweijer, M., editors, Overheidsbeleid, pages 17 - 35. Samson, Alphen aan den Rijn.

Hubbard, D. W. (2007). How to Measure Anything: Finding the Value of "Intangibles" in Business. Wiley.

IAP2 (2008). The IAP2 Public participation toolbox: techniques to share information. International Association for Public Participation, Thornton, USA. first published in 2000.

Inglehart, R. (1977). The Silent Revolution: Changing Values and Political Styles among Western Publics. Princeton University Press, Princeton, NJ.

ISO (2000). Iso 9001:2000. international standards for business, government and society: quality management.

IUCN, UNEP, and WWF (1991). Caring for the Earth: A Strategy for Sustainable Living. Gland, Switserland.

Janssen, R. (2001). On the use of Multi-Criteria Analysis in Environmental Impact Assessment in The Netherlands. Journal of Multi-Criteria Decision Analysis, 10:101109.

Jasanoff, S. (1990). The fifth branch: science advisers as policymakers. Harvard University Press, Boston, Mass.

Kaldor, N. (1939). Welfare propositions in economics and interpersonal comparisons of utility. Economic Journal, 49(195):549-552.

Klein, J. T. (1990). Intersiciplinarity: History, Theory \& Practice. Wayne State University Press, Detroit, MI.

Knight, F. H. (1921). Risk, Uncertainty, and Profit. Hart, Schaffner \& Marx Houghton Mifflin Co. Pub., Boston. Retrieved 10/03/2009 from: http://www.econlib.org/library/Knight/knRUP11.html\#Pt.III,Ch.XII. 
Koestler, A. (1978). Janus: A Summing Up. Hutchinson.

Kondyles, P. (1984). Macht Und Entscheidung. Klett-Cotta, Stuttgart.

Kooiman, J. (1993). Findings, speculations and recommendations. In Kooiman, J., editor, Modern Governance, chapter 19, pages 249 - 262. Sage.

Krywkow, J. (2007). Participatory management - a brief guideline for water managers. Technical Report Seecon Report \#7 2007, Seecon Deutschland, Osnabrück, Germany.

Krywkow, J., Rasche, K., Moss, E., Mitchell, T., Vancleemput, K., van der Kroef, R., Hotting, R., Rodenbach, A., and Noordanus, C. (2007). Public and stakeholder participation. Theme Group III final report of the trust project, Water Board (Hoogheemraadschap) of Schieland and the Krimpenerwaard, Rotterdam.

Kuhn, T. (1962). The Structure of Scientific Revolutions. University of Chicago Press, Chicago.

Landman, J., Röling, I., Peeters, R., and Damsma, P. (2006). Water en ontwikkelingsplanologie. Technical Report RWS RIZA werkdocument 2006.052x, Rijkswaterstaat, Ministerie van Verkeer en Waterstaat.

Lawrence, R. L. and Daniels, S. E. (1996). Public Involvement in Natural Resource Decision Making: Goals, Methodology, and Evaluation. Number 3 in Papers in Forest Policy. Forest Research Laboratory, Oregon State University.

Leussen, W. v. (2000). Maaswerken: van sectoraal plan naar adaptief proces. Technical report, Ministerie van Verkeer en Waterstaat, Den Haag.

Lloyd, S. (2006). Programming the Universe. Alfred A. Knopf publishers.

Loucks, D. P. and van Beek, E. (2005). Water Resources Systems Planning and Management. United Nations Educational Scientific and Cultural Organisation, Paris.

Maarse, J. A. M. (1995). De verklaring van de effectiviteit van een beleid. In Bressers, J. T. A. and Hoogerwerf, A., editors, Beleidsevaluatie, chapter 1, pages $19-32$. Samson H. D. Tjeenk Willing, Alphen aan den Rijn, 3rd edition.

Meadows, D. H., Meadows, D. L., Randers, J., and Behrens III, W. W. (1972). The Limits to Growth. Universe Books, New York.

Menger, C. (1871). Grundsätze der Volkswirtschaftslehre. K. K. Hof- und Universitätsbuchhändler. PDF-Version von Gerhard Grasruck für www.mises.de.

Mitchell, R. K., Agle, B. R., and Wood, D. (1997). Toward a theory of stakeholder identification and salience: Defining the principle of who and what really counts. Academy of Management Review, 22(4):853 - 888.

Mitchell, T. (1997). Decision tree learning. In Mitchell, T., editor, Machine Learning, pages 52 - 78. The McGraw-Hill Companies, Inc. 
Mittelstraß, J. (1987). Die Stunde der Interdisziplinarität? In Kocka, J., editor, Interdisziplinarität: Praxis, Herausforderung, Ideologie, pages 152 - 158. Suhrkamp, Frankfurt am Main.

Mohr, L. B. (1995). Impact analysis for program evaluation. Sage Publications, Thousand Oads, London, New Dehli, 2nd edition.

Mostert, E. (2003a). The challenge of public participation. Water Policy, 5:179-197.

Mostert, E. (2003b). The european water framework directive and water management research. Physics and Chemistry of the Earth, 28:523 - 527.

Newig, J. (2003). Symbolische Umweltgesetzgebung. Rechtssoziologische Untersuchungen am Beispiel des Ozongesetzes, des Kreislaufwirtschaft- und Abfallgesetzes sowie der Großfeuerungsanlagenverordnung. Schriften zur Rechtssoziologie und Rechtstatsachenforschung, 8(1):421-422.

Ng, Y. K. (1979). Welfare Economics: Introduction and Development of Basic Concepts. Macmillan, London, second, 1983 edition.

Oels, A. (2003). Evaluating stakeholder participation in the transition to sustainable development. Methodology, case studies, policy implications. $\mathrm{PhD}$ thesis, University of East Anglia, Norwich, LIT, Münster.

ÖGUT (2003). Checklisten für Rahmenbedingungen und Qualitätskriterien partizipativer Verfahren im öffentlichen Bereich. Österreichische Gesellschaft für Umwelt und Technik (ÖGUT), Wien, (www.partizipation.at). Arbeitsblätter zur Partizipation, Nr. 1.

Ostrom, E. (1998). A beahvioural approach to the rational choice theory of collective action. Presidental Address, American Political Science Association, 1997. American Political Science Review, 92(1):1-22.

Ostrom, E. (1999). Institutional rational choice: An assessment of the institutional analysis and development framework. In Sabatier, P. A., editor, Theories of the Policy Process, pages 35 - 71. Westview Press, Boulder, CO.

Ostrom, E., Gardner, R., and Walker, J. (1994). Rules, Games and Common-Pool Resources. University of Michigan Press, Ann Arbor, USA.

O’Toole Jr., L. J. (2000). Research on policy implementation: Assessment and prospects. Journal of Public Administration Research and Theory, 10(2):263 - 288.

Pahl-Wostl, C. (2002). Participative and stakeholder-based policy design, evaluation and modeling process. Integrated Assessment, 3(1):3 - 14 .

Pahl-Wostl, C. (2005). Actor based analyisis and modelling approaches. Integrated Assessment, 5:97-118. 
Pahl-Wostl, C. (2007a). The implications of complexity for integrated resources management. Environmental Modelling \& Software, 22(5):561 - 569.

Pahl-Wostl, C. (2007b). Transitions towards adaptive management of water facing climate and global change. In Craswell, E., Bonnell, M., Bossio, D., Demuth, S., and van de Giesen, N., editors, Integrated Assessment of Water Resources and Global Change: A North-South Analysis, pages 49 - 62. Springer, Dordrecht, The Netherlands. Reprinted from Water Resources Management, Vol.21(1),2007.

Pahl-Wostl, C. (2008). Requirements for adaptive water management. In C. Pahl-Wostl, P. K. and Möltgen, J., editors, Adaptive and Integrated Water Management, coping with complexity and Uncertainty, chapter 1, pages 1 - 22. Springer-Verlag Berlin Heidelberg.

Pahl-Wostl, C., Craps, M., Dewulf, A., Mostert, E., Tabara, D., and Taillieu, T. (2007). Social learning and water resources management. Ecology and Society, 12(2). URL: http://www.ecologyandsociety.org/vol12/iss2/art5/.

Panebianco, S. and Pahl-Wostl, C. (2004). Obstacles in launching a participatory group discussion and modelling process. In Pahl-Wostl, C., Schmidt, S., Rizzoli, A. E., and Jakeman, A. J., editors, Complexity and Integrated Resources Management - Transactions of the 2nd Biennial Meeting of the International Environmental Modelling and Software Society, volume 1, pages 240 - 246, Osnabrück. iEMSs.

Parsons, T. (1970). The Social System. Routledge \& Kegan Paul.

Pugh, D. and Hickson, D. (1973). The comparative study of organizations. In Salaman, G. and Thompson, K., editors, People and Organizations, pages 50 - 66. Longmans, London.

Raaijmakers, R., Krywkow, J., and van der Veen, A. (2008). Flood risk perceptions and spatial multi-criteria analysis: an exploratory research for hazard mitigation. Natural Hazards. DOI 10.1007/s11069-007-9189-z.

Rahaman, M. and Varis, O. (2005). Integrated water resources management: evolution, prospects and future challenges. Sustainability: Science, Practice, \& Policy, 1(1):1521.

Rasche, K. (2005). Praktische Hemmnisse intensiver Partizipation: Eine Untersuchung anhand von fünf Wasserbauprojekten in Nordwest-Europa. Master's thesis, University of Osnabrück, Institute of Environmental Systems Research.

Rasche, K., Krywkow, J., Newig, J., and Hare, M. (2006). Measuring the intensity of participation along six dimensions. In Participatory Approaches in Science \& Technology (PATH), Edinburgh. The Macaulay Institute. Proceedings of the PATH conference.

Renn, O., Webler, T., and Wiedemann, P. (1995). Fairness and competence in citizen participation: Evaluating models for environmental discourse. Kluwer Academic Publishers, Dordrecht, Netherlands. 
Rhodes, R. A. W. (2000). Governance and public administration. In Pierre, J., editor, Debating governance, chapter 4, pages 54 -90. Oxford University Press.

Ridder, D., Mostert, A., and Wolters, H. (2005). Learning together to manage together. Improving participation in water management. University of Osnabrück, Institute of Environmental Systems Research., Osnabrück.

Robinson, J. (2004). Squaring the circle? Some thoughts on the idea of sustainable development. Ecological Economics, 48:369 - 384.

Rosenau, J. N. (2000). The governance of fragmentation: Neither a world republic nor a global interstate sustem. In IPSA proceedings, Quebeck. IPSA.

Rotmans, J. (1998). Methods for ia: The challanges and opportunities ahead. Environmental Modelling and Assessment, 3:155 - 179.

Rouchier, J., Bousquet, F., Requier-Desjardins, M., and Antona, M. (2001). A multiagent model for describing transhumance in north cameroon: Comparison of different rationality to develop a routine. Journal of economic dynamics and control, 25(3 $-4): 527-559$.

Rowe, G. and Frewer, L. (2004). Evaluating public-participation exercises: A research agenda. Science, Technology \& Human Values, 29(4):512 - 556. DOI: $10.1177 / 0162243903259197$.

Sabatier, P. (1988). An advocacy coalition model of policy change and the role of policy-oriented learning therein. Policy Sciences, 21:129-168.

Sabatier, P. A. (2007). Theories of the Policy Process. Westview Press, Boulder, 2 edition.

Sabatier, P. A. and Jenkins-Smith, H. C., editors (1993). Policy Change and Learning: An Advocacy Coalition Approach. Theoretical Lenses on Public Policy. Westview Press, Boulder, San Francisco, Oxford.

Schaad, A. (2003). A Framework for Organisational Control Principles. PhD thesis, The University of York, Department of Computer Science.

S.J.Russel and Norvig, P., editors (2003). Artificial Intelligence. A Modern Approach. Prentice Hall Series in Artificial Intelligence. Prentice Hall, Pearson Education, Inc., Upper Saddle River, New Jersey, second edition.

Slovic, P. (1987). Perception of risk. Science, 236:280-285.

Slovic, P., Fischhoff, B., and Lichtenstein, S. (1984). Behavioral decision theory perspectives on risk and safety. Acta Psychologica, 56:183-203.

Smith, A. (1776). An Inquiry into the Nature and Causes of the Wealth of Nations. MetaLibri. Edited by Sálvio M. Soares, 2007. 
Smith, A. (1998). Studying multi-level governance. examples from french translations of the structural funds. Public Administration, 75(4):711 - 729. DOI:10.1111/14679299.00083.

Stavins, R. N. (2003). Experience with market-based environmental policy instruments. In Mäler, K. G. and Vincent, J. R., editors, Handbook of Environmental Economics, volume 1 , chapter 9 , pages 355 - 436. Elsevier.

Stiglitz, J. E. (1987). Principal and agent. In Eatwell, J., Milgate, M., and Newman, P., editors, The New Palgrave: A Dictionary of Economics, volume 3, pages 966-971. Macmillan and Stockton.

Terwisscha van Scheltinga, C., van Bers, C., and Hare, M. (2009). Learning systems for adaptive water management: experiences with the development of opencourseware and training of trainers. In Blokland, M. W., Alaerts, G. J., Kaspersma, J., and Hare, M., editors, Knowledge and Capacity Development for Improved Water Management, chapter 5, pages 45 - 60. UNW-DPC/UNESCO-IHE joint publication, Delft.

Tol, R. S. J. and Vellinga, P. (1998). The european forum on integrated environmental assessment. Environmental Modelling and Assessment, 3(3):181 - 191.

Toth, F. and Hizsnyik, E. (1998). Integrated environmental assessment methods: Evolution and Applications. Environmental Modelling and Assessment, 3(3):193 - 207.

UNECE (1998). Convention on Access to Information, Public Participation in Decisionmaking and Access to Justice in Environmental Matters. United Nations Economic Commission for Europe (UNECE). Aarhus Convention.

United Nations (1993). The Dublin Statement on Water and Sustainable Development. United Nations Conference on Environment and Development (UNCED).

United Nations General Assembly (2000). United nations millennium declaration. URL: http://www.un.org/millennium/declaration/ares552e.htm. Resolution 55/2, United Nations A/RES/55/2, 8. September 2000.

van Asselt, M. (2000). Perspectives on uncertainty and risk: the prima approach to decision support. $\mathrm{PhD}$ thesis, University of Maastricht, Dordrecht.

van Asselt, M., Mellors, J., Rijkens-Klomp, N., Greeuw, S., Molendijk, K., Beers, P., and van Notten, P. (2001). Building blocks for participation in integrated assessment: a review of participatory methods. ICIS, Maastricht. Working paper.

van der Sluijs, J. P., Craye, M., Funtowicz, S., Kloprogge, P., Ravetz, J., and Risbey, J. (2005). Combining Quantitative and Qualitative Measures of Uncertainty in ModelBased Environmental Assessment: The NUSAP System. Risk Analysis, 25(2):481 492. 
van Heffen, O., Kickert, W., and Thomassen, J. (2000). Introduction: multi-level and multi-actor governance. In van Heffen, O. and Kickert, W. J. M., editors, Governance in Modern Society: Effects, Change and Formation of Government Institutions, pages 1-11. Kluwer academic publishers, Dordrecht. url:http://doc.utwente.nl/4412/.

van Herwijnen, M. (1999). Spatial Decision Support for Environmental Mangement. $\mathrm{PhD}$ thesis, Vrije Universiteit Amsterdam, Amsterdam.

Vennix, J. (1999). Group model-building: tackling messy problems. System Dynamics Review, 15(4):379-401.

Walter, F. (2006). Zu Risiken und Nebenwirkungen einer Mittelschicht-Utopie. Spiegel online.

Walters, C. (1986). Adaptive Management of Renewable Resources. Blackburn Press. Reprinted 2002.

Wates, N. (2000). The community planning handbook. Earthscan Publications Ltd, London.

Weaver, W. (1948). Science and complexity. American Scientist, 36. retrieved 10/03/2009, from http://www.ceptualinstitute.com/genre/weaver/weaver-1947b.htm.

Weber, M. (1920). Die protestantische Ethik und der Geist des Kapitalismus. Number 8 in Gesammelte Aufsätze zur Religionssoziologie. J. C. B. Mohr (Paul Siebeck), Tübingen, 1 edition.

Weiss, G., editor (2000). Multiagent Systems: A Modern Approach to Distributed Artificial Intelligence. Massaachussetts Institute of Technology, Cambridge, Massachusetts; London, England, 2nd edition.

Wenger, E. (1998). Communities of practice. Learning in Doing: Social, cognitive, and computational perspectives. Cambridge University Press, Cambridge, New York, Melbourne.

Wesselink, A. J. (2007). Integraal waterbeheer: de verweving van expertixe en belangen. PhD thesis, University of Twente, Enschede, The Netherlands.

Weyant, J. (1996). Integrated assessment of climate change: An overview and comparison of approaches and results. In Bruce, J. P., Lee, H., and Haites, E. F., editors, Climate Change 1995: Economic and Social Dimensions of Climate Change, chapter 10, pages 367 - 396. IPCC/Cambridge University Press.

Winston, P. H. (1992). Artificial Intelligence. A-W Series in Computer Science Series. Addison-Wesley, 3 edition. ISBN-13: 9780201533774.

Wooldridge, M. (2002). An Introduction to Multiagent Systems. John Wiley \& Sons, Ltd., Chichester, West Sussex. 
World Water Council (2000). Ministerial declaration of the hague on water security in the 21st century. Ministerial Declaration, 2nd World Water Forum, The Hague.

World Water Council (2006). Local government declaration on water. Fourth World Water Forum, Mexico.

Yeh, C., Willis, R., Deng, H., and Pan, H. (1999). Task oriented weighting in multicriteria analysis. European journal of operational research, 119:130-146. 


\section{APPENDIX A}

\section{List of case study activities}

Table A.1: Overview of main TRUST TGIII activities (Krywkow, 2007, p.13)

\begin{tabular}{|l|l|l|l|}
\hline Date & Location & Activity & Main Issues \\
\hline $\begin{array}{l}10-12 / 09 / \\
2004\end{array}$ & Rotterdam & kickoff meeting & Introduction to the project \\
\hline $\begin{array}{l}23-24 / 02 / \\
2005\end{array}$ & Gloucester & $\begin{array}{l}\text { TRUST/TGIII } \\
\text { meeting }\end{array}$ & $\begin{array}{l}\text { Feedback on the inception report, tasks for partners } \\
\text { to supplement to the IR, introduction to each partners } \\
\text { project, exchanging experiences related to the projects, } \\
\text { interviews and questionnaires for inception evaluation. }\end{array}$ \\
\hline $\begin{array}{l}26-28 / 04 / \\
2005\end{array}$ & Montpellier & $\begin{array}{l}\text { TRUST/NeWater } \\
\text { joint meeting }\end{array}$ & $\begin{array}{l}\text { Workshop exchanging experience between two interna- } \\
\text { tional water management projects, capacity building on } \\
\text { participatory methods }\end{array}$ \\
\hline- & - & $\begin{array}{l}\text { Participatory } \\
\text { plans }\end{array}$ & $\begin{array}{l}\text { Participatory plans were written for each partner. PNH } \\
\text { received a review of their communication plan }\end{array}$ \\
\hline $29-30 / 09 /$ & Glasgow & $\begin{array}{l}\text { TRUST/TGIII } \\
\text { meeting }\end{array}$ & $\begin{array}{l}\text { Reporting back from all partner's recent activities in the } \\
\text { project. Presentation and agreement on the evaluation } \\
\text { concept. Development of a common set of objectives to } \\
\text { be used as a basis for the evaluation. }\end{array}$ \\
\hline $\begin{array}{l}\text { 01-02/02/ } \\
2006\end{array}$ & Glasgow & $\begin{array}{l}\text { Workshop with } \\
\text { stakeholders }\end{array}$ & $\begin{array}{l}\text { Research group supported GCC in a stakeholder work- } \\
\text { shop }\end{array}$ \\
\hline $20-21 / 02 /$ & Bruges & $\begin{array}{l}\text { TRUST/TGIII } \\
\text { meeting }\end{array}$ & $\begin{array}{l}\text { Reporting back from partners, exchange of experience, } \\
\text { discussing the TRUST game CD, filling in and presenting } \\
\text { planning sheets (team work) }\end{array}$ \\
\hline $20 / 03 / 2006$ & Rotterdam & $\begin{array}{l}\text { Interim evalua- } \\
\text { tion }\end{array}$ & $\begin{array}{l}\text { Research team visited a participatory activity (opening } \\
\text { ceremony) at HHSK, and carried out an interim evalua- } \\
\text { tion interview. }\end{array}$ \\
\hline $10 / 04 / 2006$ & Alkmaar & $\begin{array}{l}\text { Interim evalua- } \\
\text { tion }\end{array}$ & $\begin{array}{l}\text { Seecon and POM visited a participatory activity } \\
\text { (klankboardgroep meeting) at PNH; the research team } \\
\text { and PNH carried out an interim evaluation interview. }\end{array}$ \\
\hline
\end{tabular}


Table A.1: Overview of main TRUST TGIII activities (Krywkow, 2007, p.13)

\begin{tabular}{|l|l|l|l|}
\hline Date & Location & Activity & Main Issues \\
\hline $24 / 04 / 2006$ & Bruges & $\begin{array}{l}\text { Interim evalua- } \\
\text { tion }\end{array}$ & $\begin{array}{l}\text { the research team visited a participatory activity (informa- } \\
\text { tion meeting) at POM; and carried out an interim evalua- } \\
\text { tion interview. }\end{array}$ \\
\hline $07 / 06 / 2006$ & Glasgow & $\begin{array}{l}\text { Interim evalua- } \\
\text { tion }\end{array}$ & $\begin{array}{l}\text { Seecon visited a participatory activity (meeting with com- } \\
\text { munity group) at GCC; interim evaluation interview. }\end{array}$ \\
\hline $08 / 06 / 2006$ & Gloucester & $\begin{array}{l}\text { Interim evalua- } \\
\text { tion }\end{array}$ & $\begin{array}{l}\text { Interim evaluation interview carried out with BW; interim } \\
\text { evaluation report. }\end{array}$ \\
\hline 05-06/10/ & Bruges & $\begin{array}{l}\text { TRUST/TGIII } \\
\text { meeting }\end{array}$ & $\begin{array}{l}\text { Site visit Roobeek, Ardooie, the POM project, exchange } \\
\text { of experience and lessons learned, discussing the con- } \\
\text { tent and structure of the final report, meeting and discus- } \\
\text { sion with TG I and II. }\end{array}$ \\
\hline $\begin{array}{l}\text { 31/01-01/02/ } \\
2007\end{array}$ & Glasgow & $\begin{array}{l}\text { TRUST/TGIII } \\
\text { meeting }\end{array}$ & $\begin{array}{l}\text { Site visit at Ruchill Park, the GCC project, reporting back, } \\
\text { exchange of experience, feedback on interim evaluation } \\
\text { reports written for each partner, discussion and continu- } \\
\text { ation of the evaluation process, meeting and discussion } \\
\text { with TG l and II, discussing the game CD, discussing con- } \\
\text { tent and outline of the final report. }\end{array}$ \\
\hline $\begin{array}{l}\text { 03-04/04/ } \\
2007\end{array}$ & Cheltenham & $\begin{array}{l}\text { TRUST/TGIII } \\
\text { meeting }\end{array}$ & $\begin{array}{l}\text { Site visit at the Stroud canal and the Lawns, the case } \\
\text { study of BW, exchange of experience, lessons learned for } \\
\text { further projects, discussing the game CD, filling in (final) } \\
\text { evaluation questionnaires }\end{array}$ \\
\hline 2007 & Haarlem & $\begin{array}{l}\text { TRUST } \\
\text { Conference }\end{array}$ & $\begin{array}{l}\text { Presentation and discussion of the results of the TRUST } \\
\text { effort. }\end{array}$ \\
\hline
\end{tabular}


APPENDIX B

\section{Example for a catalogue entry: Large group response}

Table B.1: Summary of implementation criteria

\begin{tabular}{|l|c|c|c|c|c|c|l|l|l|}
\hline \multirow{2}{*}{$\begin{array}{l}\text { Level of } \\
\text { part. }\end{array}$} & \multicolumn{3}{|c|}{ Cost-effort share } & \multicolumn{2}{|c|}{ Level of app. skills } & $\begin{array}{l}\text { Moderator } \\
\text { skills }\end{array}$ & User mode & $\begin{array}{l}\text { Spec. } \\
\text { software }\end{array}$ \\
\cline { 2 - 10 } & (p) & (i) & (a) & (p) & (i) & (a) & & large group & no \\
\hline \hline 2 & $40 \%$ & $30 \%$ & $30 \%$ & E & E & E & high & lar \\
\hline
\end{tabular}

This participatory technique is a method to get an instant response to a pre-defined set of questions from a large number of people in a meeting. The questions, usually three, are related to the topic of the meeting, and might deal with 1) the resources, 2) the opportunities and drawbacks and 3) potential measures or policy for the planning site.

The moderator introduces the audience to the project and the related issues, and starts asking the prepared questions. Each participant has a few minutes time to write down a respond to each question, and another few minutes to highlight the most important answer. Thereafter, each participant may display the highlighted answer at a flip chart or other publicly accessible display. Each of the displays pools answers to a specific question. The moderator or an assistant reviews or summarizes the answers. The third part of the meeting is an analysis of the collected answers. This may range from a simple reading of the answers to a content analysis. This method combines individual opinions of a topic with a related group discussion. The variety of views and perspectives can be displayed, and thereafter discussed. It is a quick way of getting insights to the composition of a group of participants and their perspectives, and let them reflect on this. Even with a large number of participants all opinions have a chance to be heard. The entire procedure is quick, transparent and straightforward.

Warning: The results of this method may not be interpreted as a result of a group process. Contradictions, problems, and misunderstandings can be revealed, but not be summarised as a compromise or consensus nor solved. 
Table B.2: Resources breakdown

\begin{tabular}{|l|l|l|l|}
\hline Phases: & Preparation & Implementation & Analysis \\
\hline \hline Staff & $\begin{array}{l}\text { moderator, as- } \\
\text { sistant }\end{array}$ & $\begin{array}{l}\text { moderator, (team of assis- } \\
\text { tants) }\end{array}$ & analyst \\
\hline Time $[\mathrm{h}]$ & several hours & one to two hours & several hours \\
\hline Tools & $\begin{array}{l}\text { preparing re- } \\
\text { sponse sheets }\end{array}$ & $\begin{array}{l}\text { room for a large group, re- } \\
\text { sponse sheets and pencils, } \\
\text { flip charts }\end{array}$ & computer \\
\hline Add. costs & & & \\
\hline
\end{tabular}


About the author

Jörg Krywkow studied Geography at the University of Stuttgart, Wilfred Laurier University at Waterloo/Ontario and the Free University of Berlin, where he received his Masters degree (Diplom-Geograph) in 1997. His research analysed water balance in the Gurgueia river basin, located in North-Eastern Brazil.

Over the past 10 years Jörg has worked on a wide variety of research projects dealing with water resources management. From 1998 until 2000 he held a research position at the Potsdam Institute for Climate Impact Research (PIK). During this period his research focused on spatial analysis and GIS evaluation for the Brazilian-German project WAVES (Water Availability, Vulnerability of Ecosystmes and Society in North-Easern Brazil). From 2000 to 2004, he was employed as research scientist at the University of Maastricht and University of Twente in the European FP5 projects Firma (Freshwater Integrated Resource Management with Agents) and HarmoniCop (Harmonising Collaborative Planning). Between 2005 and 2009 Jörg worked as a research scientist in the Water Engineering Group (WEM), University of Twente carrying out research for the two European FP6 water management projects NeWater (New Approaches to Adaptive Water Management under Uncertainty) and FLOODsite (Integrated Flood Risk Analysis and Management Methodologies). The research integrated flood risk perspectives with contemporary flood risk analysis.

From July 2004, Jörg has worked as a consultant for Seecon Deutschland GmbH, Osnabrück, Germany. His research and consulting involves planning, analysis and implementation of participatory water management processes with an emphasis on translating knowledge to practice. 